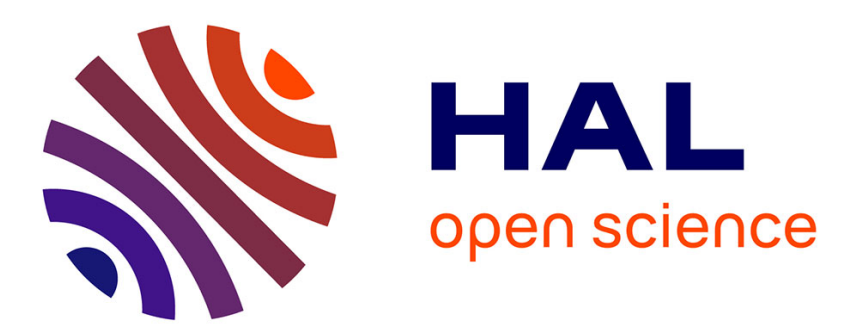

\title{
Synthesis and evaluation of substituted indolizidines as peptidomimetics of RGD tripeptide sequence
}

\author{
Joelle Pérard-Viret, Delphine Halie, Sylvie Dufour, Jacques Royer
}

\section{To cite this version:}

Joelle Pérard-Viret, Delphine Halie, Sylvie Dufour, Jacques Royer. Synthesis and evaluation of substituted indolizidines as peptidomimetics of RGD tripeptide sequence. Tetrahedron, 2009, 65 (7), pp.1402-1414. 10.1016/j.tet.2008.12.015 . hal-03385010

\section{HAL Id: hal-03385010 https://hal.science/hal-03385010}

Submitted on 19 Oct 2021

HAL is a multi-disciplinary open access archive for the deposit and dissemination of scientific research documents, whether they are published or not. The documents may come from teaching and research institutions in France or abroad, or from public or private research centers.
L'archive ouverte pluridisciplinaire HAL, est destinée au dépôt et à la diffusion de documents scientifiques de niveau recherche, publiés ou non, émanant des établissements d'enseignement et de recherche français ou étrangers, des laboratoires publics ou privés. 


\title{
Synthesis and evaluation of substituted indolizidines as peptidomimetics of RGD tripeptide sequence
}

\author{
Delphine Halie ${ }^{a}$, Joëlle Pérard-Viret ${ }^{\mathrm{a}, *}$, Sylvie Dufour ${ }^{\mathrm{b}, \dagger}$, Jacques Royer ${ }^{\mathrm{a}}$ \\ ${ }^{a}$ UMR 8638,CNRS/Université Paris Decsartes, Faculté des Sciences Pharmaceutiques et Biologiques, 4 avenue de l'observatoire, 75270 Paris Cedex 06, France \\ ${ }^{\mathrm{b}}$ UMR144, CNRS/Institut Curie, 26 rue d'Ulm, 75248 Paris cedex 05, France
}

\begin{abstract}
A B S T R A C T
The synthesis of seven peptidomimetics of RGD is presented. The indolizidine building block was obtained by condensation of allylglycine with dimethoxydihydrofuran followed by an intermolecular cyclization. The bicyclic ring was functionalised with a carboxylic acid and a guanidinium appendage. The seven peptidomimetics were evaluated by cell-adhesion assays.
\end{abstract}

\section{Introduction}

Integrins are transmembrane receptors, which regulate cell attachment and response to the extracellular matrix. They are involved in many physiopathological processes: coagulation of blood, tumor-induced angiogenesis, osteoporosis, restenosis, acute renal failure, ocular diseases, metastasis formation, and sickle cell anemia and represent an interesting target for therapeutic. ${ }^{1}$

Among the various known integrins the $\alpha_{\mathrm{v}} \beta_{3}$ and $\alpha_{\mathrm{v}} \beta_{5}$ integrin receptors are of great interest since they are involved in angiogenesis, a target for cancer therapy by inhibiting vascularization of tumors. $^{2}$

The tripeptide Arg-Gly-Asp (RGD) is the motif of recognition of most integrins on several matrix proteins (vitronectin (VN), fibronectin (FN)). The specificity of each integrin depends on the conformation of the triad induced by the other residues. ${ }^{3}$

To date, several inhibitors have been imagined and prepared. ${ }^{4} \mathrm{~A}$ cyclic pentapeptide ( $c(-\mathrm{RGDf}[\mathrm{NMe}] \mathrm{V}-$ ) cilengitide) was found quite active while a lot of studies have emerged in order to access peptidomimetics. ${ }^{5}$ In these series of compounds, azabicycloalkanes have been developed as versatile scaffolds to mimic peptide conformation. ${ }^{6}$ Their bicyclic ring backbone gives geometry with fixed dihedral angles, on which the acid (Asp) and basic (Arg) side chains can be placed at an optimal distance of $13 \AA$ allowing the recognition.

We have been interested in developing the synthesis of several new structures as integrin inhibitors since we recently developed an efficient synthesis of indolizin-3-one. ${ }^{7}$ We envisaged it as

\footnotetext{
* Corresponding author. Tel.: +3315373 9748; fax: +3314329 1403. E-mail addresses: joelle.perard@univ-paris5.fr (J. Pérard-Viret), sylvie.dufour@ curie.fr (S. Dufour).

† Tel.: +3315624 6335; fax: +33156246349.
}

a scaffold, which could be converted into a potent integrin ligand by introducing a carboxylic and a guanidine appendage (Fig. 1).

\section{Results and discussion}

In this paper, we report the synthesis and the biological activity of RGD peptidomimetics 1 . On this bicyclic compound, the length and the relative geometry of the two side chains bearing the acid and basic functions can be adapted to optimize the affinity with the receptor. The peptidomimetics were evaluated in vitro by cell-adhesion assays.

\subsection{Synthesis of the indolizidine building block}

The first step was the condensation of dimethoxydihydrofuran ${ }^{8}$ (2) with racemic allylglycine (3) in acidic medium (Scheme 1).

This condensation led to lactam $\mathbf{4}$, which was directly cyclized in refluxing formic acid to give only two diastereoisomers at the C7 position 5 and $\mathbf{6}$ (60:40), which can be separated through column chromatography. Practically, the crude reaction mixture was used. The formiate was hydrolyzed by $\mathrm{KHCO}_{3}$ (1.1 equiv) in $\mathrm{MeOH}$ to yield alcohols $\mathbf{7}$ and $\mathbf{8}$ in 86\% yield. The hydroxyl group was protected as a benzyl

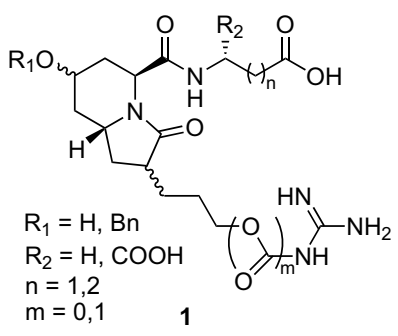

Figure 1. 

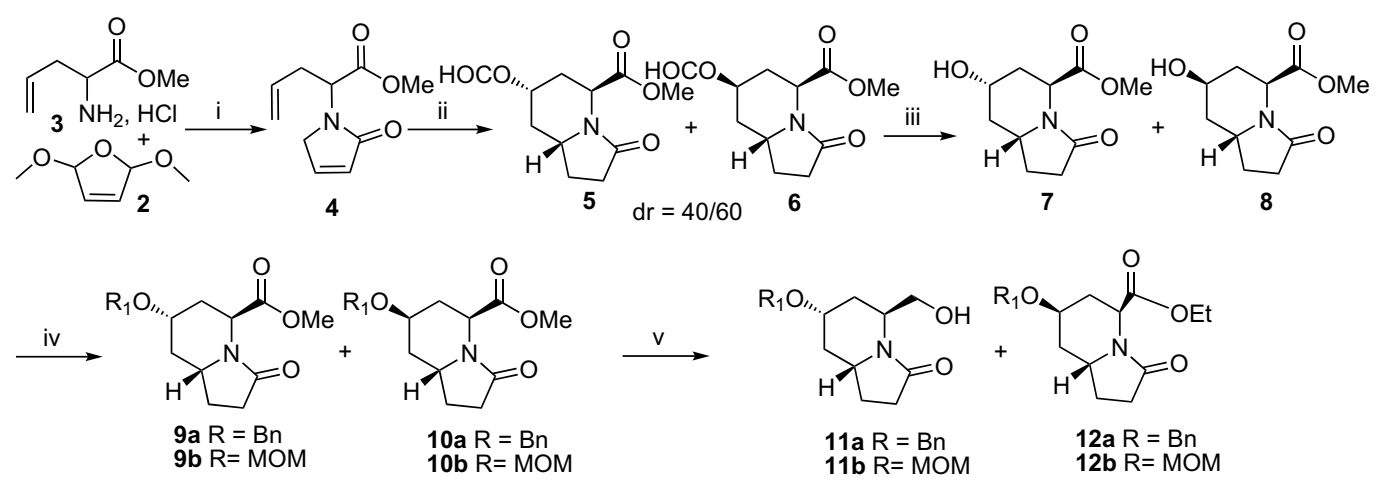

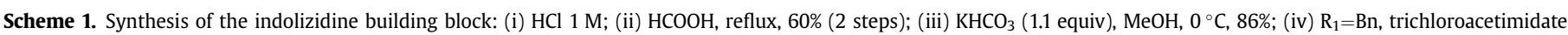

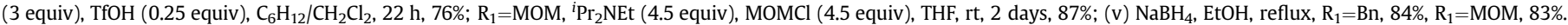

or a MOM ether in good yield to give $\mathbf{9 a}, \mathbf{1 0 a}(\mathbf{7 6} \%)$ and $\mathbf{9 b}, \mathbf{1 0 b}(87 \%)$, respectively.

Their reaction with $\mathrm{NaBH}_{4}$ in refluxing ethanol allowed an easy separation of the two diastereoisomers. Indeed isomer 10a and 10b, which exhibited a cis group were not reduced but just transesterified by ethanol. Compounds 12a, 12b and 11a, 11b were isolated in $84 \%$ and $83 \%$ overall yield. NMR studies made it possible to establish a cis-diaxial relationship between the hydroxyl and ester groups in compound $\mathbf{1 0}$ (or 12) and could explain the chemoselectivity of the $\mathrm{NaBH}_{4}$ reduction.

\subsection{Functionalization of the indolizidine building block}

Having prepared the bicyclic skeleton, we had to introduce the two side chains with an appropriate relative configuration. An allyl group was first introduced ( $\alpha$ to the carbonyl of the lactam) to be transformed into the guanidine. This allylation was performed after deprotonation using LDA in tetrahydrofuran and allyl bromide (Scheme 2). Lactams 11a and 11b bearing the ether and hydroxyl functions in a trans relationship were deprotonated with 2 equiv of LDA to furnish, after treatment with allyl bromide, 16a + 17a $(87: 13$, $46 \%$ yield) and $\mathbf{1 6 b}+\mathbf{1 7 b}(71: 29,54 \%)$, respectively. When the allylation was conducted with the diprotected derivative 13 (MOM and TBDMS ether), $\mathbf{1 4}$ and $\mathbf{1 5}$ were isolated in improved yield and diastereoselectivity $(10: 90,88 \%)$. It is noteworthy that the diastereoselectivity was inverted compared to the free hydroxyl series. Thus both isomer series can be easily attained by using protected or unprotected alcohol. In all cases, the relative configuration of the allyl group was assigned by NOE experiments.

The next task was to perform the functional group interchanges to obtain the acidic and basic side chains.

We anticipated transforming the allyl group into guanidine. Furthermore, different acid side chains could be obtained from the same intermediates. This transformation was attempted with benzyl ether 16a. Actually, this synthetic way was not useful: the yield was low (oxidation of the primary alcohol into acid) and purification of the guanidine compound was difficult (several chromatographies were needed). Consequently, we decided to begin with the acid side chain.

In this sequence, we started working on the acid side chain (Scheme 3). Alcohol 16a was oxidized by Jones reagent to give the acid $\mathbf{1 8}$ in good yield (67\%). Coupling with $\beta$-alanine tert-butyl ester and L-aspartic acid di-tert-butyl ester furnished $\mathbf{1 9}(83 \%)$ and $\mathbf{2 0}(88 \%)$, respectively.

Hydroboration of $\mathbf{1 9}$ or $\mathbf{2 0}$ gave the alcohols 21 (71\%) or 22 (68\%). Contrary to several reports, substitution of the hydroxyl group of 21 by a guanidine through a Mitsunobu reaction with $\mathrm{DIAD} / \mathrm{PPh}_{3}$ and di-Boc- or di-Cbz-guanidine was proved to be unsuccessful. ${ }^{9}$ We thus investigated the more reactive reagents dipiperidinazodicarboxylate (ADDP) and tributylphosphine $\left(\mathrm{Bu}_{3} \mathrm{P}\right){ }^{10}$ Surprisingly, use of these reagents led to an unexpected compound: the guanidine carbamate 23 . $^{11}$

Eventually, starting from compound 22, use of $\mathrm{DEAD} / \mathrm{PPh}_{3}{ }^{4}$ instead DIAD/PPh 3 permitted to access to the guanidilated product 25. Boc deprotection with trifluoroacetic acid gave two new mimics $\mathbf{2 4}$ and 26. Hydrogenation on $\mathrm{Pd} / \mathrm{C}$ of $\mathbf{2 5}$ followed by trifluoroacetic acid treatment also gave another analogue 27.

The same sequence was applied to the trans diastereoisomer 17b (Scheme 4).

Oxidation of alcohol 17b gave acid $\mathbf{2 8}$ in moderate yield (54\%), which was coupled with L-glutamic acid di-tert-butyl ester (90\%). Then after hydroboration of $\mathbf{2 9}$ (65\%), subsequent reaction of thus obtained $\mathbf{3 0}$ with di-Boc-guanidine led to $\mathbf{3 1}$ (carbamate) and $\mathbf{3 3}$ (guanidinium). TFA-cleavage of the tert-butoxy and tert-butoxycarbonyl groups of $\mathbf{3 1}$ and $\mathbf{3 3}$ afforded 32 and 34, respectively.

We investigated the transformation of compounds 12a. When these esters reacted with strong bases, a carbanion was

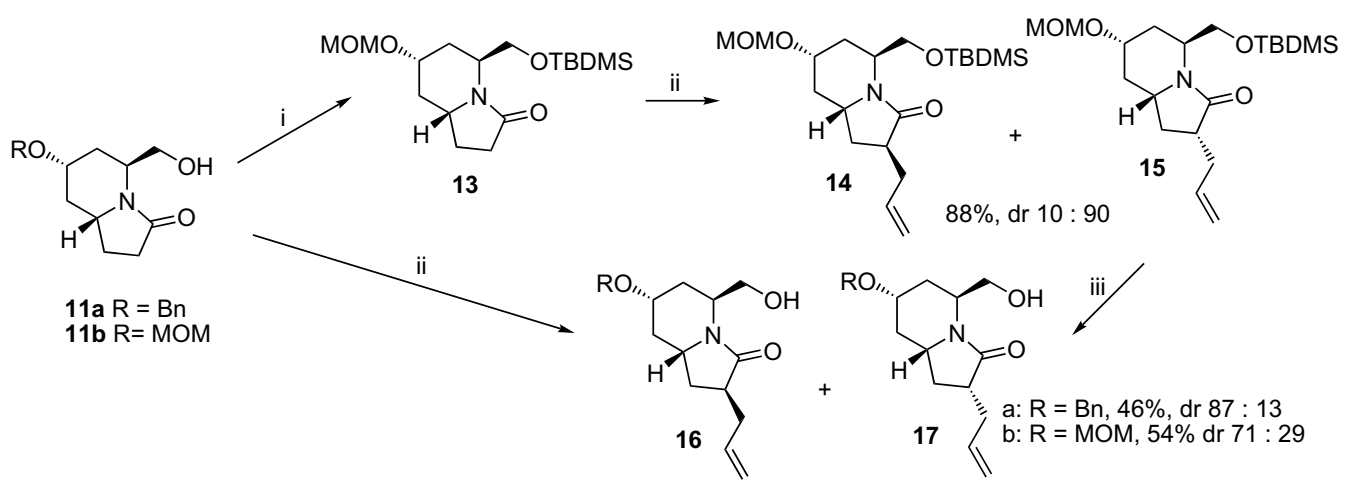

Scheme 2. Allylation of the indolizidine: (i) $\mathrm{Et}{ }_{3} \mathrm{~N}$, TBDMSOTf, $\mathrm{CH}_{2} \mathrm{Cl}_{2},-10{ }^{\circ} \mathrm{C}, 88 \%$; (ii) $\mathrm{LDA},-78{ }^{\circ} \mathrm{C}$, allyl bromide, THF; (iii) $\mathrm{Bu} 4 \mathrm{NF}$, THF, $97 \%$. 


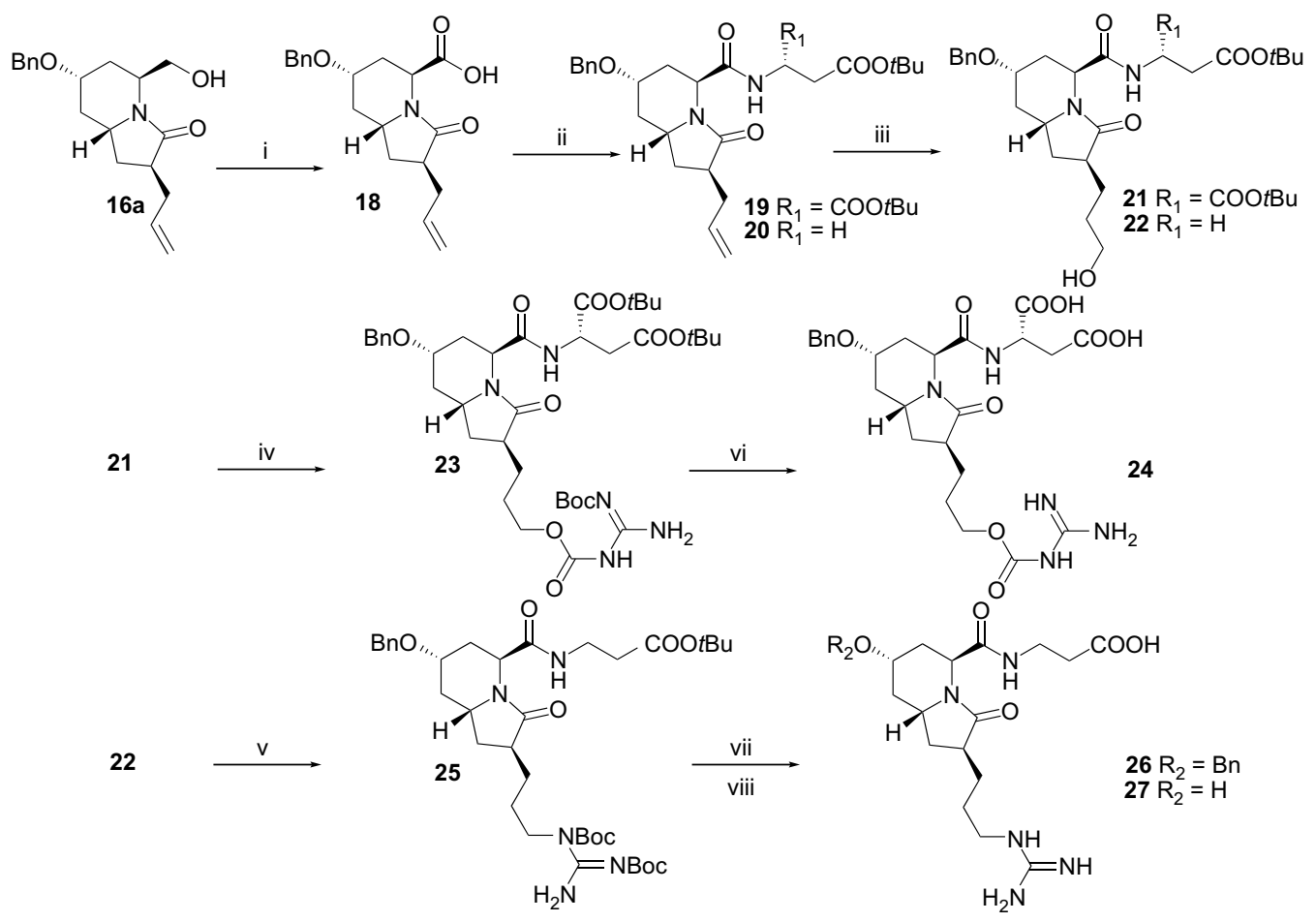

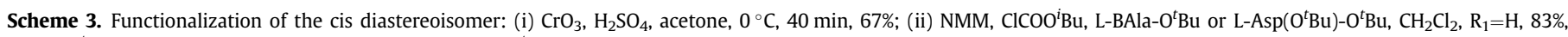

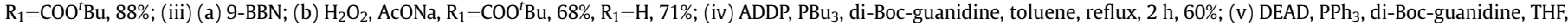
rt, 64 h, 92\%; (vi) TFA, $\mathrm{CH}_{2} \mathrm{Cl}_{2}, 100 \%$; (vii) $\mathrm{R}_{2}=\mathrm{Bn}$, TFA, $\mathrm{CH}_{2} \mathrm{Cl}_{2}, 100 \%$; (viii) $\mathrm{R}_{2}=\mathrm{H}$; (a) $\mathrm{H}_{2} \mathrm{Pd} / \mathrm{C} 10 \%$, 72\%; (b) $\mathrm{TFA}, \mathrm{CH}_{2} \mathrm{Cl}_{2}, 100 \%$.

formed at carbon 5. First, this center was methylated by using KHMDS and methyl iodide in good yield to obtain single diastereoisomer 35 (Scheme 5). Then allylation was performed with the same organic base and allyl bromide, the diastereoselectivity was low (de 20\%) and the yield was moderate (55\%) (Scheme 5).
The double bond of $\mathbf{3 6}$ and $\mathbf{3 7}$ was converted into guanidinium group with $\mathrm{DEAD} / \mathrm{PPh}_{3}$ in good overall yield (54\% and $87 \%$, respectively, for 3 steps). Saponification of ethyl ester was very difficult because of the steric hindrance. We checked several bases: $\mathrm{NaOH}, \mathrm{KOH}, \mathrm{KO}^{t} \mathrm{Bu}, \mathrm{NaSMe}$, LiSMe, leading to no reaction or degradation of the starting material. Indeed, acidic conditions were

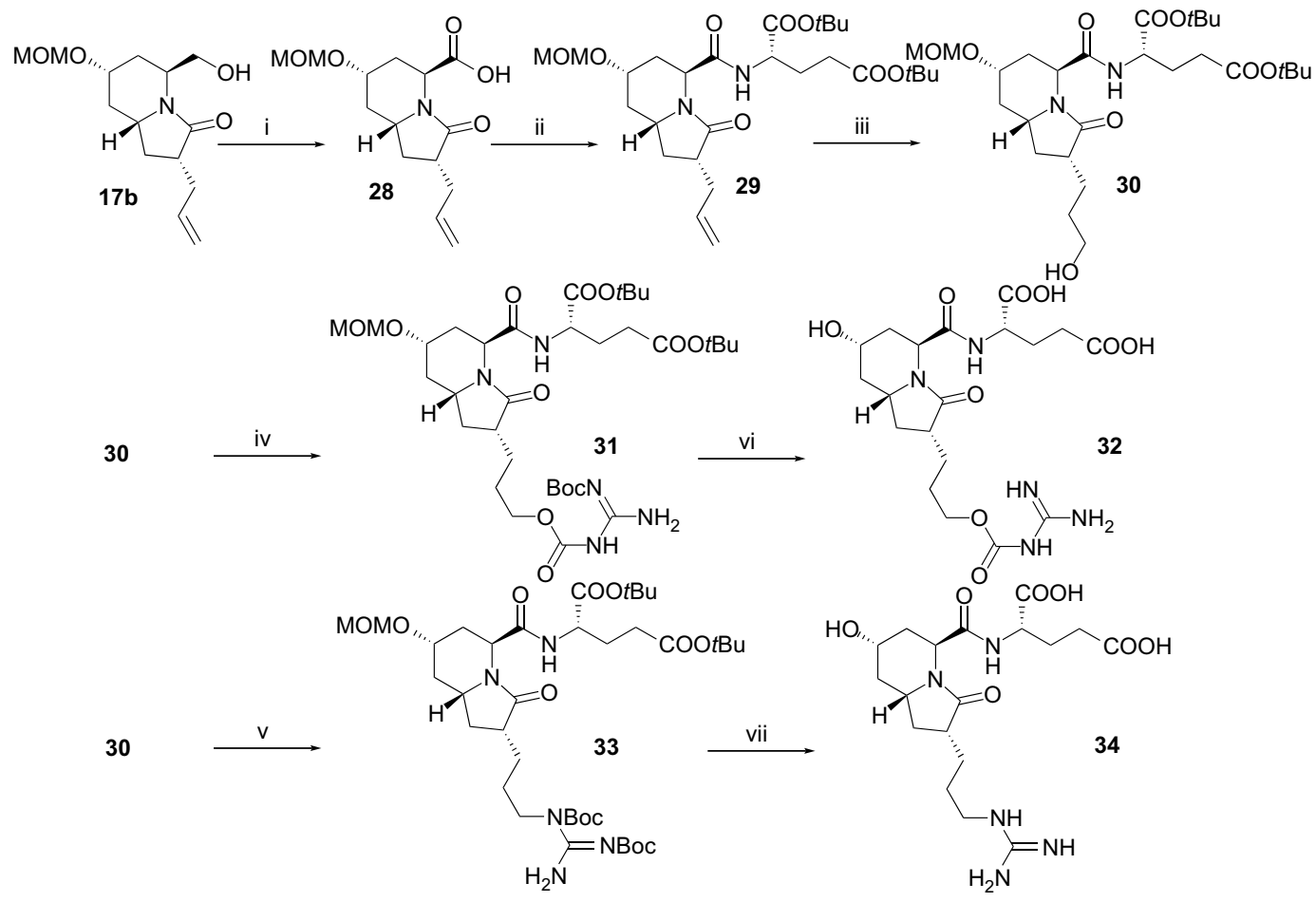

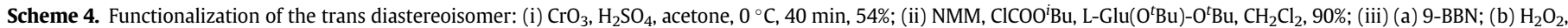
AcONa, 65\%; (iv) ADDP, $\mathrm{PBu}_{3}$, di-Boc-guanidine, THF, reflux, 2 h, 43\%; (v) DEAD, $\mathrm{PPh}_{3}$, di-Boc-guanidine, THF, rt, 64 h, $60 \%$; (vi) TFA, $\mathrm{CH}_{2} \mathrm{Cl}_{2}, 100 \%$; (vii) TFA, $\mathrm{CH}_{2} \mathrm{Cl}_{2}, 100 \%$. 


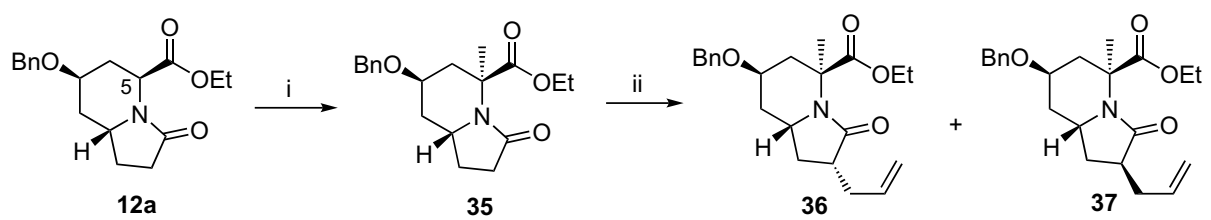

Scheme 5. Allylation of the trans diaxial diastereoisomer: (i) KHMDS, MeI, THF, 99\%; (ii) KHMDS, allyl bromide, 55\%, dr 60:40.

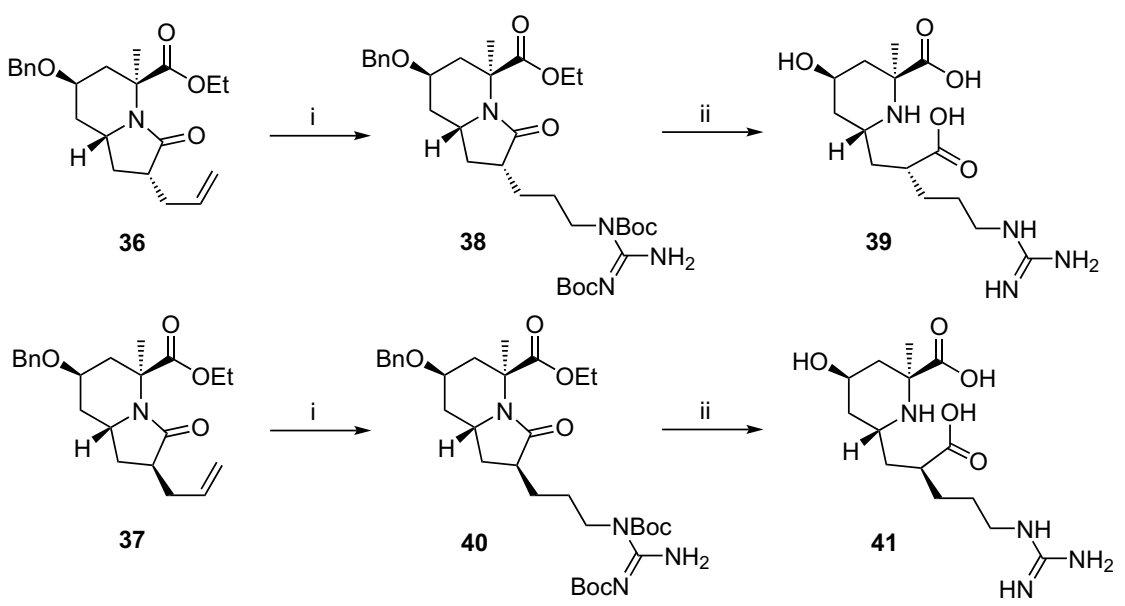

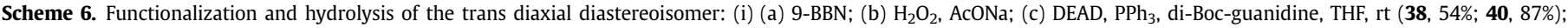
(ii) $\mathrm{EtOH} / \mathrm{H}_{2} \mathrm{O}, \mathrm{HCl} 3 \mathrm{M}, 100 \%$.

needed: hydrolysis in aqueous ethanol with $3 \mathrm{M}$ hydrochloric acid at reflux for $20 \mathrm{~h}$ gave compounds $\mathbf{3 9}$ and $\mathbf{4 1}$ of which the amide bond, the benzyl ether were also hydrolyzed (Scheme 6). These compounds 39 and $\mathbf{4 1}$ had been also considered as potential peptidomimetics and they have been tested in adhesion assays.

We synthesized seven potential peptidomimetics of RGD in racemic form, in 10 or 11 steps and in $0.6 \%$ to $3.4 \%$ total yield from racemic allylglycine.

\subsection{Biological test of the seven peptidomimetics}

The compounds $\mathbf{2 4}, \mathbf{2 6}, \mathbf{2 7}, \mathbf{3 2}, \mathbf{3 4}, \mathbf{3 9}$, and 41 were evaluated in vitro for their ability to inhibit cell adhesion. Their activity was compared to that of $c$ (RGDfV) and GRGES that were used as positive and negative competitors for cell adhesion. We used two different cell lines, mouse sarcoma S180 cells and human vascular endothelial Eahy926 cells. These cells express $\alpha 5 \beta 1$ and $\alpha v \beta 3$ integrins. ${ }^{12}$ The $c$ (RGDfV) peptide strongly inhibited S180 cell adhesion to VN (Fig. 2A, black bars) with $19 \%$ and $5 \%$ of cell adhesion in the presence of $10 \mu \mathrm{M}$ and $200 \mu \mathrm{M}$ of its competitor, respectively. This cyclic peptide inhibited less efficiently S180 cell adhesion to FN-coated surface (Fig. 2B, black bars) with $95 \%$ and $69 \%$ of adhesion in the presence of $10 \mu \mathrm{M}$ and $500 \mu \mathrm{M} c$ (RGDfV), respectively. In contrast, the control peptide GRGES has no inhibitory effect on the two types of coated surfaces (Fig. 2, white bars). Among the peptidomimetics tested, only compounds $\mathbf{2 6}$ and $\mathbf{2 7}$ showed inhibitory effect on S180 cell adhesion to VN but they are less efficient compared to the $c$ (RGDfV). We measured $65 \%$ and $74 \%$ of adhesion in the presence of compound $\mathbf{2 6}$ or $\mathbf{2 7}$ at $200 \mu \mathrm{M}$, respectively (Fig. 2A, dashed bars). They did not interfere with $\mathrm{S} 180$ cell adhesion to FN-coated surfaces.

The $c($ RGDfV) peptide also interfered with Eahy926 adhesion to VN but to a lesser extent compared to S180 cell adhesion, with $74.8 \pm 7.0 \%$ and $9.2 \pm 4.4 \%$ of adhesion measured at $10 \mu \mathrm{M}$ and $200 \mu \mathrm{M} c$ (RGDfV). All compounds tested showed no inhibitory effect on Eahy926 adhesion to VN nor FN-coated surfaces.

\section{Conclusions}

The scaffold of indolizin-3-one was used to prepare seven structures as potential mimics of the RGD tripeptide sequence. These compounds were evaluated in cell-adhesion test. Two of them showed some activities: they possess the acid and guanidine side chains in a cis relationship. This configuration corresponds to the required geometry of a $\beta$-turn (type II). Optimization of the length of the side chains and use of optically active allylglycine as starting material are under investigation.

\section{Experimental section}

\subsection{General experimental methods}

All commercially available reagents were used without further purification unless otherwise noted. Tetrahydrofuran was freshly distilled from benzophenone ketyl radical under argon prior to use. Column chromatography was performed with silica gel (35-70 mesh). Melting points are reported uncorrected.

NMR spectra were recorded on 300 and $400 \mathrm{MHz}$ Bruker Avance spectrometers. Chemical shifts are reported in parts per million. Coupling constants ( $J$ values) are reported in hertz. ${ }^{13} \mathrm{C}$ and ${ }^{1} \mathrm{H}$ peak assignments were made based on DEPT, HMQC, HSQC, HSBC, and NOESY data and IR spectra were recorded on a Perkin Elmer 1600 FT-IR spectrometer. MS experiments were performed on a Q-Tof Micromass-1 spectrometer.

4.1.1. (5S*,75*,8aR*)-7-Hydroxy-3-oxo-octahydro-indolizin-5carboxylic acid methyl ester 7 and $\left(5 S^{*}, 7 R^{*}, 8 a R^{*}\right)-7-h y d r o x y-$ 3-oxo-octahydro-indolizin-5-carboxylic acid methyl ester $\mathbf{8}$

To a solution of formiates 5 and $\mathbf{6}$ ( $10.91 \mathrm{~g}, 45.2 \mathrm{mmol}, 1.0$ equiv) in $210 \mathrm{~mL}$ of anhydrous methanol was added solid $\mathrm{KHCO}_{3}(4.54 \mathrm{~g}$, $45.4 \mathrm{mmol}, 1.0$ equiv) at $0{ }^{\circ} \mathrm{C}$ and the reaction was stirred $40 \mathrm{~min}$ at $0{ }^{\circ} \mathrm{C} . \mathrm{KHCO}_{3}$ was filtered and the filtrate was concentrated in vacuo. 

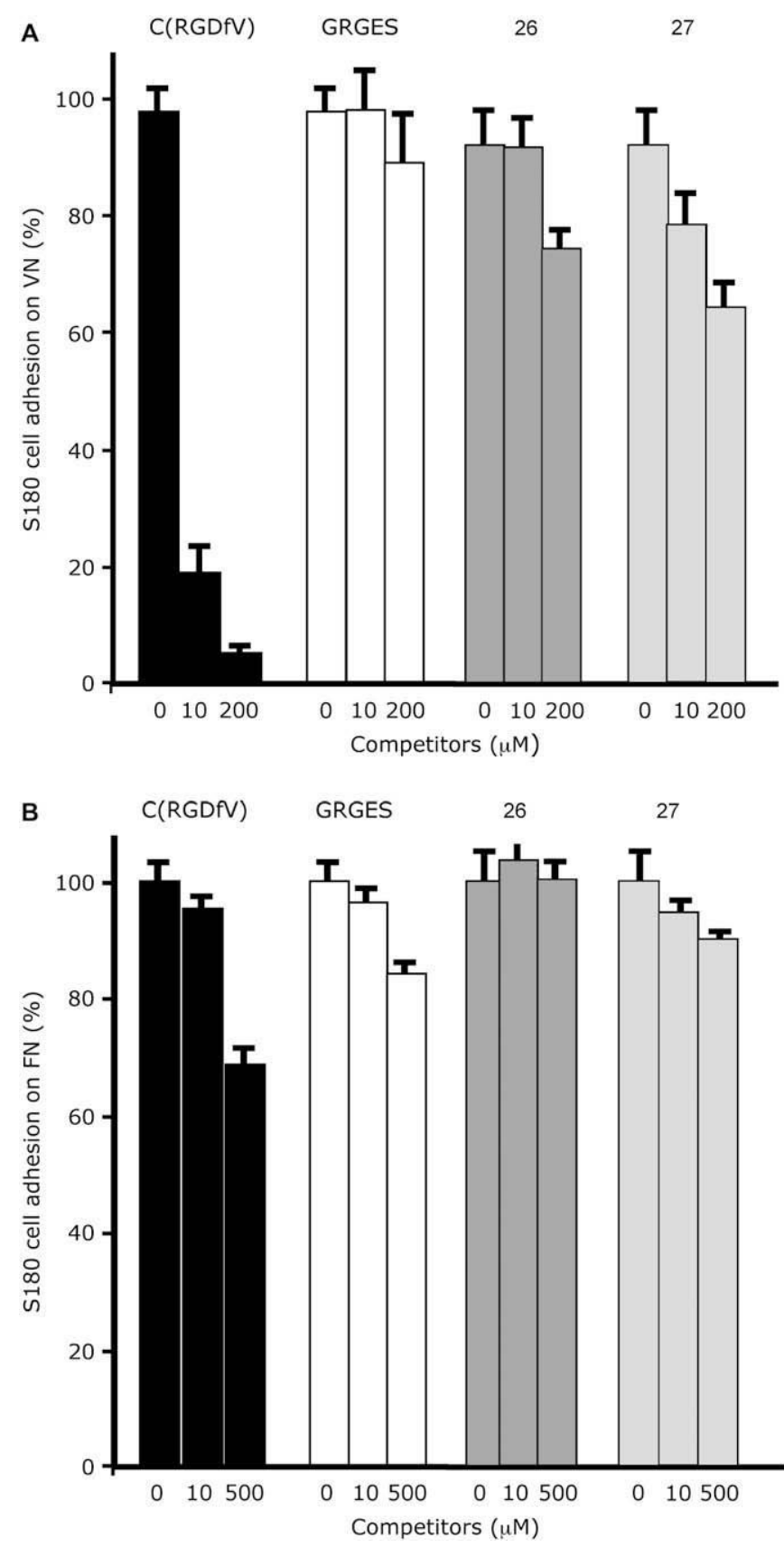

Figure 2.

Purification by flash column chromatography on silica gel (EtOAc/ $\mathrm{MeOH}=95: 5$ then 90:10) gave 7 and $\mathbf{8}$ as a yellow solid ( $8.3 \mathrm{~g}, 86 \%$ ).

A sample of each diastereoisomer was obtained.

Compound 8: $R_{f}=0.3$ (AcOEt/MeOH 90:10), mp: $127{ }^{\circ} \mathrm{C} .{ }^{1} \mathrm{H}$ NMR $\left(\mathrm{CDCl}_{3}, 300 \mathrm{MHz}\right): \delta_{\mathrm{H}} 1.30\left(1 \mathrm{H}, \mathrm{ddd}, J=13.8,12.0,2.2 \mathrm{~Hz}, \mathrm{H}_{8 \mathrm{ax}}\right) ; 1.55$ ( $1 \mathrm{H}$, dddd $\left.J=12.4,9.8,9.8,8.5 \mathrm{~Hz}, \mathrm{H}_{1}\right) ; 1.76$ (1H, ddd, $J=14.3,7.0$, $\left.2.2 \mathrm{~Hz}, \mathrm{H}_{6 \mathrm{ax}}\right) ; 2.01\left(1 \mathrm{H}, \mathrm{dm}, J=13.4 \mathrm{~Hz}, \mathrm{H}_{8 \mathrm{eq}}\right), 2.23$ ( $1 \mathrm{H}$, dddd, $J=12.3$, 9.3, 7.1, 3.0 Hz, $\mathrm{H}_{1}$ ); 2.3-2.5 (3H, m, $\left.2 \mathrm{H}_{2}, \mathrm{H}_{6}\right) ; 3.67$ (3H, s, OMe); 4.08 (1H, dddd, $\left.J=11.8,8.0,8.0,3.5 \mathrm{~Hz}, \mathrm{H}_{8 \mathrm{a}}\right) ; 4.19\left(1 \mathrm{H}, \mathrm{m}, \mathrm{H}_{7 \mathrm{eq}}\right) ; 4.68(1 \mathrm{H}$, $\left.\mathrm{d}(\mathrm{l}), J=6.0 \mathrm{~Hz}, \mathrm{H}_{5}\right) .{ }^{13} \mathrm{C}$ NMR $\left(75 \mathrm{MHz}, \mathrm{CDCl}_{3}\right): \delta_{\mathrm{C}} 25.8\left(\mathrm{C}_{1}\right) ; 30.2\left(\mathrm{C}_{2}\right)$; $32.7\left(\mathrm{C}_{6}\right) ; 38.8\left(\mathrm{C}_{8}\right) ; 48.1\left(\mathrm{C}_{5}\right) ; 49.2\left(\mathrm{C}_{8 \mathrm{a}}\right) ; 52.4\left(\mathrm{C}_{\mathrm{OMe}}\right) ; 63.7\left(\mathrm{C}_{7}\right)$; 171.9, $175.3\left(\mathrm{CO}, \mathrm{C}_{3}\right)$. IR ( NaCl disc, $\left.\mathrm{cm}^{-1}\right): \nu_{\max } 3388,2962,1749$, 1665, 1441, 1313, 1215, 1090, 1071. MS $\left(\mathrm{ES}^{+}\right): m / z=236\left([\mathrm{MNa}]^{+}\right)$. HRMS $\left(\mathrm{ES}^{+},[\mathrm{MNa}]^{+}\right)$: calcd for $\mathrm{C}_{10} \mathrm{H}_{15} \mathrm{NO}_{4}$ 236.0899, found 236.0893 .
Compound 7: $R_{f}=0.3$ (AcOEt/MeOH 90:10), mp: $94{ }^{\circ} \mathrm{C} .{ }^{1} \mathrm{H}$ NMR $\left(\mathrm{CDCl}_{3}, 300 \mathrm{MHz}\right): \delta_{\mathrm{H}} 1.1\left(1 \mathrm{H}, \mathrm{ddd}, J=11.7,11.7,11.7 \mathrm{~Hz}, \mathrm{H}_{8 \mathrm{ax}}\right) ; 1.48$ $\left(1 \mathrm{H}, \mathrm{m}, \mathrm{H}_{6}\right) ; 1.6\left(1 \mathrm{H}, \mathrm{m}, \mathrm{H}_{1}\right) ; 2.09\left(1 \mathrm{H}, \mathrm{br} \mathrm{d}, J=11.8 \mathrm{~Hz}, \mathrm{H}_{8 \mathrm{eq}}\right) ; 2.2(1 \mathrm{H}$, $\left.\mathrm{m}, \mathrm{H}_{1}\right) ; 2.38\left(3 \mathrm{H}, \mathrm{m}, 2 \mathrm{H}_{2}, \mathrm{H}_{6}\right) ; 3.66\left(4 \mathrm{H}, \mathrm{br} \mathrm{s}, \mathrm{OMe}, \mathrm{H}_{7}\right) ; 3.75(1 \mathrm{H}$, dddd, $\left.J=7.5,7.5,7.5,7.5 \mathrm{~Hz}, \mathrm{H}_{8 \mathrm{a}}\right) ; 4.8\left(1 \mathrm{H}, \mathrm{d}(\mathrm{l}), J=5.7 \mathrm{~Hz}, \mathrm{H}_{5}\right) .{ }^{13} \mathrm{C}$ NMR (75 MHz, CDCl 3$): \delta_{\mathrm{C}} 25.5\left(\mathrm{C}_{1}\right) ; 30.4\left(\mathrm{C}_{2}\right) ; 34.7\left(\mathrm{C}_{6}\right) ; 41.8\left(\mathrm{C}_{8}\right)$; $50.2\left(\mathrm{C}_{5}\right) ; 52.6(\mathrm{OMe}) ; 53.9\left(\mathrm{C}_{8 \mathrm{a}}\right) ; 65.2\left(\mathrm{C}_{7}\right) ; 170.9,174.8\left(\mathrm{CO}, \mathrm{C}_{3}\right)$. IR $\left(\mathrm{NaCl}\right.$ disc, $\left.\mathrm{cm}^{-1}\right): \nu_{\max } 3432,2952,1736,1666,1432,1213$. HRMS $\left(\mathrm{ES}^{+},[\mathrm{MNa}]^{+}\right.$): calcd for $\mathrm{C}_{10} \mathrm{H}_{15} \mathrm{NO}_{4}$ 236.0899, found 236. 0909 .

\subsection{2. (5S*,7S*,8aR*)-7-Benzyloxy-3-oxo-octahydro-indolizin-5-} carboxylic acid methyl ester $9 \boldsymbol{a}$ and $\left(5 S^{*}, 7 R^{*}, 8 a R^{*}\right)$-7-benzyloxy-3oxo-octahydro-indolizin-5-carboxylic acid methyl ester 10a

Alcohols 7 and 8 (10.7 g, $50.4 \mathrm{mmol}$ ) were dissolved in $40 \mathrm{~mL}$ of dichloromethane under argon, and $80 \mathrm{~mL}$ of cyclohexane was added. At rt, $19 \mathrm{~mL}$ ( $102 \mathrm{mmol}, 2$ equiv) of benzyl-trichloroacetimidate was added, followed by $440 \mu \mathrm{L}(5 \mathrm{mmol}$, 0.1 equiv) of triflic acid. The mixture was refluxed for $16 \mathrm{~h}, 3 \mathrm{~mL}$ of benzyl-trichloroacetimidate was further added and the reflux was continued for $20 \mathrm{~h}$. The mixture was filtered on silica gel and washed with dichloromethane. The filtrate was evaporated and purification by flash column chromatography on silica gel (EtOAc/ cyclohexane/MeOH=80:15:5) gave 9a and 10a as a colorless oil (13.6 g, 89\%).

Compound 9a: $R_{f}=0.49$ (AcOEt/cyclohexane/MeOH 80:15:5). ${ }^{1} \mathrm{H}$ $\operatorname{NMR}\left(\mathrm{CDCl}_{3}, 300 \mathrm{MHz}\right): \delta_{\mathrm{H}} 1.16\left(1 \mathrm{H}, \mathrm{ddd}, J=11.7,11.7,11.7 \mathrm{~Hz}, \mathrm{H}_{8 \mathrm{ax}}\right)$; $1.58\left(2 \mathrm{H}, \mathrm{m}, \mathrm{H}_{1}, \mathrm{H}_{6 \mathrm{ax}}\right) ; 2.2\left(2 \mathrm{H}, \mathrm{m}, \mathrm{H}_{1}, \mathrm{H}_{8 \mathrm{eq}}\right) ; 2.38\left(2 \mathrm{H}, \mathrm{m}, \mathrm{H}_{2}\right) ; 2.55$ $\left(1 \mathrm{H}, \mathrm{dm}, J=7,5 \mathrm{~Hz}, \mathrm{H}_{6 \mathrm{eq}}\right) ; 3.44(1 \mathrm{H}$, dddd, $J=11.3,11.3,3.8,3.8 \mathrm{~Hz}$, $\left.\mathrm{H}_{7 \mathrm{ax}}\right) ; 3.66$ (3H, s, OMe); $3.73\left(1 \mathrm{H}, \mathrm{m}, \mathrm{H}_{8 \mathrm{a}}\right) ; 4.51\left(2 \mathrm{H}, \mathrm{s}, \mathrm{CH}_{2} \mathrm{Ph}\right) ; 4.89$ $\left(1 \mathrm{H}, \mathrm{d}, J=5.6 \mathrm{~Hz}, \mathrm{H}_{5}\right) ; 7.26(5 \mathrm{H}, \mathrm{m}, \mathrm{Ar}) .{ }^{13} \mathrm{C} \mathrm{NMR}\left(75 \mathrm{MHz}, \mathrm{CDCl}_{3}\right): \delta_{\mathrm{C}}$ $25.2\left(\mathrm{C}_{1}\right) ; 29.9\left(\mathrm{C}_{2}\right) ; 31.7\left(\mathrm{C}_{6}\right) ; 38.8\left(\mathrm{C}_{8}\right) ; 49.8\left(\mathrm{C}_{5}\right) ; 52.2(\mathrm{OMe}) ; 53.3$ $\left(\mathrm{C}_{8 \mathrm{a}}\right) ; 69.9\left(\mathrm{CH}_{2} \mathrm{Ph}\right) ; 72.0\left(\mathrm{C}_{7}\right) ; 127.4\left(3 \mathrm{C}_{\mathrm{Ar}}\right) ; 128.1\left(\mathrm{C}_{\mathrm{Ar}}\right) ; 137.8\left(\mathrm{C}_{\mathrm{Ar}-}\right.$ quat); $170.9,174.8\left(\mathrm{CO}, \mathrm{C}_{3}\right)$. IR ( $\mathrm{NaCl}$ disc, $\left.\mathrm{cm}^{-1}\right): \nu_{\max } 3352,2926$, $1732,1682,1454,1366,1291,1208,1110 . \mathrm{HRMS}\left(\mathrm{ES}^{+},[\mathrm{MNa}]^{+}\right)$: calcd for $\mathrm{C}_{17} \mathrm{H}_{21} \mathrm{NO}_{4} 326.1368$, found 326.1365.

Compound 10a: $R_{f}=0.43$ (AcOEt/cyclohexane/MeOH 80:15:5). ${ }^{1} \mathrm{H}$ $\operatorname{NMR}\left(\mathrm{CDCl}_{3}, 300 \mathrm{MHz}\right): \delta_{\mathrm{H}} 1.29\left(1 \mathrm{H}, \mathrm{ddd}, J=13.7,12.0,2.2 \mathrm{~Hz}, \mathrm{H}_{8 \mathrm{ax}}\right)$; $1.57\left(1 \mathrm{H}\right.$, dddd, $\left.J=12.4,10.5,10.5,8.7 \mathrm{~Hz}, \mathrm{H}_{1}\right) ; 1.71(1 \mathrm{H}, \mathrm{ddd}, J=14.3$, 7.0, $\left.2.1 \mathrm{~Hz}, \mathrm{H}_{6 \mathrm{ax}}\right) ; 2.19$ (1H, dddd, $J=13.4,13.4,13.4,13.4 \mathrm{~Hz}, \mathrm{H}_{8 \mathrm{eq}}$ ); $2.28\left(1 \mathrm{H}, \mathrm{m}, \mathrm{H}_{1}\right) ; 2.40\left(2 \mathrm{H}, \mathrm{m}, 2 \mathrm{H}_{2}\right) ; 2.71(1 \mathrm{H}$, dddd, $J=14.2,3.3,1.7$, $\left.1.7 \mathrm{~Hz}, \mathrm{H}_{6 \mathrm{eq}}\right)$; 3.51 (3H, s, OMe); 3.84 (1H, br s, $\mathrm{H}_{7 \mathrm{eq}}$ ); 4.11 (1H, dddd, $\left.J=11.8,8.4,8.4,3.6 \mathrm{~Hz}, \mathrm{H}_{8 \mathrm{a}}\right) ; 4.41\left(1 \mathrm{H}, \mathrm{d}, J=11.8 \mathrm{~Hz}, \mathrm{CH}_{2} \mathrm{Ph}\right) ; 4.51$ $\left(1 \mathrm{H}, \mathrm{d}, J=11.8 \mathrm{~Hz}, \mathrm{CH}_{2} \mathrm{Ph}\right) ; 4.74\left(1 \mathrm{H}, \mathrm{d}, J=6.0 \mathrm{~Hz}, \mathrm{H}_{5}\right) ; 7.25(5 \mathrm{H}, \mathrm{m}$, $\left.\mathrm{H}_{\mathrm{Ar}}\right) .{ }^{13} \mathrm{C}$ NMR $\left(75 \mathrm{MHz}, \mathrm{CDCl}_{3}\right): \delta_{\mathrm{C}} 25.9\left(\mathrm{C}_{1}\right) ; 29.3\left(\mathrm{C}_{6}\right) ; 30.1\left(\mathrm{C}_{2}\right)$; $37.1\left(\mathrm{C}_{8}\right) ; 48.2\left(\mathrm{C}_{5}\right) ; 49.4\left(\mathrm{C}_{8 \mathrm{a}}\right) ; 52.0(\mathrm{OMe}) ; 70.1\left(\mathrm{CH}_{2} \mathrm{Ph}\right) ; 70.7\left(\mathrm{C}_{7}\right)$; $127.0\left(2 \mathrm{C}_{\mathrm{Ar}}\right) ; 127.4\left(\mathrm{C}_{\mathrm{Ar}}\right) ; 128.2\left(\mathrm{C}_{\mathrm{Ar}}\right) ; 138.2\left(\mathrm{C}_{\mathrm{Arquat}}\right) ; 171.0,174.6$ (CO, C 3 ). IR $\left(\mathrm{NaCl}\right.$ disc, $\left.\mathrm{cm}^{-1}\right): \nu_{\max } 3448,2951,1747,1696,1417$, 1359, 1293, 1209, 1093. MS (ES $\left.{ }^{+}\right): m / z 326\left([\mathrm{MNa}]^{+}\right)$.

\subsection{3. (5S*,7S*,8aR*)-7-Methoxymethoxy-3-oxo-octahydro-} indolizin-5-carboxylic acid methyl ester $\mathbf{9 b}$ and $\left(5 S^{*}, 7 R^{*}, 8 a R^{*}\right)$ 7-methoxymethoxy-3-oxo-octahydro-indolizin-5-carboxylic acid methyl ester $\mathbf{1 0 b}$

To alcohols 7 and 8 (371 $\mathrm{mg}, 1.74 \mathrm{mmol}$ ) dissolved in $7 \mathrm{~mL}$ of anhydrous THF under argon and cooled to $0^{\circ} \mathrm{C}$, were successively added diisopropylethylamine $(860 \mu \mathrm{L}, 5.2 \mathrm{mmol}, 3$ equiv) and chloromethoxymethane ( $395 \mu \mathrm{L}, 5.2 \mathrm{mmol}, 3$ equiv). The mixture was stirred for $20 \mathrm{~h}, 1.5$ equiv of each reagent was added again and stirring was continued for 16 additional hours. After addition of a saturated solution of $\mathrm{NH}_{4} \mathrm{Cl}$, the ester was extracted by $\mathrm{CH}_{2} \mathrm{Cl}_{2}$, the organic layers were dried $\left(\mathrm{MgSO}_{4}\right)$, and concentrated under vacuum. Purification by flash column chromatography on silica gel gave $388 \mathrm{mg}(87 \%)$ of $\mathbf{9 b}$ and $\mathbf{1 0 b}$.

Compound 10b: $R_{f}=0.39$ (AcOEt/cyclohexane/MeOH 80:15:5). ${ }^{1} \mathrm{H}$ $\operatorname{NMR}\left(\mathrm{CDCl}_{3}, 300 \mathrm{MHz}\right): \delta_{\mathrm{H}} 1.25\left(1 \mathrm{H}\right.$, ddd, $\left.J=13.6,11.7,1.9 \mathrm{~Hz}, \mathrm{H}_{8 \mathrm{ax}}\right)$; $1.52\left(1 \mathrm{H}, \mathrm{m}, \mathrm{H}_{1}\right) ; 1.66\left(1 \mathrm{H}, \mathrm{ddd}, J=14.4,7.0,2.0 \mathrm{~Hz}, \mathrm{H}_{6}\right) ; 2.03(1 \mathrm{H}$, 
$\left.\mathrm{dm}, J=13.4 \mathrm{~Hz}, \mathrm{H}_{8 \mathrm{eq}}\right) ; 2.21\left(1 \mathrm{H}, \mathrm{m}, \mathrm{H}_{1}\right) ; 2.26-2.44\left(2 \mathrm{H}, \mathrm{m}, 2 \mathrm{H}_{2}\right) ; 2.48$ $\left(1 \mathrm{H}, \mathrm{br} \mathrm{d}, J=14.4 \mathrm{~Hz}, \mathrm{H}_{6 \mathrm{eq}}\right) ; 3.26$ (3H, s, COOMe); 3.63 (3H, s, OMe); $4.0\left(2 \mathrm{H}, \mathrm{m}, \mathrm{H}_{7}, \mathrm{H}_{8 \mathrm{a}}\right) ; 4.41\left(1 \mathrm{H}, \mathrm{d}, J=6.8 \mathrm{~Hz}, \mathrm{OCH}_{2} \mathrm{O}\right) ; 4.55(1 \mathrm{H}, \mathrm{d}$, $\left.J=6.8 \mathrm{~Hz}, \mathrm{OCH}_{2} \mathrm{O}\right) ; 4.66\left(1 \mathrm{H}, \mathrm{d}, J=6.6 \mathrm{~Hz}, \mathrm{H}_{5}\right) .{ }^{13} \mathrm{C} \mathrm{NMR}(75 \mathrm{MHz}$, $\left.\mathrm{CDCl}_{3}\right): \delta_{\mathrm{C}} 25.9\left(\mathrm{C}_{1}\right) ; 29.9\left(\mathrm{C}_{6}\right) ; 30.2\left(\mathrm{C}_{2}\right) ; 37.2\left(\mathrm{C}_{8}\right) ; 48.2\left(\mathrm{C}_{5}\right) ; 49.5$ $\left(\mathrm{C}_{8 \mathrm{a}}\right) ; 52.2\left(\mathrm{CH}_{2} \mathrm{OMe}\right) ; 55.5(\mathrm{OMe}) ; 67.7\left(\mathrm{C}_{7}\right) ; 94.0\left(\mathrm{OCH}_{2} \mathrm{O}\right) ; 171.2$, $174.9\left(\mathrm{CO}, \mathrm{C}_{3}\right)$. IR $\left(\mathrm{NaCl}\right.$ disc, $\left.\mathrm{cm}^{-1}\right): \nu_{\max } 3478,2950,1747,1682$, 1417, 1209, 1038, 919. MS $\left(\mathrm{ES}^{+}\right): m / z 280\left([\mathrm{MNa}]^{+}\right)$. HRMS $\left(\mathrm{ES}^{+}\right.$, $[\mathrm{MH}]^{+}$): calcd for $\mathrm{C}_{12} \mathrm{H}_{19} \mathrm{NO}_{5} 258.1341$, found 258.1351 .

Compound 9b: $R_{f}=0.46$ (AcOEt/cyclohexane/MeOH 80:15:5). ${ }^{1} \mathrm{H}$ NMR $\left(\mathrm{CDCl}_{3}, 300 \mathrm{MHz}\right): \delta_{\mathrm{H}} 1.19\left(1 \mathrm{H}, \mathrm{ddd}, J=11.7,11.7,11.7 \mathrm{~Hz}, \mathrm{H}_{8 \mathrm{ax}}\right) ; 1.61(2 \mathrm{H}$, $\left.\mathrm{m}, \mathrm{H} 1, \mathrm{H}_{6}\right) ; 2.24\left(2 \mathrm{H}, \mathrm{m}, \mathrm{H} 1, \mathrm{H}_{8}\right) ; 2.3-2.5\left(3 \mathrm{H}, \mathrm{m}, \mathrm{H}_{2}, \mathrm{H}_{6}\right) ; 3.34(3 \mathrm{H}, \mathrm{s}$, $\mathrm{OMe}) ; 3.63\left(1 \mathrm{H}, \mathrm{m}, \mathrm{H}_{7}\right) ; 3.72(3 \mathrm{H}, \mathrm{s}, \mathrm{OMe}) ; 3.80\left(1 \mathrm{H}, \mathrm{m}, \mathrm{H}_{8 \mathrm{a}}\right) ; 4.65(2 \mathrm{H}, \mathrm{s}$, $\left.\mathrm{OCH}_{2} \mathrm{O}\right) ; 4.9\left(1 \mathrm{H}, \mathrm{d}, J=5.7 \mathrm{~Hz}, \mathrm{H}_{5}\right) .{ }^{13} \mathrm{CNMR}\left(75 \mathrm{MHz}, \mathrm{CDCl}_{3}\right): \delta_{\mathrm{C}} 25.5\left(\mathrm{C}_{1}\right)$; $30.2\left(\mathrm{C}_{2}\right)$; $32.5\left(\mathrm{C}_{6}\right)$; $39.7\left(\mathrm{C}_{8}\right) ; 50.1\left(\mathrm{C}_{5}\right)$; $52.2(\mathrm{OMe}) ; 53.5\left(\mathrm{C}_{8 \mathrm{a}}\right) ; 70.9\left(\mathrm{C}_{7}\right)$; $95.0\left(\mathrm{OCH}_{2} \mathrm{O}\right) ; 170.9,174.2\left(\mathrm{CO}, \mathrm{C}_{3}\right)$.

\subsection{4. (5S*,7R*,8aR*)-7-Benzyloxy-3-oxo-octahydro-indolizin-}

5-carboxylic acid ethyl ester 12a

To a mixture of 9a and 10a $(4.7 \mathrm{~g}, 15.5 \mathrm{mmol}$, cis/trans 20:80) dissolved in $250 \mathrm{~mL}$ of absolute alcohol, sodium borohydride $(6 \mathrm{~g}$, $159 \mathrm{mmol}, 10$ equiv) was added. The mixture was refluxed for $3 \mathrm{~h}$. After cooling, the solution was concentrated under vacuum, borane precipitates were filtrated and washed with $\mathrm{CH}_{2} \mathrm{Cl}_{2}$. The filtrate was concentrated under reduced pressure and the residue was diluted with $\mathrm{CH}_{2} \mathrm{Cl}_{2}$ and $\mathrm{H}_{2} \mathrm{O}$, extracted twice by $\mathrm{CH}_{2} \mathrm{Cl}_{2}$. The organic phase was dried with $\mathrm{MgSO}_{4}$ and evaporated to dryness, where after the residue was purified by flash chromatography on silica gel (EtOAc/MeOH 99:1 to $90: 10)$ to afford $780 \mathrm{mg}$ of 11a as a light yellow oil (16\%, $80 \%$ from 10a) and $2.9 \mathrm{~g}$ of 12a as a white solid (68\%, 85\% from $\mathbf{9 a}$ ).

$R_{f}=0.28$ (AcOEt). ${ }^{1} \mathrm{H}$ NMR $\left(\mathrm{CDCl}_{3}, 300 \mathrm{MHz}\right): \delta_{\mathrm{H}} 1.11(3 \mathrm{H}, \mathrm{t}, J=7.2$, $\left.\mathrm{CH}_{3}\right) ; 1.28\left(1 \mathrm{H}\right.$, ddd, $\left.J=13.8,12.0,2.3 \mathrm{~Hz}, \mathrm{H}_{8 \mathrm{ax}}\right) ; 1.56(1 \mathrm{H}$, dddd, $\left.J=12.4,9.6,9.6,9.1 \mathrm{~Hz}, \mathrm{H}_{1}\right) ; 1.70$ (1H, ddd, $\left.J=14.4,7.1,2.2 \mathrm{~Hz}, \mathrm{H}_{6 \mathrm{ax}}\right)$; $2.10\left(1 \mathrm{H}\right.$, ddd, $\left.J=13.4,13.4,13.4 \mathrm{~Hz}, \mathrm{H}_{8 \mathrm{eq}}\right) ; 2.25$ (1H, dddd, $J=12.2$, 9.4, 6.8, $\left.2.7 \mathrm{~Hz}, \mathrm{H}_{1}\right) ; 2.42\left(2 \mathrm{H}, \mathrm{m}, 2 \mathrm{H}_{2}\right) ; 2.71$ (1H, dddd, $J=14.3,3.2$, 1.6, $\left.1.6 \mathrm{~Hz}, \mathrm{H}_{6 \mathrm{eq}}\right) ; 3.83\left(1 \mathrm{H}, \mathrm{m}, \mathrm{H}_{7}\right) ; 3.92(1 \mathrm{H}, \mathrm{dq}, J=10.7,7.2 \mathrm{~Hz}$, $\left.\mathrm{OCH}_{2}\right) ; 4.02\left(1 \mathrm{H}, \mathrm{dq}, J=10.7,7.2 \mathrm{~Hz}, \mathrm{OCH}_{2}\right) ; 4.11(1 \mathrm{H}$, dddd, $J=11.8$, 8.5, 8.5, 3.4 Hz, $\left.\mathrm{H}_{8 \mathrm{a}}\right) ; 4.41\left(1 \mathrm{H}, \mathrm{d}, J=11.9 \mathrm{~Hz}, \mathrm{CH}_{2} \mathrm{Ph}\right) ; 4.52(1 \mathrm{H}, \mathrm{d}$, $\left.J=11.9 \mathrm{~Hz}, \mathrm{CH}_{2} \mathrm{Ph}\right) ; 4.72\left(1 \mathrm{H}, \mathrm{br} \mathrm{d}, J=5.9 \mathrm{~Hz}, \mathrm{H}_{5}\right) ; 7.27(5 \mathrm{H}, \mathrm{m}, \mathrm{Ar}) .{ }^{13} \mathrm{C}$ $\operatorname{NMR}\left(75 \mathrm{MHz}, \mathrm{CDCl}_{3}\right): \delta_{\mathrm{C}} 14.0\left(\mathrm{CH}_{3}\right) ; 26.1\left(\mathrm{C}_{1}\right) ; 29.3\left(\mathrm{C}_{6}\right) ; 30.4\left(\mathrm{C}_{2}\right)$; $37.1\left(\mathrm{C}_{8}\right) ; 48.4\left(\mathrm{C}_{5}\right) ; 49.6\left(\mathrm{C}_{8 \mathrm{a}}\right) ; 61.3\left(\mathrm{CH}_{2} \mathrm{O}\right) ; 70.2\left(\mathrm{CH}_{2} \mathrm{Ph}\right) ; 70.6\left(\mathrm{C}_{7}\right)$; $94.0\left(\mathrm{OCH}_{2} \mathrm{O}\right) ; 127.1\left(2 \mathrm{C}_{\mathrm{Ar}}\right) ; 127.5\left(\mathrm{C}_{\mathrm{Ar}}\right) ; 128.3\left(2 \mathrm{C}_{\mathrm{Ar}}\right) ; 138.4\left(\mathrm{C}_{\text {Arquat }}\right)$; 170.7, 174.9 (CO, $\left.\mathrm{C}_{3}\right)$. IR ( $\mathrm{NaCl}$ disc, $\left.\mathrm{cm}^{-1}\right): \nu_{\max } 3468,2935,1742$, 1694, 1417, 1292, 1198, 1093. MS $\left(\mathrm{ES}^{+}\right): \mathrm{m} / z 340\left([\mathrm{MNa}]^{+}\right)$. HRMS $\left(\mathrm{ES}^{+},[\mathrm{MNa}]^{+}\right)$: calcd for $\mathrm{C}_{18} \mathrm{H}_{23} \mathrm{NO}_{4} 340.1525$, found 340.1534 .

\subsection{5. (5S*,7S*,8aR*)-7-Benzyloxy-5-hydroxymethyl-hexahydro- indolizin-3-one 11a}

$R_{f}=0.39$ (AcOEt/MeOH 90:10), mp: $95{ }^{\circ} \mathrm{C} .{ }^{1} \mathrm{H}$ NMR $\left(\mathrm{CDCl}_{3}\right.$, $300 \mathrm{MHz}): \delta_{\mathrm{H}} 1.17\left(1 \mathrm{H}, \mathrm{ddd}, J=11.8,11.8,11.8 \mathrm{~Hz}, \mathrm{H}_{8 \mathrm{ax}}\right) ; 1.47(1 \mathrm{H}$, ddd, $\left.J=12.9,11.6,6.6 \mathrm{~Hz}, \mathrm{H}_{6 \mathrm{ax}}\right) ; 1.59$ (1H, dddd, $J=12.5,9.6,9.6$, $\left.7.3 \mathrm{~Hz}, \mathrm{H}_{1}\right) ; 2.2\left(3 \mathrm{H}, \mathrm{m}, \mathrm{H}_{6}, \mathrm{H}_{8 \mathrm{eq}}, \mathrm{H}_{1}\right) ; 2.38\left(2 \mathrm{H}, \mathrm{m}, \mathrm{H}_{2}\right) ; 3.56(2 \mathrm{H}, \mathrm{d}$, $\left.J=7.0 \mathrm{~Hz}, \mathrm{CH}_{2} \mathrm{O}\right) ; 3.7\left(2 \mathrm{H}, \mathrm{m}, \mathrm{H}_{7}, \mathrm{H}_{8 \mathrm{a}}\right) ; 4.35(1 \mathrm{H}$, ddd, $J=6.7,6.7$, $\left.6.7 \mathrm{~Hz}, \mathrm{H}_{5}\right) ; 4.54\left(2 \mathrm{H}, \mathrm{s}, \mathrm{OCH}_{2} \mathrm{Ph}\right) ; 7.30(5 \mathrm{H}, \mathrm{m}, \mathrm{Ar}) .{ }^{13} \mathrm{C} \mathrm{NMR}$ $\left(75 \mathrm{MHz}, \mathrm{CDCl}_{3}\right): \delta_{\mathrm{C}} 19.7\left(\mathrm{C}_{1}\right) ; 29.2\left(\mathrm{C}_{2}\right) ; 29.9\left(\mathrm{C}_{6}\right) ; 38.4\left(\mathrm{C}_{8}\right) ; 48.5$ $\left(\mathrm{C}_{5}\right) ; 52.0\left(\mathrm{C}_{8 \mathrm{a}}\right) ; 60.5\left(\mathrm{CH}_{2} \mathrm{O}\right) ; 68.7\left(\mathrm{CH}_{2} \mathrm{Ph}\right) ; 70.8\left(\mathrm{C}_{7}\right) ; 126.2\left(3 \mathrm{C}_{\mathrm{Ar}}\right)$; $127.2\left(2 \mathrm{C}_{\mathrm{Ar}}\right) ; 137.6\left(\mathrm{C}_{\text {Arquat }}\right) ; 174.9\left(\mathrm{C}_{3}\right)$. IR $\left(\mathrm{KBr}\right.$ disc, $\left.\mathrm{cm}^{-1}\right): \nu_{\max }$ 3319, 2943, 1742, 1664, 1458, 1290, 1100, 1074, 740. HRMS $\left(\mathrm{ES}^{+}\right.$, $[\mathrm{MH}]^{+}$): calcd for $\mathrm{C}_{16} \mathrm{H}_{21} \mathrm{NO}_{3} 276.1600$, found 276.1602. Anal. Calcd for $\mathrm{C}_{16} \mathrm{H}_{21} \mathrm{NO}_{3}$ : C, 69.79; $\mathrm{H}, 7.69 ; \mathrm{N}, 5.09$. Found: C, 69.33; H, 7.74; $\mathrm{N}$, $4.99 \%$.

\subsection{6. (5S*,7R*,8aR*)-7-Methoxymethoxy-3-oxo-octahydro-} indolizin-5-carboxylic acid ethyl ester $\mathbf{1 2 b}$

To a mixture of $\mathbf{9 b}$ and $\mathbf{1 0 b} 128 \mathrm{mg}(0.5 \mathrm{mmol}$, cis/trans 74:26) dissolved in $10 \mathrm{~mL}$ of absolute alcohol, sodium borohydride
(189 mg, $5 \mathrm{mmol}, 10$ equiv) was added. The solution was refluxed for $3 \mathrm{~h}$. After cooling, the solution was concentrated under vacuum, borane precipitates were filtrated, and washed with $\mathrm{CH}_{2} \mathrm{Cl}_{2}$. The filtrate was concentrated under reduced pressure, the residue was diluted with $\mathrm{CH}_{2} \mathrm{Cl}_{2}$ and $10 \mathrm{~mL}$ of $\mathrm{H}_{2} \mathrm{O}$, extracted twice by $\mathrm{CH}_{2} \mathrm{Cl}_{2}$. The organic phase was dried with $\mathrm{MgSO}_{4}$ and evaporated to dryness, where after the residue was purified by flash chromatography on silica gel (EtOAc/cyclohexane 95:5, 99:1 to EtOAc/MeOH 95:5) to afford $86 \mathrm{mg}$ of $\mathbf{1 2 b}$ as a colorless oil (63\%,86\% from 10b) and $23 \mathrm{mg}$ of $\mathbf{1 1 b}$ as a colorless oil $(20 \%, 77 \%$ from $\mathbf{9 b})$.

$R_{f}=0.38$ (AcOEt/cyclohexane/MeOH 80:15:5). ${ }^{1} \mathrm{H}$ NMR $\left(\mathrm{CDCl}_{3}\right.$, $300 \mathrm{MHz}$ ): $\delta_{\mathrm{H}} 1.10\left(3 \mathrm{H}, \mathrm{t}, J=7.2 \mathrm{~Hz}, \mathrm{CH}_{2} \mathrm{CH}_{3}\right) ; 1.25$ ( $1 \mathrm{H}$, ddd, $J=13.8$, 12.1, $\left.2.2 \mathrm{~Hz}, \mathrm{H}_{8 \mathrm{ax}}\right) ; 1.43$ (1H, dddd, $\left.J=12.4,9.8,9.8,8.9 \mathrm{~Hz}, \mathrm{H}_{1}\right) ; 1.58$ (1H, ddd, $\left.J=14.4,7.1,2.3 \mathrm{~Hz}, \mathrm{H}_{6}\right) ; 1.95$ (1H, ddd, $J=13.4,13.4,13.4 \mathrm{~Hz}$, $\left.\mathrm{H}_{8 \mathrm{eq}}\right) ; 2.12\left(1 \mathrm{H}\right.$, dddd, $\left.J=12.3,8.3,5.4,2.6 \mathrm{~Hz}, \mathrm{H}_{1}\right) ; 2.22(1 \mathrm{H}$, ddd, $\left.J=17.0,9.7,2.6 \mathrm{~Hz}, \mathrm{H}_{2}\right) ; 2.29\left(1 \mathrm{H}, \mathrm{m}, \mathrm{H}_{2}\right) ; 2.40(1 \mathrm{H}, \mathrm{dddd}, J=14.4,3.3$, 1.7, $\left.1.7 \mathrm{~Hz}, \mathrm{H}_{6 \mathrm{eq}}\right)$; 3.19 (3H, s, OMe); $3.89\left(2 \mathrm{H}, \mathrm{m}, \mathrm{H}_{7}, \mathrm{H}_{8 \mathrm{a}}\right) ; 3.97(1 \mathrm{H}$, dq, $\left.J=10.8,7.1 \mathrm{~Hz}, \mathrm{CH}_{2} \mathrm{O}\right) ; 4.03\left(1 \mathrm{H}, \mathrm{dq}, J=10.8,7.2 \mathrm{~Hz}, \mathrm{CH}_{2} \mathrm{O}\right) ; 4.27$ $\left(1 \mathrm{H}, \mathrm{d}, J=6.8 \mathrm{~Hz}, \mathrm{OCH}_{2} \mathrm{O}\right) ; 4.43\left(1 \mathrm{H}, \mathrm{d}, J=6.7 \mathrm{~Hz}, \mathrm{OCH}_{2} \mathrm{O}\right) ; 4.48(1 \mathrm{H}$, $\left.\mathrm{dd}, J=6.6,1.1 \mathrm{~Hz}, \mathrm{H}_{5}\right) .{ }^{13} \mathrm{C}$ NMR $\left(75 \mathrm{MHz}, \mathrm{CDCl}_{3}\right): \delta_{\mathrm{C}} 14.1\left(\mathrm{CH}_{3} \mathrm{CH}_{2} \mathrm{O}\right)$; $26.0\left(\mathrm{C}_{1}\right) ; 29.3\left(\mathrm{C}_{6}\right) ; 30.3\left(\mathrm{C}_{2}\right) ; 37.1\left(\mathrm{C}_{8}\right) ; 48.3\left(\mathrm{C}_{5}\right) ; 49.5\left(\mathrm{C}_{8 \mathrm{a}}\right) ; 55.4$ $\left(\mathrm{CH}_{2} \mathrm{OMe}\right) ; 61.1\left(\mathrm{OCH}_{2} \mathrm{CH}_{3}\right) ; 67.7\left(\mathrm{C}_{7}\right) ; 93.9\left(\mathrm{OCH}_{2} \mathrm{O}\right) ; 170.4,174.8$ $\left(\mathrm{CO}, \mathrm{C}_{3}\right)$. IR ( $\mathrm{NaCl}$ disc, $\left.\mathrm{cm}^{-1}\right): \nu_{\max } 3468,2938,1744,1694,1417$, $1292,1199,1038 . \mathrm{MS}\left(\mathrm{ES}^{+}\right): \mathrm{m} / z 294\left([\mathrm{MNa}]^{+}\right) . \operatorname{HRMS}\left(\mathrm{ES}^{+},[\mathrm{MH}]^{+}\right)$: calcd for $\mathrm{C}_{13} \mathrm{H}_{21} \mathrm{NO}_{5} 272.1498$, found 272.1494.

\subsection{7. (5S*,7S*,8aR*)-5-Hydroxymethyl-7-methoxymethoxy- \\ hexahydro-indolizin-3-one 11b}

$R_{f}=0.09$ (AcOEt/cyclohexane/MeOH 80:15:5). ${ }^{1} \mathrm{H}$ NMR $\left(\mathrm{CDCl}_{3}\right.$, $300 \mathrm{MHz}): \delta_{\mathrm{H}} 1.13\left(1 \mathrm{H}\right.$, ddd, $\left.J=11.7,11.7,11.7 \mathrm{~Hz}, \mathrm{H}_{8 \mathrm{ax}}\right) ; 1.44(1 \mathrm{H}$, ddd, $\left.J=13.2,13.2,6.6 \mathrm{~Hz}, \mathrm{H}_{6}\right) ; 1.58\left(1 \mathrm{H}, \mathrm{m}, \mathrm{H}_{1}\right) ; 2.05(1 \mathrm{H}, \mathrm{br} \mathrm{d}$, $\left.J=13.2 \mathrm{~Hz}, \mathrm{H}_{6}\right) ; 2.18\left(2 \mathrm{H}, \mathrm{m}, \mathrm{H}_{1}, \mathrm{H}_{8 \mathrm{eq}}\right) ; 2.35\left(2 \mathrm{H}, \mathrm{m}, 2 \mathrm{H}_{2}\right) ; 3.30$ (3H, s, OMe); $3.57\left(2 \mathrm{H}\right.$, br d, $\left.J=6.7 \mathrm{~Hz}, \mathrm{CH}_{2} \mathrm{OH}\right) ; 3.67\left(1 \mathrm{H}, \mathrm{m}, \mathrm{H}_{8 \mathrm{a}}\right) ; 3.83(1 \mathrm{H}$, $\left.\mathrm{m}, \mathrm{H}_{7}\right) ; 4.30\left(1 \mathrm{H}\right.$, ddd, $\left.J=6.6,6.6,6.6 \mathrm{~Hz}, \mathrm{H}_{5}\right) ; 4.62\left(2 \mathrm{H}, \mathrm{br} \mathrm{s}, \mathrm{OCH}_{2} \mathrm{O}\right)$. ${ }^{13} \mathrm{C}$ NMR $\left(75 \mathrm{MHz}, \mathrm{CDCl}_{3}\right): \delta_{\mathrm{C}} 25.4\left(\mathrm{C}_{1}\right) ; 30.5\left(\mathrm{C}_{2}\right) ; 31.6\left(\mathrm{C}_{6}\right) ; 40.3$ $\left(\mathrm{C}_{8}\right) ; 49.7\left(\mathrm{C}_{5}\right) ; 53.2\left(\mathrm{C}_{8 \mathrm{a}}\right) ; 55.4\left(\mathrm{CH}_{2} \mathrm{OMe}\right) ; 62.5\left(\mathrm{CH}_{2} \mathrm{OH}\right) ; 70.4\left(\mathrm{C}_{7}\right)$; $94.9\left(\mathrm{OCH}_{2} \mathrm{O}\right) ; 175.0\left(\mathrm{C}_{3}\right)$. IR $\left(\mathrm{NaCl}\right.$ disc, $\left.\mathrm{cm}^{-1}\right): \nu_{\max } 2943,1672$, 1656, 1421, 1287, 1111, 1064. HRMS $\left(\mathrm{ES}^{+},[\mathrm{MH}]^{+}\right)$: calcd for $\mathrm{C}_{11} \mathrm{H}_{19} \mathrm{NO}_{4}$ 252.1212, found 272.1205.

4.1.8. (2S*,5S*,7S*,8aR*)-2-Allyl-7-benzyloxy-5-hydroxymethylhexahydro-indolizin-3-one 16a and $\left(2 R^{*}, 5 S^{*}, 7 S^{*}, 8 a R^{*}\right)-2$-allyl-7benzyloxy-5-hydroxymethyl-hexahydro-indolizin-3-one 17a

A $15 \mathrm{~mL}$ LDA solution in THF (from diisopropylamine, $22.1 \mathrm{mmol}, 3.1 \mathrm{~mL}, 2.1$ equiv) and $\operatorname{BuLi}(1.94 \mathrm{M})$ in hexane (22.1 mmol, $11.4 \mathrm{~mL}$ ) cooled to $-78{ }^{\circ} \mathrm{C}$ was cannulated to amide $11 \mathrm{a}$ (10.5 mmol, $2.9 \mathrm{~g})$ in THF $(35 \mathrm{~mL})$ maintained at $-78^{\circ} \mathrm{C}$ under argon. The solution was stirred at the same temperature for $20 \mathrm{~min}$ and allyl bromide ( $11.6 \mathrm{mmol}, 1 \mathrm{~mL}, 1.1$ equiv) was slowly added. The mixture was stirred at $-78^{\circ} \mathrm{C}$ for $2 \mathrm{~h}$ and then treated with an aqueous saturated $\mathrm{NH}_{4} \mathrm{Cl}$ solution $(20 \mathrm{~mL})$. The aqueous phase was extracted several times with $\mathrm{CH}_{2} \mathrm{Cl}_{2}$. The organic phase was then dried with $\mathrm{MgSO}_{4}$ and the solvent removed in vacuo. The residue was purified by flash chromatography (AcOEt/MeOH 99.5:0.5 to 95:5) to give the two diastereomeric compounds 16a and 17a in a $87: 13$ ratio and a $46 \%$ overall yield ( $827 \mathrm{mg}$ of pure $\mathbf{1 6 a}$ as a pale yellow oil, $97 \mathrm{mg}$ of pure 17a as a pale yellow oil and $778 \mathrm{mg}$ of a mixture were isolated).

Compound 16a: $R_{f}=0.42$ (AcOEt/MeOH: 98/2). ${ }^{1} \mathrm{H} \mathrm{NMR}\left(\mathrm{CDCl}_{3}\right.$, $400 \mathrm{MHz}): \delta_{\mathrm{H}} 1.17\left(1 \mathrm{H}, \mathrm{ddd}, J=11.6,11.6,11.6 \mathrm{~Hz}, \mathrm{H}_{8 \mathrm{ax}}\right) ; 1.51(1 \mathrm{H}, \mathrm{m}$, $\left.\mathrm{H}_{6}\right) ; 1.79\left(1 \mathrm{H}, \mathrm{m}, \mathrm{H}_{1}\right) ; 2.01\left(1 \mathrm{H}, \mathrm{m}, \mathrm{H}_{1}\right) ; 2.13-2.28\left(3 \mathrm{H}, \mathrm{m}, \mathrm{H}_{6}, \mathrm{H}_{8}\right.$, $\left.\mathrm{CH}_{2} \mathrm{CH}=\mathrm{CH}_{2}\right) ; 2.44\left(1 \mathrm{H}, \mathrm{m}, \mathrm{CH}_{2} \mathrm{CH}=\mathrm{CH}_{2}\right) ; 2.59\left(1 \mathrm{H}, \mathrm{m}, \mathrm{H}_{2}\right) ; 3.1(1 \mathrm{H}$, br s, $\mathrm{H}-\mathrm{O})$; $3.5-3.8\left(4 \mathrm{H}, \mathrm{m}, \mathrm{CH}_{2} \mathrm{OH}, \mathrm{H}_{8 \mathrm{a}}, \mathrm{H}_{7}\right) ; 4.38$ (1H, ddbr d, $J=6.8$, $\left.6.8,6.8 \mathrm{~Hz}, \mathrm{H}_{5}\right) ; 4.55\left(2 \mathrm{H}, \mathrm{s}, \mathrm{CH}_{2} \mathrm{Ph}\right) ; 5.06(1 \mathrm{H}$, br d, $J=9.1 \mathrm{~Hz}$, $\left.\mathrm{CH}_{2}=\mathrm{CH}\right) ; 5.09\left(1 \mathrm{H}\right.$, br d, $\left.J=9.1 \mathrm{~Hz}, \mathrm{CH}_{2}=\mathrm{CH}\right) ; 5.77(1 \mathrm{H}$, dddd, $\left.J=16.0,9.0,7.0,7.0 \mathrm{~Hz}, \mathrm{CH}_{2}=\mathrm{CH}\right) ; 7.27$ (5H, m, Ar). ${ }^{13} \mathrm{C}$ NMR 
(75 MHz, $\left.\mathrm{CDCl}_{3}\right): \delta_{\mathrm{C}} 30.3\left(\mathrm{C}_{1}\right) ; 30.8\left(\mathrm{C}_{6}\right) ; 35.8\left(\mathrm{CH}_{2} \mathrm{CH}=\mathrm{CH}_{2}\right) ; 39.4$ $\left(\mathrm{C}_{8}\right) ; 40.9\left(\mathrm{C}_{2}\right) ; 49.7\left(\mathrm{C}_{5}\right) ; 51.4\left(\mathrm{C}_{8 \mathrm{a}}\right) ; 62.4\left(\mathrm{CH}_{2} \mathrm{OH}\right) ; 70.1\left(\mathrm{CH}_{2} \mathrm{Ph}\right)$; $71.8\left(\mathrm{C}_{7}\right) ; 117.3\left(\mathrm{CH}_{2}=\mathrm{CH}\right) ; 127.5 ; 127.6 ; 128.3\left(2 \mathrm{C}_{\mathrm{Ar}}, \mathrm{C}_{\mathrm{Ar}}, 2 \mathrm{C}_{\mathrm{Ar}}\right)$; $135.0\left(\mathrm{CH}_{2}=\mathrm{CH}\right) ; 138.1$ ( $\left.\mathrm{C}_{\text {Arquat }}\right) ; 176.4\left(\mathrm{C}_{3}\right)$. IR ( $\left.\mathrm{NaCl} \operatorname{disc}, \mathrm{cm}^{-1}\right)$ : $\nu_{\max } 3391,2942,1681,1650,1454,1367,1280,1094,917,739 . \mathrm{MS}$ $\left(\mathrm{ES}^{+}\right): \mathrm{m} / z 338\left([\mathrm{MNa}]^{+}\right) \cdot \mathrm{HRMS}\left(\mathrm{ES}^{+},[\mathrm{MNa}]^{+}\right)$: calcd for $\mathrm{C}_{19} \mathrm{H}_{25} \mathrm{NO}_{3}$ 338.1732, found 338.1717 .

Compound 17a: $R_{f}=0.5 \quad$ (AcOEt/MeOH 98:2). ${ }^{1} \mathrm{H} \quad\left(\mathrm{CDCl}_{3}\right.$, $300 \mathrm{MHz}$ ): $\delta_{\mathrm{H}} 1.11\left(1 \mathrm{H}, \mathrm{ddd}, J=11.7,11.7,11.7 \mathrm{~Hz}, \mathrm{H}_{8 \mathrm{ax}}\right) ; 1.3$ (1H, ddd, $\left.J=11.3,11.3,11.3 \mathrm{~Hz}, \mathrm{H}_{1}\right) ; 1.49$ (1H, ddd, $\left.J=13.1,11.6,6.6 \mathrm{~Hz}, \mathrm{H}_{6}\right) ; 2.1$ $\left(2 \mathrm{H}, \mathrm{m}, \mathrm{H}_{6}, \mathrm{CH}_{2} \mathrm{CH}=\mathrm{CH}_{2}\right) ; 2.3\left(2 \mathrm{H}, \mathrm{m}, \mathrm{H}_{1}, \mathrm{H}_{8}\right) ; 2.57\left(2 \mathrm{H}, \mathrm{m}, \mathrm{H}_{2}\right.$, $\left.\mathrm{CH}_{2} \mathrm{CH}=\mathrm{CH}_{2}\right)$; $3.1(1 \mathrm{H}$, br s, $\mathrm{H}-\mathrm{O}) ; 3.57\left(3 \mathrm{H}, \mathrm{m}, \mathrm{H}_{8 \mathrm{a}}, \mathrm{CH}_{2} \mathrm{OH}\right) ; 3.68$ (1H, dddd, $\left.J=11.2,11.2,4.0,4.0 \mathrm{~Hz}, \mathrm{H}_{7}\right) ; 4.37$ (1H, ddd, $J=6.7,6.7$, $\left.6.7 \mathrm{~Hz}, \mathrm{H}_{5}\right) ; 4.52\left(2 \mathrm{H}, \mathrm{s}, \mathrm{CH}_{2} \mathrm{Ph}\right) ; 5.02\left(1 \mathrm{H}, \mathrm{dd}, J=10.1,1.6 \mathrm{~Hz}, \mathrm{H}_{14}\right.$, $\left.\mathrm{CH}_{2 \mathrm{cis}}=\mathrm{CH}\right) ; 5.05\left(1 \mathrm{H}, \mathrm{dd}, J=17.1,1.6 \mathrm{~Hz}, \mathrm{CH}_{2 \text { trans }}=\mathrm{CH}\right) ; 5.71(1 \mathrm{H}$, dddd, $\left.J=16.9,10.1,6.8,6.8 \mathrm{~Hz}, \mathrm{CH}_{2}=\mathrm{CH}\right) ; 7.3(5 \mathrm{H}, \mathrm{m}, \mathrm{Ar}) .{ }^{13} \mathrm{C} \mathrm{NMR}$ $\left(100 \mathrm{MHz}, \mathrm{CDCl}_{3}\right): \delta_{\mathrm{C}} 31.1\left(\mathrm{C}_{6}\right) ; 32.4\left(\mathrm{C}_{1}\right) ; 35.4\left(\mathrm{CH}_{2} \mathrm{CH}=\mathrm{CH}_{2}\right) ; 40.0$ $\left(\mathrm{C}_{8}\right) ; 41.3\left(\mathrm{C}_{2}\right) ; 49.9\left(\mathrm{C}_{5}\right) ; 51.5\left(\mathrm{C}_{8 \mathrm{a}}\right) ; 62.5\left(\mathrm{CH}_{2} \mathrm{OH}\right) ; 70.4\left(\mathrm{CH}_{2} \mathrm{Ph}\right)$; $72.0\left(\mathrm{C}_{7}\right) ; 117.0\left(\mathrm{CH}_{2}=\mathrm{CH}\right) ; 127.7\left(2 \mathrm{C}_{\mathrm{Ar}}\right) ; 127.8\left(\mathrm{C}_{\mathrm{Ar}}\right) ; 128.5\left(2 \mathrm{C}_{\mathrm{Ar}}\right)$; $135.5\left(\mathrm{CH}_{2}=\mathrm{CH}\right) ; 138.4$ (C $\left.\mathrm{C}_{\text {Arquat }}\right) ; 176.0\left(\mathrm{C}_{3}\right)$. IR ( $\left.\mathrm{NaCl} \mathrm{disc,} \mathrm{cm}^{-1}\right)$ : $\nu_{\max } 3396,2927,2867,1666,1454,1367 . \mathrm{MS}\left(\mathrm{ES}^{+}\right): \mathrm{m} / z 316\left([\mathrm{MH}]^{+}\right)$, $338\left([\mathrm{MNa}]^{+}\right), 354\left([\mathrm{MK}]^{+}\right)$. HRMS $\left(\mathrm{ES}^{+},[\mathrm{MNa}]^{+}\right)$: calcd for $\mathrm{C}_{19} \mathrm{H}_{25} \mathrm{NO}_{3} 338.1732$, found 338.1732 .

4.1.9. (2S*,5S*,7S*,8aR*)-2-Allyl-5-hydroxymethyl-7methoxymethoxy-hexahydro-indolizin-3-one $\mathbf{1 6 b}$ and $\left(2 R^{*}, 5 S^{*}, 7 S^{*}, 8 a R^{*}\right)$-2-allyl-5-hydroxymethyl-7-methoxy-

methoxy-hexahydro-indolizin-3-one 17b

The same experimental procedure as described for allylation was applied to lactam 11b (100 mg, $0.43 \mathrm{mmol}$ ) using LDA prepared from diisopropylamine ( $152 \mu \mathrm{L}, 1.07 \mathrm{mmol}, 2.5$ equiv) and butyllithium $2.28 \mathrm{M}(471 \mu \mathrm{L}, 1.07 \mathrm{mmol}, 2.5$ equiv). Stirring was maintained $3 \mathrm{~h}$ after addition of allyl bromide ( $41 \mu \mathrm{L}, 0.47 \mathrm{mmol}$, 1.1 equiv). Flash chromatography on silica gel (AcOEt/MeOH 95:5) allowed the isolation of $\mathbf{1 6 b}$ and $\mathbf{1 7 b}$ as a $71: 29$ ratio in a $54 \%$ yield (17b: $8 \mathrm{mg}$ as a pale yellow oil, 16b: $22 \mathrm{mg}$ as a pale yellow oil and $32 \mathrm{mg}$ of a mixture).

Compound 16b: $R_{f}=0.38$ (AcOEt/MeOH 90:10). ${ }^{1} \mathrm{H} \mathrm{NMR}\left(\mathrm{CDCl}_{3}\right.$, $300 \mathrm{MHz}): \delta_{\mathrm{H}} 1.15\left(1 \mathrm{H}, \mathrm{ddd}, J=11.7,11.7,11.7 \mathrm{~Hz}, \mathrm{H}_{8 \mathrm{ax}}\right) ; 1.33(1 \mathrm{H}, \mathrm{m}$, $\left.\mathrm{H}_{1}\right) ; 1.55\left(1 \mathrm{H}\right.$, ddd, $\left.J=13.2,11.7,6.7 \mathrm{~Hz}, \mathrm{H}_{6 \mathrm{ax}}\right) ; 2.11\left(2 \mathrm{H}, \mathrm{m}, \mathrm{H}_{6 \mathrm{eq}}, \mathrm{CH}_{2}\right.$ $\left.\mathrm{CH}=\mathrm{CH}_{2}\right) ; 2.28\left(1 \mathrm{H}\right.$, br d, $\left.J=12.1 \mathrm{~Hz}, \mathrm{H}_{8 \mathrm{eq}}\right) ; 2.37(1 \mathrm{H}$, ddd, $J=12.6$, 8.5, $\left.6.7 \mathrm{~Hz}, \mathrm{H}_{1}\right) ; 2.61\left(2 \mathrm{H}, \mathrm{m}, \mathrm{H}_{2}, \mathrm{CH}_{2} \mathrm{CH}=\mathrm{CH}_{2}\right) ; 3.39(3 \mathrm{H}, \mathrm{s}$, $\left.\mathrm{CH}_{2} \mathrm{OMe}\right) ; 3.62\left(1 \mathrm{H}, \mathrm{m}, \mathrm{H}_{8 \mathrm{a}}\right) ; 3.66\left(2 \mathrm{H}, \mathrm{d}, J=6.9 \mathrm{~Hz}, \mathrm{CH}_{2} \mathrm{OH}\right) ; 3.87$ (1H, dddd, $\left.J=11.4,11.4,4.3,4.3 \mathrm{~Hz}, \mathrm{H}_{7 \mathrm{ax}}\right) ; 4.4$ (1H, ddd, $J=6.7,6.7$, $\left.6.7 \mathrm{~Hz}, \mathrm{H}_{5 \mathrm{eq}}\right) ; 4.7\left(2 \mathrm{H}, \mathrm{s}, \mathrm{OCH}_{2} \mathrm{O}\right) ; 5.06(1 \mathrm{H}, \mathrm{dd}, J=10.1,1.6 \mathrm{~Hz}$, $\left.\mathrm{CH}_{2}=\mathrm{CH}\right) ; 5.11\left(1 \mathrm{H}, \mathrm{dd}, J=17.1,1.6 \mathrm{~Hz}, \mathrm{CH}_{2}=\mathrm{CH}\right) ; 5.27(1 \mathrm{H}$, dddd, $\left.J=17.0,10.1,6.8,6.8 \mathrm{~Hz}, \mathrm{CH}_{2}=\mathrm{CH}\right) .{ }^{13} \mathrm{C} \mathrm{NMR}\left(\mathrm{CDCl}_{3}, 100 \mathrm{MHz}\right): \delta_{\mathrm{C}}$ $31.6\left(\mathrm{C}_{6}\right) ; 32.6\left(\mathrm{C}_{1}\right) ; 35.4\left(\mathrm{CH}_{2} \mathrm{CH}=\mathrm{CH}_{2}\right) ; 40.4\left(\mathrm{C}_{8}\right) ; 41.3\left(\mathrm{C}_{2}\right) ; 49.8$ $\left(\mathrm{C}_{5}\right) ; 51.3\left(\mathrm{C}_{8 \mathrm{a}}\right) ; 55.5\left(\mathrm{CH}_{2} \mathrm{OMe}\right) ; 63.5\left(\mathrm{CH}_{2} \mathrm{OH}\right) ; 70.5\left(\mathrm{C}_{7}\right) ; 95.0$ $\left(\mathrm{OCH}_{2} \mathrm{O}\right) ; 126.9\left(\mathrm{CH}_{2}=\mathrm{CH}\right) ; 135.5\left(\mathrm{CH}_{2}=\mathrm{CH}\right) ; 176.3\left(\mathrm{C}_{3}\right)$. IR $(\mathrm{NaCl}$ disc, $\left.\mathrm{cm}^{-1}\right): \nu_{\max } 3403,2931,1667,1436,1276,1151,1105,1039,916$. MS $\left(\mathrm{ES}^{+}\right): m / z 270\left([\mathrm{MH}]^{+}\right), 292\left([\mathrm{MNa}]^{+}\right) . \mathrm{HRMS}\left(\mathrm{ES}^{+},[\mathrm{MNa}]^{+}\right)$: calcd for $\mathrm{C}_{14} \mathrm{H}_{23} \mathrm{NO}_{4} 292.1525$, found 292.1534 .

From 15: to silyl compound 15 (35 $\mathrm{mg} ; 0.87 \mathrm{mmol}$ ) dissolved in $14 \mathrm{~mL}$ of anhydrous THF was added slowly a solution $1 \mathrm{M}$ of tetrabutylammonium fluoride in THF ( $2.6 \mathrm{~mL}, 2.6 \mathrm{mmol}, 3$ equiv) at $0{ }^{\circ} \mathrm{C}$. Stirring was continued $30 \mathrm{~min}$ after removal of the ice bath. At $0{ }^{\circ} \mathrm{C} 7 \mathrm{~mL}$ of water was added and the mixture was extracted three times with dichloromethane. The organic phase was dried with $\mathrm{MgSO}_{4}$ and the solvent removed in vacuo. The residue was purified by flash chromatography (AcOEt/MeOH 97:3) to give 17b as a pale yellow oil (226 mg, 97\%).

Compound 17b: $R_{f}=0.44$ (AcOEt/MeOH 90:10). ${ }^{1} \mathrm{H}$ NMR $\left(\mathrm{CDCl}_{3}\right.$, $300 \mathrm{MHz}): \delta_{\mathrm{H}} 1.16\left(1 \mathrm{H}\right.$, ddd, $\left.J=11.6,11.6,11.6 \mathrm{~Hz}, \mathrm{H}_{8 \mathrm{ax}}\right) ; 1.48(1 \mathrm{H}$, ddd, $\left.J=13.1,11.7,6.7 \mathrm{~Hz}, \mathrm{H}_{6 \mathrm{ax}}\right) ; 1.77$ (1H, ddd, $J=13.1,9.5,6.3 \mathrm{~Hz}, \mathrm{H}_{1}$ ); $2.0\left(1 \mathrm{H}, \mathrm{m}, \mathrm{H}_{1}\right) ; 2.07\left(1 \mathrm{H}, \mathrm{ddd}, J=13.3,13.3,13.3 \mathrm{~Hz}, \mathrm{H}_{6 \mathrm{eq}}\right) ; 2.2(2 \mathrm{H}$, $\left.\mathrm{m}, \mathrm{H}_{8 \mathrm{eq}}, \mathrm{CH}_{2} \mathrm{CH}=\mathrm{CH}_{2}\right) ; 2.45\left(1 \mathrm{H}, \mathrm{m}, \mathrm{CH}_{2} \mathrm{CH}=\mathrm{CH}_{2}\right) ; 2.57$ (1H, dddd, $\left.J=4.3,4.3,8.8,8.8 \mathrm{~Hz}, \mathrm{H}_{2}\right) ; 3.34\left(3 \mathrm{H}, \mathrm{s}, \mathrm{CH}_{2} \mathrm{OMe}\right) ; 3.61(2 \mathrm{H}, \mathrm{d}$, $\left.J=7.2 \mathrm{~Hz}, \mathrm{CH}_{2} \mathrm{OH}\right) ; 3.65\left(1 \mathrm{H}, \mathrm{m}, \mathrm{H}_{8 \mathrm{a}}\right) ; 3.85(1 \mathrm{H}$, dddd, $J=11.3,11.3$, $\left.4.2,4.2 \mathrm{~Hz}, \mathrm{H}_{7 \mathrm{ax}}\right) ; 4.38$ (1H, ddd, $\left.J=6.7,6.7,6.7 \mathrm{~Hz}, \mathrm{H}_{5 \mathrm{eq}}\right) ; 4.65(2 \mathrm{H}, \mathrm{d}$, $\left.J=1.2 \mathrm{~Hz}, \mathrm{OCH}_{2} \mathrm{O}\right) ; 5.06\left(2 \mathrm{H}, \mathrm{m}, \mathrm{CH}_{2}=\mathrm{CH}\right) ; 5.76(1 \mathrm{H}$, dddd, $J=17.0$, 10.1, 7.0, 7.0 Hz, $\left.\mathrm{CH}_{2}=\mathrm{CH}\right) .{ }^{13} \mathrm{C}$ NMR $\left(75 \mathrm{MHz}, \mathrm{CDCl}_{3}\right): \delta_{\mathrm{C}} 30.3\left(\mathrm{C}_{1}\right)$; $31.4\left(\mathrm{C}_{6}\right) ; 35.8\left(\mathrm{CH}_{2}-\mathrm{CH}=\mathrm{CH}_{2}\right) ; 40.0\left(\mathrm{C}_{8}\right) ; 40.9\left(\mathrm{C}_{2}\right) ; 49.7\left(\mathrm{C}_{5}\right) ; 51.4$ $\left(\mathrm{C}_{8 \mathrm{a}}\right) ; 55.4\left(\mathrm{CH}_{2} \mathrm{OMe}\right) ; 62.5\left(\mathrm{CH}_{2} \mathrm{OH}\right) ; 70.4\left(\mathrm{C}_{7}\right) ; 94.8\left(\mathrm{OCH}_{2} \mathrm{O}\right) ; 117.3$ $\left(\mathrm{CH}_{2}=\mathrm{CH}\right) ; 135.1\left(\mathrm{CH}_{2}=\mathrm{CH}\right) ; 176.4\left(\mathrm{C}_{3}\right)$. IR $\left(\mathrm{NaCl}\right.$ disc, $\left.\mathrm{cm}^{-1}\right): \nu_{\max }$

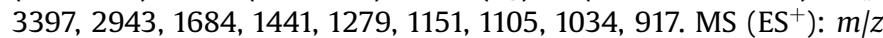
$270\left([\mathrm{MH}]^{+}\right)$. HRMS $\left(\mathrm{ES}^{+},[\mathrm{MNa}]^{+}\right)$: calcd for $\mathrm{C}_{14} \mathrm{H}_{23} \mathrm{NO}_{4} 292.1525$, found 292.1520 .

\subsubsection{0. (5S*,7S*,8aR*)-5-(tert-Butyl-dimethyl-silyloxymethyl)- \\ 7-methoxymethoxy-hexahydro-indolizin-3-one 13}

Alcohol $11 b$ (343 mg, $1.5 \mathrm{mmol}$ ) in $\mathrm{CH}_{2} \mathrm{Cl}_{2}(10 \mathrm{~mL})$ was cooled to $-10{ }^{\circ} \mathrm{C}$ and triethylamine ( $525 \mu \mathrm{L}, 3.75 \mathrm{mmol}, 2.5$ equiv) and tertbutyl-dimethylsilyl triflate $(444 \mu \mathrm{L}, 1.95 \mathrm{mmol}, 1.3$ equiv) were added. The solution was stirred between -5 and $-10{ }^{\circ} \mathrm{C}$ for $30 \mathrm{~min}$ and an aqueous saturated $\mathrm{NaHCO}_{3}$ solution $(3 \mathrm{~mL})$ was added. The aqueous solution was extracted with $\mathrm{CH}_{2} \mathrm{Cl}_{2}$. The organic phase was washed with water $(2 \mathrm{~mL})$ and then $\mathrm{NaCl}$ solution, dried, and the solvent removed in vacuo. The residue was purified by flash chromatography on silica gel (ether/MeOH 99.5:0.5). Silyl ether 13 was obtained as a pale yellow oil in $88 \%$ yield ( $453 \mathrm{mg}$ ).

$R_{f}=0.45$ (ether/MeOH 99:1). ${ }^{1} \mathrm{H}$ NMR $\left(\mathrm{CDCl}_{3}, 300 \mathrm{MHz}\right): \delta_{\mathrm{H}} 0.04$ (3H, s, SiMe); 0.06 (3H, s, SiMe); 0.89 (9H, s, Sit $\left.{ }^{t} \mathrm{Bu}\right) ; 1.15$ (1H, ddd, $\left.J=11.8,11.8,11.8 \mathrm{~Hz}, \mathrm{H}_{8 \mathrm{ax}}\right) ; 1.49$ (1H, ddd, $J=13.2,11.8,6.7 \mathrm{~Hz}, \mathrm{H}_{6 \mathrm{ax}}$ ); $1.61\left(1 \mathrm{H}\right.$, dddd, $\left.J=12.4,9.5,9.5,7.5 \mathrm{~Hz}, \mathrm{H}_{1}\right) ; 2.20\left(3 \mathrm{H}, \mathrm{m}, \mathrm{H}_{6 \mathrm{eq}}, \mathrm{H}_{8 \mathrm{eq}}\right.$, $\left.\mathrm{H}_{1}\right) ; 2.37\left(2 \mathrm{H}, \mathrm{m}, 2 \mathrm{H}_{2}\right) ; 3.36(3 \mathrm{H}, \mathrm{s}, \mathrm{OMe}) ; 3.61(1 \mathrm{H}, \mathrm{dd}, J=10.0$, $4.7 \mathrm{~Hz}, \mathrm{CH}_{2} \mathrm{O}$ ); 3.68 ( $1 \mathrm{H}, \mathrm{dd}, J=10.0,6.0 \mathrm{~Hz}, \mathrm{CH}_{2} \mathrm{OH}$ ); 3.76 (1H, dddd, $\left.J=11.5,7.3,7.3,3.1 \mathrm{~Hz}, \mathrm{H}_{8 \mathrm{a}}\right) ; 4.06(1 \mathrm{H}$, dddd, $J=11.3,11.3,4.2,4.2 \mathrm{~Hz}$, $\left.\mathrm{H}_{7 \mathrm{ax}}\right) ; 4.30\left(1 \mathrm{H}\right.$, ddd, $\left.J=5.8,5.8,5.8 \mathrm{~Hz}, \mathrm{H}_{5 \mathrm{eq}}\right) ; 4.68\left(2 \mathrm{H}, \mathrm{s}, \mathrm{OCH}_{2} \mathrm{O}\right)$. ${ }^{13} \mathrm{C}$ NMR $\left(\mathrm{CDCl}_{3}, 100 \mathrm{MHz}\right): \delta_{\mathrm{C}}-5.49, \quad-5.53$ (2SiMe); 18.1 $\left(\mathrm{SiC}\left(\mathrm{CH}_{3}\right)_{3}\right) ; 25.7\left(\mathrm{C}_{1}\right) ; 25.9\left(3 \mathrm{SiC}\left(\mathrm{CH}_{3}\right)_{3}\right) ; 30.5\left(\mathrm{C}_{2}\right) ; 32.1\left(\mathrm{C}_{6}\right) ; 40.1$ $\left(\mathrm{C}_{8}\right) ; 49.0\left(\mathrm{C}_{5}\right) ; 54.2\left(\mathrm{C}_{8 \mathrm{a}}\right) ; 55.3(\mathrm{OMe}) ; 64.0\left(\mathrm{CH}_{2} \mathrm{O}\right) ; 70.5\left(\mathrm{C}_{7}\right) ; 94.8$ $\left(\mathrm{OCH}_{2} \mathrm{O}\right) ; 173.8\left(\mathrm{C}_{3}\right)$. IR ( $\mathrm{NaCl}$ disc, $\left.\mathrm{cm}^{-1}\right): \nu_{\max } 2886,1689,1416$,

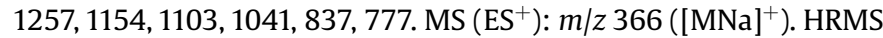
$\left(\mathrm{ES}^{+},[\mathrm{MNa}]^{+}\right)$: calcd for $\mathrm{C}_{17} \mathrm{H}_{33} \mathrm{NO}_{4} \mathrm{Si} 366.2077$, found 366.2072.

4.1.11. $\left(2 S^{*}, 5 S^{*}, 7 S^{*}, 8 a R^{*}\right)-2-$ Allyl-5-(tert-butyl-dimethyl-silyloxymethyl)-7-methoxymethoxy-hexahydro-indolizin-3-one 14 and $\left(2 R^{*}, 5 S^{*}, 7 S^{*}, 8 a R^{*}\right)$-2-allyl-5-(tert-butyl-dimethyl-silyloxy-

methyl)-7-methoxymethoxy-hexahydro-indolizin-3-one 15

The same experimental procedure as described for allylation was applied to lactame $13(120 \mathrm{mg}, 0.35 \mathrm{mmol})$ using LDA prepared from diisopropylamine ( $63 \mu \mathrm{L}, 0.45 \mathrm{mmol}, 1.3$ equiv) and butyllithium $2.3 \mathrm{M}$ ( $195 \mu \mathrm{L}, 0.45 \mathrm{mmol}, 1.3$ equiv). Stirring was maintained $3 \mathrm{~h}$ after addition of allyl bromide $(33 \mu \mathrm{L}, 0.39 \mathrm{mmol}$, 1.1 equiv). Flash chromatography on silica gel (ether) allowed the isolation of 15 and 14 as a 90:10 ratio in a 88\% yield (14: $12 \mathrm{mg}$ as a yellow oil, 15: $106 \mathrm{mg}$ as yellow oil).

Compound $\left(2 R^{*}, 5 S^{*}, 7 R^{*}, 8 a R^{*}\right)-15: \quad R_{f}=0.66$ (AcOEt). ${ }^{1} \mathrm{H} \quad \mathrm{NMR}$ $\left(\mathrm{CDCl}_{3}, 300 \mathrm{MHz}\right): \delta_{\mathrm{H}} 0.04$ (3H, s, SiMe); 0.05 (3H, s, SiMe); 0.87 $\left(9 \mathrm{H}, \mathrm{s}, \mathrm{Si}^{\mathrm{t}} \mathrm{Bu}\right) ; 1.1\left(1 \mathrm{H}, \mathrm{ddd}, J=11.8 \mathrm{~Hz}, \mathrm{H}_{8 \mathrm{ax}}\right) ; 1.47$ (1H, ddd, $J=13.6$, $\left.11.6,6.9 \mathrm{~Hz}, \mathrm{H}_{6 \mathrm{ax}}\right) ; 1.73\left(1 \mathrm{H}, \mathrm{ddd}, J=13.0,11.6,6.9 \mathrm{~Hz}, \mathrm{H}_{1}\right) ; 1.96(1 \mathrm{H}$, ddd, $\left.J=12.9,7.6,4.1 \mathrm{~Hz}, \mathrm{H}_{1}\right) ; 2.17\left(3 \mathrm{H}, \mathrm{m}, \mathrm{H}_{6}, \mathrm{CH}_{2} \mathrm{CH}=\mathrm{CH}_{2} \mathrm{H}_{8}\right) ; 2.48$ $\left(1 \mathrm{H}, \mathrm{m}, \mathrm{CH}_{2} \mathrm{CH}=\mathrm{CH}_{2}\right) ; 2.52\left(1 \mathrm{H}, \mathrm{m}, \mathrm{H}_{2}\right) ; 3.32(3 \mathrm{H}, \mathrm{s}, \mathrm{OMe}) ; 3.60(1 \mathrm{H}$, dd, $\left.J=10.0,4.7 \mathrm{~Hz}, \mathrm{CH}_{2} \mathrm{O}\right)$; $3.65\left(1 \mathrm{H}, \mathrm{dd}, J=10.0,5.8 \mathrm{~Hz}, \mathrm{CH}_{2} \mathrm{O}\right) ; 3.70$ $\left(1 \mathrm{H}, \mathrm{m}, \mathrm{H}_{8 \mathrm{a}}\right) ; 4.05\left(1 \mathrm{H}\right.$, dddd, $\left.J=11.3,11.3,4.3,4.3 \mathrm{~Hz}, \mathrm{H}_{7 \mathrm{ax}}\right) ; 4.29$ $\left(1 \mathrm{H}\right.$, ddd, $\left.J=5.6,5.6,5.6 \mathrm{~Hz}, \mathrm{H}_{5 \mathrm{ax}}\right) ; 4.64\left(2 \mathrm{H}, \mathrm{d}, J=0.6 \mathrm{~Hz}, \mathrm{OCH}_{2} \mathrm{O}\right)$; $5.06\left(2 \mathrm{H}, \mathrm{m}, \mathrm{CH}_{2}=\mathrm{CH}\right) ; 5.74(1 \mathrm{H}$, dddd, $J=16.9,10.1,6.8,6.8 \mathrm{~Hz}$ $\left.\mathrm{CH}_{2}=\mathrm{CH}\right) .{ }^{13} \mathrm{C}$ NMR $\left(75 \mathrm{MHz}, \mathrm{CDCl}_{3}\right): \delta_{\mathrm{C}}-5.6$ (2SiMe); 18.1 $\left(\mathrm{SiC}\left(\mathrm{CH}_{3}\right)_{3}\right) ; 25.8\left(\mathrm{SiC}\left(\mathrm{CH}_{3}\right)_{3}\right) ; 30.5\left(\mathrm{C}_{1}\right) ; 32.1\left(\mathrm{C}_{6}\right) ; 35.9\left(\mathrm{CH}_{2}\right.$ $\left.\mathrm{CH}=\mathrm{CH}_{2}\right) ; 39.8\left(\mathrm{C}_{8}\right) ; 40.7\left(\mathrm{C}_{2}\right) ; 49.0\left(\mathrm{C}_{5}\right) ; 52.5\left(\mathrm{C}_{8 \mathrm{a}}\right) ; 55.6(\mathrm{OMe})$; $64.4\left(\mathrm{CH}_{2} \mathrm{O}\right) ; 70.6\left(\mathrm{C}_{7}\right) ; 94.6\left(\mathrm{OCH}_{2} \mathrm{O}\right) ; 117.1\left(\mathrm{CH}_{2}=\mathrm{CH}\right) ; 135.2$ 
$\left(\mathrm{CH}_{2}=\mathrm{CH}\right) ; 175.1\left(\mathrm{C}_{3}\right)$. IR $\left(\mathrm{NaCl}\right.$ disc, $\left.\mathrm{cm}^{-1}\right): \nu_{\max } 2953,2856,1694$, 1422, 1257, 1151, 1106, 1037, 916, 837, 777. MS $\left(\mathrm{ES}^{+}\right): \mathrm{m} / z 406$ $\left([\mathrm{MNa}]^{+}\right)$. HRMS $\left(\mathrm{ES}^{+},[\mathrm{MNa}]^{+}\right)$: calcd for $\mathrm{C}_{20} \mathrm{H}_{37} \mathrm{NO}_{4} \mathrm{Si} 384.2570$, found 384.2575 .

Compound $\left(2 S^{*}, 5 S^{*}, 7 R^{*}, 8 a R^{*}\right)-\mathbf{1 4}: R_{f}=0.86$ (AcOEt). ${ }^{1} \mathrm{H}$ NMR $\left(\mathrm{CDCl}_{3}\right.$, $300 \mathrm{MHz}$ ): $\delta_{\mathrm{H}} 0.04$ (3H, s, SiMe); 0.06 (3H, s, SiMe); 0.89 (9H, s, Sit Bu); 1.1 $\left(1 \mathrm{H}, \mathrm{ddd}, J=11.7,11.7,11.7 \mathrm{~Hz}, \mathrm{H}_{8 \mathrm{ax}}\right) ; 1.27\left(1 \mathrm{H}, \mathrm{m}, \mathrm{H}_{1}\right) ; 1.5(1 \mathrm{H}, \mathrm{ddd}, J=11.8$, $\left.11.8,6.9 \mathrm{~Hz}, \mathrm{H}_{6 \mathrm{ax}}\right) ; 2.07-2.28\left(3 \mathrm{H}, \mathrm{m}, \mathrm{CH}_{2} \mathrm{CH}=\mathrm{CH}_{2}, \mathrm{H}_{8 \mathrm{eq}}, \mathrm{H}_{6 \mathrm{eq}}\right) ; 2.33(1 \mathrm{H}$, $\left.\mathrm{m}, \mathrm{H}_{1}\right) ; 2.5\left(1 \mathrm{H}\right.$, dddd, $\left.J=9.9,9.9,9.9,3.9 \mathrm{~Hz}, \mathrm{H}_{2}\right) ; 2.65$ (1H, ddd, $J=14.1$, 5.3, $\left.5.3 \mathrm{~Hz}, \mathrm{CH}_{2} \mathrm{CH}=\mathrm{CH}_{2}\right) ; 3.36(3 \mathrm{H}, \mathrm{s}, \mathrm{OMe}) ; 3.64\left(3 \mathrm{H}, \mathrm{m}, \mathrm{H}_{8 \mathrm{a}}, \mathrm{CH}_{2}\right.$ $\left.\mathrm{CH}=\mathrm{CH}_{2}\right) ; 4.08\left(1 \mathrm{H}\right.$, dddd, $\left.J=11.2,11.2,4.0,4.0 \mathrm{~Hz}, \mathrm{H}_{7 \mathrm{ax}}\right) ; 4.28(1 \mathrm{H}$, ddd, $\left.J=5.8,5.8,5.8 \mathrm{~Hz}, \mathrm{H}_{5 \mathrm{eq}}\right) ; 4.68\left(2 \mathrm{H}\right.$, br s, $\left.\mathrm{OCH}_{2} \mathrm{O}\right) ; 5.06\left(2 \mathrm{H}, \mathrm{m}, \mathrm{CH}_{2}=\mathrm{CH}\right)$; $5.77\left(1 \mathrm{H}\right.$, dddd, $\left.J=17.0,10.1,6.9,6.9 \mathrm{~Hz}, \mathrm{CH}_{2}=\mathrm{CH}\right) .{ }^{13} \mathrm{C} \mathrm{NMR}\left(\mathrm{CDCl}_{3}\right.$, $100 \mathrm{MHz}): \delta_{\mathrm{C}}-5.6(2 \mathrm{SiMe}) ; 18.1\left(\mathrm{SiC}\left(\mathrm{CH}_{3}\right)_{3}\right) ; 25.8\left(\mathrm{SiC}\left(\mathrm{CH}_{3}\right)_{3}\right) ; 32.1\left(\mathrm{C}_{6}\right)$; $32.9\left(\mathrm{C}_{1}\right) ; 35.4\left(\mathrm{CH}_{2} \mathrm{CH}=\mathrm{CH}_{2}\right) ; 40.2\left(\mathrm{C}_{8}\right) ; 41.3\left(\mathrm{C}_{2}\right) ; 49.1\left(\mathrm{C}_{5}\right) ; 52.4\left(\mathrm{C}_{8 \mathrm{a}}\right)$; 55.2 (OMe); $63.9\left(\mathrm{CH}_{2} \mathrm{O}\right) ; 70.6\left(\mathrm{C}_{7}\right) ; 94.8\left(\mathrm{OCH}_{2} \mathrm{O}\right) ; 116.7\left(\mathrm{CH}_{2}=\mathrm{CH}\right)$; $135.7\left(\mathrm{CH}_{2}=\mathrm{CH}\right) ; 174.5\left(\mathrm{C}_{3}\right)$. IR $\left(\mathrm{NaCl}\right.$ disc, $\left.\mathrm{cm}^{-1}\right): \nu_{\max } 2930,1691,1419$, $1255,1104,1042,840 . \mathrm{MS}\left(\mathrm{ES}^{+}\right): \mathrm{m} / z=384\left([\mathrm{MH}]^{+}\right), 406\left([\mathrm{MNa}]^{+}\right)$. HRMS $\left(\mathrm{ES}^{+},[\mathrm{MNa}]^{+}\right.$): calcd for $\mathrm{C}_{20} \mathrm{H}_{37} \mathrm{NO}_{4} \mathrm{Si} 406.2390$, found 406.2386 .

\subsubsection{2. (2S*,5S*,7S*,8aR*)-2-Allyl-7-benzyloxy-3-oxo-octahydro- indolizin-5-carboxylic acid $\mathbf{1 8}$}

To alcohol 16a (757 mg, $2.4 \mathrm{mmol}$ ) dissolved in $22 \mathrm{~mL}$ in acetone was added dropwise Jones reagent $2.67 \mathrm{M}(1.1 \mathrm{~mL}, 2.9 \mathrm{mmol}$, 1.2 equiv) at $0{ }^{\circ} \mathrm{C}$. Stirring was continued for $40 \mathrm{~min}, 10 \mathrm{~mL}$ of isopropanol was added, and the mixture was stirred for $20 \mathrm{~min}$ at $0{ }^{\circ} \mathrm{C}$. After addition of $0.5 \mathrm{~mL}$ of water and $5 \mathrm{~mL}$ of $1 \mathrm{M} \mathrm{HCl}$, the mixture was extracted twice with $100 \mathrm{~mL}$ of dichloromethane. The organic phase was dried $\left(\mathrm{MgSO}_{4}\right)$ and the solvent removed in vacuo. The residue was purified by flash chromatography on silica gel (AcOEt/ $\mathrm{MeOH} / \mathrm{AcOH}$ 96:2:2) and the carboxylic acid $\mathbf{2 3}$ was isolated as a beige solid $(67 \%, 530 \mathrm{mg})$.

$R_{f}=0.27 \quad$ (AcOEt/MeOH/AcOH 96:2:2), mp: $146{ }^{\circ} \mathrm{C} .{ }^{1} \mathrm{H} \quad \mathrm{NMR}$ $\left(\mathrm{CDCl}_{3}, 400 \mathrm{MHz}\right): \delta_{\mathrm{H}} 1.18\left(1 \mathrm{H}, \mathrm{ddd}, J=11.7,11.7,11.7 \mathrm{~Hz}, \mathrm{H}_{8 \mathrm{ax}}\right) ; 1.36$ $\left(1 \mathrm{H}, \mathrm{m}, \mathrm{H}_{1}\right) ; 1.63\left(1 \mathrm{H}\right.$, ddd, $\left.J=12.1,12.1,6.7 \mathrm{~Hz}, \mathrm{H}_{6}\right) ; 2.18(1 \mathrm{H}, \mathrm{m}$, $\left.\mathrm{CH}_{2} \mathrm{CH}=\mathrm{CH}_{2}\right) ; 2.27-2.4\left(2 \mathrm{H}, \mathrm{m}, \mathrm{H}_{1}, \mathrm{H}_{8}\right) ; 2.58-2.69\left(3 \mathrm{H}, \mathrm{m}, \mathrm{H}_{6}, \mathrm{H}_{2}\right.$, $\left.\mathrm{CH}_{2} \mathrm{CH}=\mathrm{CH}_{2}\right) ; 3.57\left(1 \mathrm{H}, \mathrm{m}, \mathrm{H}_{7}\right) ; 3.72\left(1 \mathrm{H}, \mathrm{m}, \mathrm{H}_{8 \mathrm{a}}\right) ; 4.54(1 \mathrm{H}, \mathrm{d}$, $\left.J=9.1 \mathrm{~Hz}, \mathrm{CH}_{2} \mathrm{Ph}\right) ; 4.59\left(1 \mathrm{H}, \mathrm{d}, J=9.1 \mathrm{~Hz}, \mathrm{CH}_{2} \mathrm{Ph}\right) ; 4.91(1 \mathrm{H}, \mathrm{br} \mathrm{d}$, $\left.J=6.2 \mathrm{~Hz}, \mathrm{H}_{5}\right) ; 5.03-5.13\left(2 \mathrm{H}, \mathrm{m}, \mathrm{CH}_{2}=\mathrm{CH}\right) ; 5.75(1 \mathrm{H}$, dddd, $J=16.9$, 10.1, 6.8, $\left.6.8 \mathrm{~Hz}, \mathrm{CH}_{2}=\mathrm{CH}\right)$; $7.31(5 \mathrm{H}, \mathrm{m}, \mathrm{Ar}) .{ }^{13} \mathrm{C}$ NMR $(75 \mathrm{MHz}$, $\left.\mathrm{CDCl}_{3}\right): \delta_{\mathrm{C}} 31.9\left(\mathrm{C}_{6}\right) ; 32.4\left(\mathrm{C}_{1}\right) ; 35.0\left(\mathrm{CH}_{2} \mathrm{CH}=\mathrm{CH}_{2}\right) ; 39.2\left(\mathrm{C}_{8}\right) ; 41.4$ $\left(\mathrm{C}_{2}\right) ; 50.5\left(\mathrm{C}_{5}\right) ; 52.4\left(\mathrm{C}_{8 \mathrm{a}}\right) ; 70.6\left(\mathrm{CH}_{2} \mathrm{Ph}\right) ; 72.7\left(\mathrm{C}_{7}\right) ; 117.3\left(\mathrm{CH}_{2}=\mathrm{CH}\right)$; $127.7 ; 127.9 ; 128.6\left(2 \mathrm{C}_{\mathrm{Ar}}, \mathrm{C}_{\mathrm{Ar}}, 2 \mathrm{C}_{\mathrm{Ar}}\right) ; 135.2\left(\mathrm{CH}_{2}=\mathrm{CH}\right) ; 138.1\left(\mathrm{C}_{\mathrm{Ar}-}\right.$ quat); $173.1(\mathrm{COOH}) ; 176.4\left(\mathrm{C}_{3}\right)$. $\mathrm{MS}\left(\mathrm{ES}^{+}\right): \mathrm{m} / z 352\left([\mathrm{MNa}]^{+}\right)$.

\subsubsection{3. (2S)-2-[(2S*,5S*,7S*,8aR*)-(2-Allyl-7-benzyloxy-3-oxo-} octahydro-indolizin-5-carbonyl)-amino]succinic acid di-tert-butyl ester 19

To carboxylic acid 18 (55 mg, $0.167 \mathrm{mmol}$ ) dissolved in $1.5 \mathrm{~mL}$ of anhydrous dichloromethane was added $N$-methylmorpholine (NMM) (20 $\mu \mathrm{L}, 0.18 \mathrm{mmol}, 1.1$ equiv) at $-10^{\circ} \mathrm{C}$ under argon, and the mixture was stirred for $30 \mathrm{~min}$ at the same temperature. Isobutyl chloroformiate ( $23 \mu \mathrm{L}, 0.18 \mathrm{mmol}, 1.1$ equiv) was added dropwise and stirring was continued for $1 \mathrm{~h}$ at $-10^{\circ} \mathrm{C}$. The amino acid $(51 \mathrm{mg}, 0.18 \mathrm{mmol}$, 1.1 equiv) was dissolved in $1.5 \mathrm{~mL}$ of anhydrous dichloromethane under argon and NMM ( $40 \mu \mathrm{L}, 0.36 \mathrm{mmol}, 2.2$ equiv) was added at $0{ }^{\circ} \mathrm{C}$. This solution was stirred for $30 \mathrm{~min}$ and added via a syringe to the mixed anhydride solution. Stirring was continued for $20 \mathrm{~h}$ at rt. The residue was taken off with $10 \mathrm{~mL}$ of ethyl acetate, washed with $5 \mathrm{~mL}$ of $10 \% \mathrm{Na}_{2} \mathrm{CO}_{3}$ solution, $5 \mathrm{~mL}$ of $10 \% \mathrm{KHSO}_{4}$ solution, and $5 \mathrm{~mL}$ of brine. The organic phase was dried over $\mathrm{Na}_{2} \mathrm{SO}_{4}$ and the solvent removed in vacuo. The residue was purified by flash chromatography on silica gel (AcOEt/cyclohexane 25:75 to 70:30) and the compound was isolated as a white foam $(88 \%, 65 \mathrm{mg})$.

Two diastereoisomers: $R_{f}=0.53$ (AcOEt/cyclohexane 40:60). ${ }^{1} \mathrm{H}$ NMR $\left(\mathrm{CDCl}_{3}, 400 \mathrm{MHz}\right): \delta_{\mathrm{H}} 1.16 / 1.17(1 \mathrm{H}$, ddd, $J=11.8,11.8$, $\left.11.8 \mathrm{~Hz}, \mathrm{H}_{8 \mathrm{ax}}\right)$; $1.23-1.52\left(20 \mathrm{H}, \mathrm{m}, \mathrm{H}_{1}, \mathrm{H}_{6}, 2 \mathrm{C}\left(\mathrm{CH}_{3}\right)_{3}\right) ; 2.11-2.5$ $\left(3 \mathrm{H}, \mathrm{m}, \mathrm{H}_{1}, \mathrm{CH}_{2} \mathrm{CH}=\mathrm{CH}_{2}, \mathrm{H}_{8}\right) ; 2.51-2.9\left(5 \mathrm{H}, \mathrm{m}, \mathrm{CH}_{2} \mathrm{CH}=\mathrm{CH}_{2}\right.$, $\left.\mathrm{CH}_{2} \mathrm{CO}, \mathrm{H}_{2}, \mathrm{H}_{6}\right) ; 3.58-3.89\left(2 \mathrm{H}, \mathrm{m}, \mathrm{H}_{7}, \mathrm{H}_{8 \mathrm{a}}\right) ; 4.51-4.67(3 \mathrm{H}, \mathrm{m}$, $\left.\mathrm{CH}_{2} \mathrm{Ph}, \mathrm{NHCHCO}\right) ; 4.85\left(1 \mathrm{H}\right.$, br d, $\left.J=6.2 \mathrm{~Hz}, \mathrm{H}_{5}\right) ; 5.02-5.14$ $\left(2 \mathrm{H}, \mathrm{m}, \mathrm{CH}_{2}=\mathrm{CH}\right) ; 5.67-5.84\left(1 \mathrm{H}, \mathrm{m}, \mathrm{CH}_{2}=\mathrm{CH}\right) ; 6.96 / 7.20$ $(1 \mathrm{H}, \mathrm{d} / \mathrm{d}, J=8.0 / 8.6 \mathrm{~Hz}, \mathrm{NH}) ; 7.23-7.37(5 \mathrm{H}, \mathrm{m}, \mathrm{Ar}) .{ }^{13} \mathrm{C} \mathrm{NMR}$ $\left(75 \mathrm{MHz}, \mathrm{CDCl}_{3}\right): \delta_{\mathrm{C}} 27.9$ and $28.0\left(\mathrm{C}_{\left.\left(\mathrm{CH}_{3}\right)_{3}\right) ; 30.8 / 31.2,32.2 /}\right.$ $32.4,35.1,37.2 / 37.3\left(\mathrm{C}_{6}, \mathrm{C}_{1}, \mathrm{CH}_{2} \mathrm{CH}=\mathrm{CH}_{2}, \mathrm{CH}_{2} \mathrm{CO}\right) ; 39.6 / 39.7$ $\left(\mathrm{C}_{8}\right) ; 40.9 / 41.0 \quad\left(\mathrm{C}_{2}\right) ; 49.1 / 49.3, \quad 50.9, \quad 52 / 52.1 \quad\left(\mathrm{C}_{5}, \mathrm{C}_{8 \mathrm{a}}\right.$, $\mathrm{NHCHCO}) ; 70.5\left(\mathrm{CH}_{2} \mathrm{Ph}\right) ; 72.4\left(\mathrm{C}_{7}\right) ; 81.6 / 81.9$ and $82.2 / 82.4$

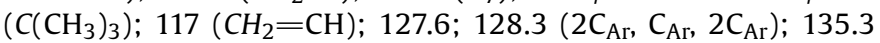
$\left(\mathrm{CH}_{2}=\mathrm{CH}\right) ; 138.1$ ( $\left.\mathrm{C}_{\text {Arquat }}\right) ; 169.2 / 169.3,169.5 / 169.5,169.9 /$ 170, 175.6/175.7 (3CO, $\left.\mathrm{C}_{3}\right)$. HRMS $\left(\mathrm{ES}^{+},[\mathrm{MNa}]^{+}\right)$: calcd for $\mathrm{C}_{31} \mathrm{H}_{44} \mathrm{~N}_{2} \mathrm{O}_{7}$ 579.3046, found 579.3019.

\subsubsection{3-[(2S*,5S*,7S*,8aR*)-(2-Allyl-7-benzyloxy-3-oxo-} octahydro-indolizin-5-carbonyl)-aminolpropionic acid tert-butyl ester 20

The same experimental procedure as described for peptide coupling was applied to carboxylic acid 18 (136 mg, $0.41 \mathrm{mmol})$ using NMM ( $50 \mu \mathrm{L}, 0.45 \mathrm{mmol}, 1.1$ equiv) and isobutyl chloroformiate ( $60 \mu \mathrm{L}, 0.45 \mathrm{mmol}, 1.1$ equiv). Stirring was maintained $20 \mathrm{~h}$ after addition of amino acid ( $82 \mathrm{mg}, 0.45 \mathrm{mmol}, 1.1$ equiv) and NMM ( $100 \mu \mathrm{L}, 0.9 \mathrm{mmol}, 2.2$ equiv). Flash chromatography on silica gel (AcOEt/cyclohexane 50:50 to 70:30) allowed the isolation of a colorless oil ( $83 \%, 154 \mathrm{mg})$.

$R_{f}=0.45 \quad$ (AcOEt/cyclohexane 60:40). ${ }^{1} \mathrm{H}$ NMR $\left(\mathrm{CDCl}_{3}\right.$, $400 \mathrm{MHz}): \delta_{\mathrm{H}} 1.17\left(1 \mathrm{H}\right.$, ddd, $\left.J=11.8,11.8,11.8 \mathrm{~Hz}, \mathrm{H}_{8 \mathrm{ax}}\right) ; 1.2-1.5$ $\left(11 \mathrm{H}, \mathrm{m}, \mathrm{H}_{1}, \mathrm{H}_{6}, 2 \mathrm{C}\left(\mathrm{CH}_{3}\right)_{3}\right) ; 2.18\left(1 \mathrm{H}, \mathrm{m}, \mathrm{H}_{1}\right) ; 2.29(1 \mathrm{H}, \mathrm{br}$, $\left.J=12 \mathrm{~Hz}, \mathrm{H}_{8}\right) ; 2.35\left(1 \mathrm{H}, \mathrm{m}, \mathrm{CH}_{2} \mathrm{CH}=\mathrm{CH}_{2}\right) ; 2.41(2 \mathrm{H}, \mathrm{t}, J=6 \mathrm{~Hz}$, $\left.\mathrm{NHCH}_{2} \mathrm{CH}_{2} \mathrm{CO}\right) ; 2.52-2.7\left(3 \mathrm{H}, \mathrm{m}, \mathrm{H}_{2}, \mathrm{H}_{6}, \mathrm{CH}_{2} \mathrm{CH}=\mathrm{CH}_{2}\right) ; 3.32-$ $3.52\left(2 \mathrm{H}, \mathrm{m}, \mathrm{NHCH}_{2} \mathrm{CH}_{2} \mathrm{CO}\right) ; 3.57\left(1 \mathrm{H}, \mathrm{m}, \mathrm{H}_{8 \mathrm{a}}\right) ; 3.9(1 \mathrm{H}$, dddd, $\left.J=11,11,4.5,4.5 \mathrm{~Hz}, \mathrm{H}_{7}\right) ; 4.57\left(1 \mathrm{H}, \mathrm{d}, J=11.6 \mathrm{~Hz}, \mathrm{CH}_{2} \mathrm{Ph}\right) ; 4.63$ $\left(1 \mathrm{H}, \mathrm{d}, J=11.6 \mathrm{~Hz}, \mathrm{CH}_{2} \mathrm{Ph}\right)$; $4.78\left(1 \mathrm{H}, \mathrm{d}, J=5.9 \mathrm{~Hz}, \mathrm{H}_{5}\right) ; 5.02-$ $5.12\left(2 \mathrm{H}, \mathrm{m}, \mathrm{CH}_{2}=\mathrm{CH}\right) ; 5.77(1 \mathrm{H}$, dddd, $J=15,12,5.9,5.9 \mathrm{~Hz}$, $\left.\mathrm{CH}_{2}=\mathrm{CH}\right) ; 6.65\left(1 \mathrm{H}\right.$, br s, NH); 7.25-7.4 (5H, m, Ar). ${ }^{13} \mathrm{C}$ NMR $\left(75 \mathrm{MHz}, \mathrm{CDCl}_{3}\right): \delta_{\mathrm{C}} 28.1\left(\mathrm{C}\left(\mathrm{CH}_{3}\right)_{3}\right) ; 30.9\left(\mathrm{C}_{6}\right) ; 32.3\left(\mathrm{C}_{1}\right) ; 35.1$ $\left(\mathrm{CH}_{2} \mathrm{CH}=\mathrm{CH}_{2}, \mathrm{NHCH}_{2} \mathrm{CH}_{2} \mathrm{CO}\right) ; 39.5\left(\mathrm{C}_{8}\right) ; 41.1\left(\mathrm{C}_{2}\right) ; 50.9\left(\mathrm{C}_{5}\right)$;

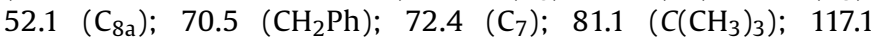
$\left(\mathrm{CH}_{2}=\mathrm{CH}\right) ; 127.6 ; 128.4\left(2 \mathrm{C}_{\mathrm{Ar}}, \mathrm{C}_{\mathrm{Ar}}, 2 \mathrm{C}_{\mathrm{Ar}}\right) ; 135.2\left(\mathrm{CH}_{2}=\mathrm{CH}\right)$; 138.5 ( $\left.\mathrm{C}_{\text {Arquat }}\right) ; 169.9,171.4,176.4\left(2 \mathrm{CO}, \mathrm{C}_{3}\right) . \mathrm{IR}$ ( $\mathrm{NaCl}$ disc, $\left.\mathrm{cm}^{-1}\right): \nu_{\max } 3307,2929,1727,1682,1427,1278,1156,737 . \mathrm{MS}$ $\left(\mathrm{ES}^{+}\right): \mathrm{m} / \mathrm{z} 479\left([\mathrm{MNa}]^{+}\right)$.

\subsubsection{5. (S)-2-[[(2S*,5S*,7S*,8aR*)-7-Benzyloxy-2-(3-hydroxy-}

propyl)-3-oxo-octahydro-indolizin-5-carbonyl]-amino]-

succinic acid di-tert-butyl ester $\mathbf{2 1}$

The same experimental procedure as described for hydroboration was applied to alkene $19(81 \mathrm{mg}, 0.14 \mathrm{mmol})$ using a $0.5 \mathrm{M}$ solution of 9-BBN (1.5 mL, $0.73 \mathrm{mmol}, 5$ equiv). Stirring was maintained $15 \mathrm{~h}$ after addition of sodium acetate $5 \mathrm{M}(570 \mu \mathrm{L}$, $2.8 \mathrm{mmol}, 20$ equiv) and a $30 \% \mathrm{H}_{2} \mathrm{O}_{2}$ solution $(0.160 \mathrm{~mL}, 22$ equiv). Flash chromatography on silica gel (AcOEt/cyclohexane 50:50 to 90:10) allowed the isolation of a yellow oil $(68 \%, 57 \mathrm{mg})$.

Two diastereoisomers: $R_{f}=0.16$ (AcOEt/cyclohexane 90:10). ${ }^{1} \mathrm{H}$ NMR $\left(\mathrm{CDCl}_{3}, 400 \mathrm{MHz}\right): \delta_{\mathrm{H}} 1.13 / 1.15(1 \mathrm{H}$, ddd/ddd, $J=11.7,11.7$, $\left.11.7 \mathrm{~Hz}, \mathrm{H}_{8}\right)$; $1.3-1.98$ (23H, m, $\left.\mathrm{H}_{6}, 2 \mathrm{C}\left(\mathrm{CH}_{3}\right)_{3}, \mathrm{CH}_{2} \mathrm{CH}_{2} \mathrm{CH}_{2} \mathrm{OH}\right) ; 2.27$ $\left(1 \mathrm{H}, \mathrm{m}, \mathrm{H}_{8}\right) ; 2.32-2.87\left(5 \mathrm{H}, \mathrm{m}, \mathrm{H}_{1}, \mathrm{CH}_{2} \mathrm{CO}, \mathrm{H}_{2}, \mathrm{H}_{6}\right) ; 3.6-3.66(3 \mathrm{H}, \mathrm{m}$, $\left.\mathrm{CH}_{2} \mathrm{OH}, \mathrm{H}_{8 \mathrm{a}}\right) ; 3.72-3.82\left(1 \mathrm{H}, \mathrm{m}, \mathrm{H}_{7}\right) ; 4.5-4.64\left(3 \mathrm{H}, \mathrm{m}, \mathrm{CH}_{2} \mathrm{Ph}\right.$, NHCHCO); $4.79 / 4.85\left(1 \mathrm{H}, \mathrm{m}, \mathrm{H}_{5}\right) ; 6.74 / 6.82(1 \mathrm{H}, \mathrm{d} / \mathrm{d}, J=8.0 / 8.6 \mathrm{~Hz}$, $\mathrm{NH})$; 7.25-7.35 (5H, m, Ar). ${ }^{13} \mathrm{C}$ NMR $\left(75 \mathrm{MHz} \mathrm{CDCl}_{3}\right): \delta_{\mathrm{C}} 20.2 / 27.1$ $\left(\mathrm{CH}_{2}\right) ; 28.0$ and $28.1\left(\mathrm{C}\left(\mathrm{CH}_{3}\right)_{3}\right) ; 30.3,31.0,31.4,36.4,37.3\left(\mathrm{CH}_{2}\right)$; 39.6/39.7 ( $\left.\mathrm{C}_{8}\right)$; 41.2/41.3 $\left(\mathrm{C}_{2}\right) ; 49.1 / 49.4$ (NHCHCO); $51.0\left(\mathrm{C}_{5}\right) ; 52.1 /$ $52.3\left(\mathrm{C}_{8 \mathrm{a}}\right) ; 62.2\left(\mathrm{CH}_{2} \mathrm{OH}\right) ; 70.6\left(\mathrm{CH}_{2} \mathrm{Ph}\right) ; 72.4 / 72.5\left(\mathrm{C}_{7}\right) ; 81.7,82.0$,

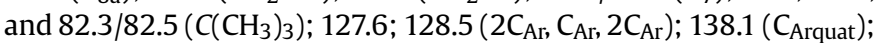
$169.4 / 169.6,170.1,170.2,176.7 / 176.8\left(3 \mathrm{CO}, \mathrm{C}_{3}\right)$. 
4.1.16. 3-[[(2S*,5S*,7S*,8aR*)-7-Benzyloxy-2-(3-hydroxy-propyl)3-oxo-octahydro-indolizin-5-carbonyl]-amino]propionic acid tert-butyl ester 22

The same experimental procedure as described for hydroboration was applied to alkene 20 (106 $\mathrm{mg}, 0.23 \mathrm{mmol}$ ) using a $0.4 \mathrm{M}$ solution of $9-\mathrm{BBN}$ in hexane $(1.5 \mathrm{~mL}, 0.58 \mathrm{mmol}, 2.5$ equiv). Stirring was maintained $16 \mathrm{~h}$ after addition of sodium acetate $5 \mathrm{M}$ ( $550 \mu \mathrm{L}, 2.76 \mathrm{mmol}, 12$ equiv) and a $30 \% \mathrm{H}_{2} \mathrm{O}_{2}$ solution $(0.280 \mathrm{~mL}$, 12 equiv). Flash chromatography on silica gel (AcOEt/MeOH 100 to 99:1) allowed the isolation of a yellow oil ( $71 \%, 74 \mathrm{mg})$.

$R_{f}=0.3$ (AcOEt/MeOH 95:5). ${ }^{1} \mathrm{H}$ NMR $\left(\mathrm{CDCl}_{3}, 300 \mathrm{MHz}\right): \delta_{\mathrm{H}} 1.14$ (1H, ddd, $\left.J=11.8,11.8,11.8 \mathrm{~Hz}, \mathrm{H}_{8 \mathrm{ax}}\right) ; 1.22-1.52\left(12 \mathrm{H}, \mathrm{m}, \mathrm{H}_{1}, \mathrm{H}_{6}\right.$, $\left.\mathrm{CH}_{2} \mathrm{CH}_{2} \mathrm{CH}_{2} \mathrm{OH}, 2 \mathrm{C}\left(\mathrm{CH}_{3}\right)_{3}\right) ; 1.6\left(2 \mathrm{H}, \mathrm{q}, \mathrm{J}=11.8 \mathrm{~Hz}, \mathrm{CH}_{2} \mathrm{CH}_{2} \mathrm{CH}_{2} \mathrm{OH}\right)$; $1.93\left(1 \mathrm{H}, \mathrm{m}, \mathrm{CH}_{2} \mathrm{CH}_{2}-\mathrm{CH}_{2} \mathrm{OH}\right) ; 2.27\left(1 \mathrm{H}, \mathrm{br} \mathrm{d}, J=12 \mathrm{~Hz}, \mathrm{H}_{8}\right) ; 2.39(2 \mathrm{H}$, $\left.\mathrm{t}, \mathrm{J}=6 \mathrm{~Hz}, \mathrm{NHCH}_{2} \mathrm{CH}_{2} \mathrm{CO}\right) ; 2.41-2.54\left(2 \mathrm{H}, \mathrm{m}, \mathrm{H}_{2}, \mathrm{H}_{1}\right) ; 2.6(1 \mathrm{H}, \mathrm{br} \mathrm{d}$, $\left.J=12 \mathrm{~Hz}, \mathrm{H}_{6}\right) ; 3.04(1 \mathrm{H}, \mathrm{s}, \mathrm{OH}) ; 3.2-3.5\left(2 \mathrm{H}, \mathrm{m}, \mathrm{NHCH}_{2} \mathrm{CH}_{2} \mathrm{CO}\right) ; 3.63$ $\left(1 \mathrm{H}, \mathrm{m}, \mathrm{H}_{8 \mathrm{a}}\right) ; 3.63\left(2 \mathrm{H}, \mathrm{t}, J=6.1 \mathrm{~Hz}, \mathrm{CH}_{2} \mathrm{OH}\right) ; 3.88(1 \mathrm{H}$, dddd, $J=12,12$, $\left.4.5,4.5 \mathrm{~Hz}, \mathrm{H}_{7}\right) ; 4.55\left(1 \mathrm{H}, \mathrm{d}, J=11.7 \mathrm{~Hz}, \mathrm{CH}_{2} \mathrm{Ph}\right) ; 4.62(1 \mathrm{H}, \mathrm{d}$, $\left.J=11.7 \mathrm{~Hz}, \mathrm{CH}_{2} \mathrm{Ph}\right) ; 4.74\left(1 \mathrm{H}, \mathrm{d}, J=5.9 \mathrm{~Hz}, \mathrm{H}_{5}\right) ; 6.79(1 \mathrm{H}, \mathrm{t}, J=6 \mathrm{~Hz}$, $\mathrm{NH}) ; 7.2-7.45(5 \mathrm{H}, \mathrm{m}, \mathrm{Ar}) .{ }^{13} \mathrm{C}$ NMR $\left(75 \mathrm{MHz}, \mathrm{CDCl}_{3}\right): \delta_{\mathrm{C}} 27.2$ $\left(\mathrm{CH}_{2} \mathrm{CH}_{2} \mathrm{CH}_{2} \mathrm{OH}\right) ; 28.1\left(\mathrm{C}\left(\mathrm{CH}_{3}\right)_{3}\right) ; 29.7\left(\mathrm{CH}_{2} \mathrm{CH}_{2} \mathrm{CH}_{2} \mathrm{OH}\right) ; 31.1\left(\mathrm{C}_{6}\right)$; $33.3\left(\mathrm{C}_{1}\right) ; 35.1\left(\mathrm{NHCH}_{2} \mathrm{CH}_{2} \mathrm{CO}\right) ; 39.5\left(\mathrm{C}_{8}\right) ; 41.3\left(\mathrm{C}_{2}\right) ; 50.9\left(\mathrm{C}_{5}\right) ; 52.3$ $\left(\mathrm{C}_{8 \mathrm{a}}\right) ; 62.1\left(\mathrm{CH}_{2} \mathrm{OH}\right) ; 70.5\left(\mathrm{CH}_{2} \mathrm{Ph}\right) ; 72.3\left(\mathrm{C}_{7}\right) ; 81.1\left(\mathrm{C}\left(\mathrm{CH}_{3}\right)_{3}\right) ; 127.6$; $128.4\left(2 \mathrm{C}_{\mathrm{Ar}}, \mathrm{C}_{\mathrm{Ar}}, 2 \mathrm{C}_{\mathrm{Ar}}\right) ; 138.4$ ( $\left.\mathrm{C}_{\text {Arquat }}\right) ; 169.9,171.4,176.4\left(2 \mathrm{CO}, \mathrm{C}_{3}\right)$.

\subsubsection{Guanidine carbamate 23}

Alcohol 21 (60 mg, $0.1 \mathrm{mmol}$ ) and 1,3-bis(tert-butoxycarbonyl) guanidine (53 $\mathrm{mg}, 0.2 \mathrm{mmol}, 2$ equiv) were dried under vacuo, and dissolved in $2.5 \mathrm{~mL}$ of anhydrous toluene under argon. Tributylphosphine ( $50 \mu \mathrm{L}, 0.2 \mathrm{mmol}$, 2 equiv) was added to the solution at rt, then dipiperidinazodicarboxylate (ADDP) (52 mg, $0.2 \mathrm{mmol}$, 2 equiv) at $0{ }^{\circ} \mathrm{C}$. The mixture was refluxed for $4 \mathrm{~h}$. After removal of the toluene under vacuo, the residue was purified by flash chromatography on silica gel $\left(\mathrm{Et}_{2} \mathrm{O} /\right.$ cyclohexane/MeOH 85:14:1) allowed the isolation of $\mathbf{2 3}$ as a colorless oil ( $46 \mathrm{mg}, 60 \%$ ).

Two diastereoisomers: $R_{f}=0.14 \quad\left(\mathrm{Et}_{2} \mathrm{O} /\right.$ cyclohexane/MeOH 85:14:1). ${ }^{1} \mathrm{H}$ NMR $\left(\mathrm{CDCl}_{3}, 400 \mathrm{MHz}\right): \delta_{\mathrm{H}} 1.01-1.4\left(31 \mathrm{H}, \mathrm{m}, \mathrm{H}_{8}, \mathrm{H}_{6}\right.$, $\left.3 \mathrm{C}\left(\mathrm{CH}_{3}\right)_{3}, \mathrm{CH}_{2} \mathrm{CH}_{2} \mathrm{CH}_{2} \mathrm{OH}\right) ; 1.5-1.7\left(2 \mathrm{H}, \mathrm{m}, \mathrm{CH}_{2} \mathrm{CH}_{2} \mathrm{CH}_{2} \mathrm{OH}\right) ; 1.5-1.7$ $\left(1 \mathrm{H}, \mathrm{m}, \mathrm{CH}_{2} \mathrm{CH}_{2} \mathrm{CH}_{2} \mathrm{OH}\right) ; 2.1-2.4\left(2 \mathrm{H}, \mathrm{m}, \mathrm{H}_{1}, \mathrm{H}_{8}\right) ; 2.4-2.88(4 \mathrm{H}, \mathrm{m}$, $\left.\mathrm{CH}_{2} \mathrm{CO}, \mathrm{H}_{2}, \mathrm{H}_{6}\right)$; 3.48-3.62 (1H, m, $\left.\mathrm{H}_{8 \mathrm{a}}\right) ; 3.62-3.78\left(1 \mathrm{H}, \mathrm{m}, \mathrm{H}_{7}\right)$; 4.03 (2H, br s, $\left.\mathrm{CH}_{2} \mathrm{OH}\right) ; 4.43-4.59$ (3H, m, $\left.\mathrm{CH}_{2} \mathrm{Ph}, \mathrm{NHCHCO}\right) ; 4.76$ $\left(1 \mathrm{H}, \mathrm{d}, J=11.7 \mathrm{~Hz}, \mathrm{H}_{5}\right) ; 7.21 / 7.26(1 \mathrm{H}, \mathrm{d} / \mathrm{d}, J=8.1 / 8.6 \mathrm{~Hz}, \mathrm{NH}) ; 7.15-$ $7.29(5 \mathrm{H}, \mathrm{m}, \mathrm{Ar}) .{ }^{13} \mathrm{C}$ NMR $\left(75 \mathrm{MHz}, \mathrm{CDCl}_{3}\right): \delta_{\mathrm{C}} 26.7,27.6 / 27.7\left(\mathrm{CH}_{2^{-}}\right.$ $\left.\mathrm{CH}_{2} \mathrm{CH}_{2} \mathrm{OH}\right) ; 28.0$ and $28.1\left(3 \mathrm{C}\left(\mathrm{CH}_{3}\right)_{3}\right) ; 29.8 / 30.4,30.9 / 31.3,33.3 /$ $33.4\left(\mathrm{C}_{6}, \mathrm{C}_{1}, \mathrm{CH}_{2} \mathrm{CO}\right)$; 39.6/39.8 $\left(\mathrm{C}_{8}\right) ; 41.2 / 41.3\left(\mathrm{C}_{2}\right) ; 49.1 / 49.4,50.9 /$ 51.0, 52.0/52.2 ( $\left.\mathrm{C}_{5}, \mathrm{NHCHCO}, \mathrm{C}_{8 \mathrm{a}}\right) ; 65.5\left(\mathrm{CH}_{2} \mathrm{OH}\right) ; 70.9\left(\mathrm{CH}_{2} \mathrm{Ph}\right)$;

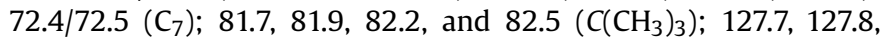
$128.5\left(2 \mathrm{C}_{\mathrm{Ar}}, \mathrm{C}_{\mathrm{Ar}}, 2 \mathrm{C}_{\mathrm{Ar}}\right) ; 138.6$ ( $\left.\mathrm{C}_{\text {Arquat }}\right) ; 158.5,169.4,169.7,169.8$, $170,170.1,170.2,176 / 176.2\left(\mathrm{C}=\mathrm{N}, 5 \mathrm{CO}, \mathrm{C}_{3}\right) . \mathrm{MS}\left(\mathrm{ES}^{+}\right): \mathrm{m} / \mathrm{z} 760$ $\left([\mathrm{MH}]^{+}\right)$. HRMS $\left(\mathrm{ES}^{+},[\mathrm{MNa}]^{+}\right)$: calcd for $\mathrm{C}_{38} \mathrm{H}_{57} \mathrm{~N}_{5} \mathrm{O}_{11} 782.3952$, found 782.3969 .

\subsubsection{Peptidomimetic 24}

TFA $(0.5 \mathrm{~mL}, 6.5 \mathrm{mmol})$ was added to a cooled $\left(0^{\circ} \mathrm{C}\right)$ solution of compound 23 (46 mg, $0.06 \mathrm{mmol}$ ) dissolved in $\mathrm{CH}_{2} \mathrm{Cl}_{2}(2 \mathrm{~mL})$ with a droplet of water. The mixture was stirred at $\mathrm{rt}$ for $4 \mathrm{~h}$. The mixture was concentrated in vacuo after addition of toluene $(2 \mathrm{~mL})$. Two more additions and evaporations of toluene were done and finally the residue was taken in ether $(1 \mathrm{~mL})$ and extracted with water (three times). The aqueous phase was lyophilized to leave $\mathbf{2 4}$ as a foam in a quantitative yield (33 $\mathrm{mg}$ ).

Two diastereoisomers: mp: $60{ }^{\circ} \mathrm{C} .{ }^{1} \mathrm{H}$ NMR $\left(\mathrm{D}_{2} \mathrm{O}, 400 \mathrm{MHz}\right): \delta_{\mathrm{H}}$ $1.07\left(1 \mathrm{H}\right.$, ddd, $\left.J=11.7,11.7,11.7 \mathrm{~Hz}, \mathrm{H}_{8}\right) ; 1.32\left(2 \mathrm{H}, \mathrm{m}, \mathrm{CH}_{2} \mathrm{CH}_{2} \mathrm{CH}_{2} \mathrm{O}\right.$, $\left.\mathrm{H}_{1}\right) ; 1.52\left(1 \mathrm{H}, \mathrm{m}, \mathrm{H}_{6}\right) ; 1.65\left(2 \mathrm{H}, \mathrm{m}, \mathrm{CH}_{2} \mathrm{CH}_{2} \mathrm{CH}_{2} \mathrm{O}\right) ; 1.75(1 \mathrm{H}, \mathrm{m}$, $\left.\mathrm{CH}_{2} \mathrm{CH}_{2} \mathrm{CH}_{2} \mathrm{O}\right) ; 2.1\left(1 \mathrm{H}\right.$, br d, $\left.J=10.3 \mathrm{~Hz}, \mathrm{H}_{8}\right) ; 2.24\left(1 \mathrm{H}, \mathrm{m}, \mathrm{H}_{6}\right) ; 2.4(1 \mathrm{H}$, $\left.\mathrm{m}, \mathrm{H}_{1}\right) ; 2.59\left(1 \mathrm{H}, \mathrm{m}, \mathrm{H}_{2}\right) ; 2.7-2.88\left(2 \mathrm{H}, \mathrm{m}, \mathrm{CH}_{2} \mathrm{COOH}\right) ; 3.65-3.8(2 \mathrm{H}$, $\left.\mathrm{m}, \mathrm{H}_{7}, \mathrm{H}_{8 \mathrm{a}}\right) ; 4.12\left(2 \mathrm{H}, \mathrm{t}, J=6.0 \mathrm{~Hz}, \mathrm{CH}_{2} \mathrm{OCO}\right) ; 4.48-4.70(3 \mathrm{H}, \mathrm{m}$, $\left.\mathrm{NHCHCO}, \mathrm{CH}_{2} \mathrm{Ph}\right) ; 4.70\left(1 \mathrm{H}, \mathrm{m}, \mathrm{H}_{5}\right) ; 7.29(5 \mathrm{H}, \mathrm{m}, \mathrm{Ar}) .{ }^{13} \mathrm{C}$ NMR (100 MHz, MeOD): $\delta_{\mathrm{C}} 25.6\left(\mathrm{CH}_{2} \mathrm{CH}_{2} \mathrm{CH}_{2} \mathrm{OH}\right) ; 26.6\left(\mathrm{CH}_{2} \mathrm{CH}_{2} \mathrm{CH}_{2} \mathrm{OH}\right)$; 32.6 and $32.7\left(\mathrm{C}_{1}\right)$; 34.4 and $34.5\left(\mathrm{C}_{6}\right) ; 35.4\left(\mathrm{CH}_{2} \mathrm{COOH}\right) ; 41.0\left(\mathrm{C}_{8}\right)$; $41.3\left(\mathrm{C}_{2}\right) ; 48.9(\mathrm{NHCHCO}) ; 51\left(\mathrm{C}_{5}\right) ; 52.7$ and $52.9\left(\mathrm{C}_{8 \mathrm{a}}\right) ; 64.2\left(\mathrm{C}_{7}\right) ; 67.0$ $\left(\mathrm{CH}_{2} \mathrm{OCO}\right) ; 70.3\left(\mathrm{CH}_{2} \mathrm{Ph}\right) ; 127.5 ; 127.7 ; 128.1$ and $128.3\left(2 \mathrm{C}_{\mathrm{Ar}}, \mathrm{C}_{\mathrm{Ar}}\right.$, $\left.2 \mathrm{C}_{\mathrm{Ar}}\right) ; 138.1$ ( $\left.\mathrm{C}_{\text {Arquat }}\right) ; 153.0$ and $155.4(\mathrm{C}=\mathrm{N}, \mathrm{OCONH}) ; 170.7 ; 170.8$; $172.6 ; 173 ; 173.1$ and 177.2 (2NHCO, 2COOH, C3). HRMS (ES ${ }^{+}$, $[\mathrm{MH}]^{+}$): calcd for $\mathrm{C}_{25} \mathrm{H}_{33} \mathrm{~N}_{5} \mathrm{O}_{9} 548.2357$, found 548.2339.

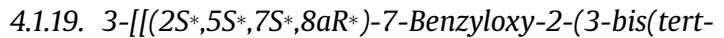

butyloxycarbonyl)guanidino-propyl)-3-oxo-octahydro-indolizin5-carbonyl-amino]propionic acid tert-butyl ester 25

Alcohol 22 (76 mg, $0.16 \mathrm{mmol}$ ) and 1,3-bis(tert-butoxycarbonyl) guanidine ( $70 \mathrm{mg}, 0.27 \mathrm{mmol}, 2.1$ equiv) were dried under vacuo, and dissolved in $5 \mathrm{~mL}$ of anhydrous THF under argon. Triphenylphosphine ( $87 \mathrm{mg}, 0.33 \mathrm{mmol}$, 2 equiv) was added to the solution at $\mathrm{rt}$, then diethylazodicarboxylate (DEAD) $(52 \mu \mathrm{L}, 0.33 \mathrm{mmol}$, 2 equiv) at $0{ }^{\circ} \mathrm{C}$. The mixture was stirred for $60 \mathrm{~h}$ at rt. After addition of dichloromethane, the solvent was removed in vacuo. The residue was purified by flash chromatography on silica gel $\left(\mathrm{Et}_{2} \mathrm{O} /\right.$ cyclohexane 90:10) to give a white foam (105 mg, 92\%).

$R_{f}=0.22\left(\mathrm{Et}_{2} \mathrm{O} /\right.$ cyclohexane 90:10). ${ }^{1} \mathrm{H} \mathrm{NMR}\left(\mathrm{CDCl}_{3}, 300 \mathrm{MHz}\right)$ : $\delta_{\mathrm{H}} 1.15\left(1 \mathrm{H}, \mathrm{ddd}, J=11.7,11.7,11.7 \mathrm{~Hz}, \mathrm{H}_{8}\right) ; 1.18-1.4\left(3 \mathrm{H}, \mathrm{m}, \mathrm{H}_{1}, \mathrm{H}_{6}\right.$ $\left.\mathrm{CH}_{2} \mathrm{CH}_{2} \mathrm{CH}_{2} \mathrm{~N}\right) ; 1.44\left(9 \mathrm{H}, \mathrm{s}, \mathrm{C}\left(\mathrm{CH}_{3}\right)_{3}\right) ; 1.49\left(9 \mathrm{H}, \mathrm{s}, \mathrm{C}\left(\mathrm{CH}_{3}\right)_{3}\right) ; 1.55(9 \mathrm{H}$, s, $\left.\mathrm{C}\left(\mathrm{CH}_{3}\right)_{3}\right) ; 1.65\left(2 \mathrm{H}, \mathrm{m}, \mathrm{CH}_{2} \mathrm{CH}_{2} \mathrm{CH}_{2} \mathrm{~N}\right) ; 1.94\left(1 \mathrm{H}, \mathrm{m}, \mathrm{CH}_{2} \mathrm{CH}_{2} \mathrm{CH}_{2} \mathrm{~N}\right)$; $2.28\left(1 \mathrm{H}\right.$, br d, $\left.J=11.6 \mathrm{~Hz}, \mathrm{H}_{8}\right) ; 2.39\left(2 \mathrm{H}, \mathrm{t}, J=6 \mathrm{~Hz}, \mathrm{NHCH}_{2} \mathrm{CH}_{2} \mathrm{CO}\right)$; 2.43-2.49 (2H, m, H $\left.\mathrm{H}_{1}\right)$; $2.63\left(1 \mathrm{H}, \mathrm{br} \mathrm{d}, J=12.7 \mathrm{~Hz}, \mathrm{H}_{6}\right) ; 3.34-3.49$ $\left(2 \mathrm{H}, \mathrm{m}, \mathrm{NHCH}_{2} \mathrm{CH}_{2} \mathrm{CO}\right) ; 3.56\left(1 \mathrm{H}, \mathrm{m}, \mathrm{H}_{8 \mathrm{a}}\right) ; 3.7-4.05\left(3 \mathrm{H}, \mathrm{m}, \mathrm{H}_{7}\right.$, $\left.\mathrm{CH}_{2} \mathrm{~N}\right) ; 4.55\left(1 \mathrm{H}, \mathrm{d}, J=11.8 \mathrm{~Hz}, \mathrm{CH}_{2} \mathrm{Ph}\right) ; 4.63(1 \mathrm{H}, \mathrm{d}, J=11.8 \mathrm{~Hz}$, $\left.\mathrm{CH}_{2} \mathrm{Ph}\right) ; 4.74\left(1 \mathrm{H}, \mathrm{d}, J=5.6 \mathrm{~Hz}, \mathrm{H}_{5}\right) ; 6.68(1 \mathrm{H}, \mathrm{t}, J=5.9 \mathrm{~Hz}, \mathrm{NH}) ; 7.3$ $(5 \mathrm{H}, \mathrm{m}, \mathrm{Ar}) ; 9.1-9.4\left(2 \mathrm{H}\right.$, br s, $\left.\mathrm{NH}_{2}\right) .{ }^{13} \mathrm{C} \mathrm{NMR}\left(75 \mathrm{MHz}, \mathrm{CDCl}_{3}\right): \delta_{\mathrm{C}}$ $26.2\left(\mathrm{CH}_{2} \mathrm{CH}_{2} \mathrm{CH}_{2} \mathrm{~N}\right) ; 28.1$ and $28.3\left(3 \mathrm{C}\left(\mathrm{CH}_{3}\right)_{3}, \mathrm{CH}_{2} \mathrm{CH}_{2} \mathrm{CH}_{2} \mathrm{~N}\right) ; 30.8$ $\left(\mathrm{C}_{6}\right) ; 33.3\left(\mathrm{C}_{1}\right) ; 35.2\left(\mathrm{NHCH}_{2} \mathrm{CH}_{2} \mathrm{CO}\right) ; 39.6\left(\mathrm{C}_{8}\right) ; 41.1\left(\mathrm{C}_{2}\right) ; 44.3$ $\left(\mathrm{CH}_{2} \mathrm{CH}_{2} \mathrm{CH}_{2} \mathrm{~N}\right) ; 50.9\left(\mathrm{C}_{5}\right) ; 52.3\left(\mathrm{C}_{8 \mathrm{a}}\right) ; 70.6\left(\mathrm{CH}_{2} \mathrm{Ph}\right) ; 72.4\left(\mathrm{C}_{7}\right) ; 78.6$ 81.1 and $83.7\left(3 \mathrm{C}\left(\mathrm{CH}_{3}\right)_{3}\right) ; 127.6 ; 128.3\left(2 \mathrm{C}_{\mathrm{Ar}}, \mathrm{C}_{\mathrm{Ar}}, 2 \mathrm{C}_{\mathrm{Ar}}\right) ; 138.5\left(\mathrm{C}_{\mathrm{Ar}-}\right.$ quat $) ; 155,160.5$, and $163.8(\mathrm{C}=\mathrm{N}, \mathrm{CON}) ; 169.9,171.3,176.4\left(2 \mathrm{CO}, \mathrm{C}_{3}\right)$. IR ( $\mathrm{NaCl}$ disc, $\left.\mathrm{cm}^{-1}\right): \nu_{\max } 3382,2977,1715,1608,1514,1368,1251$, 1152, 737. MS $\left(\mathrm{ES}^{+}\right): m / z 739\left([\mathrm{MNa}]^{+}\right)$.

\subsubsection{3-[[(2S*,5S*,7S*,8aR*)-7-Benzyloxy-2-(3-guanidino-propyl)-} 3-oxo-octahydro-indolizin-5-carbonyl]-amino]propionic acid 26

The same protocol for deprotection with TFA was applied to compound 25 ( $43 \mathrm{mg}, 0.06 \mathrm{mmol}$ ). Guanidyl compound was obtained as foam in a quantitative yield $(28 \mathrm{mg})$.

${ }^{1} \mathrm{H}$ NMR $\left(\mathrm{D}_{2} \mathrm{O}, 300 \mathrm{MHz}\right): \delta_{\mathrm{H}} 1.04(1 \mathrm{H}$, ddd, $J=11.7,11.7,11.7 \mathrm{~Hz}$, $\left.\mathrm{H}_{8}\right) ; 1.28\left(2 \mathrm{H}, \mathrm{m}, \mathrm{H}_{1}, \mathrm{CH}_{2} \mathrm{CH}_{2} \mathrm{CH}_{2} \mathrm{NH}\right) ; 1.48\left(3 \mathrm{H}, \mathrm{m}, \mathrm{CH}_{2} \mathrm{CH}_{2} \mathrm{CH}_{2} \mathrm{NH}\right.$, $\left.\mathrm{H}_{6}\right) ; 1.7\left(1 \mathrm{H}, \mathrm{m}, \mathrm{CH}_{2} \mathrm{CH}_{2} \mathrm{CH}_{2} \mathrm{NH}\right) ; 2.21\left(1 \mathrm{H}, \mathrm{br} \mathrm{d}, J=11.7 \mathrm{~Hz}, \mathrm{H}_{8}\right)$; $2.27-2.48\left(4 \mathrm{H}, \mathrm{m}, \mathrm{NHCH}_{2} \mathrm{CH}_{2} \mathrm{CO}, \mathrm{H}_{6}, \mathrm{H}_{1}\right) ; 2.55\left(1 \mathrm{H}, \mathrm{m}, \mathrm{H}_{2}\right) ; 3.06(2 \mathrm{H}$, $\left.\mathrm{t}, \mathrm{J}=6.0 \mathrm{~Hz}, \mathrm{CH}_{2} \mathrm{CH}_{2} \mathrm{CH}_{2} \mathrm{NH}\right) ; 3.31\left(2 \mathrm{H}, \mathrm{t}, J=5.7 \mathrm{~Hz}, \mathrm{NHCH}_{2} \mathrm{CH}_{2} \mathrm{CO}\right)$; $3.51\left(1 \mathrm{H}, \mathrm{m}, \mathrm{H}_{7}\right) ; 3.65\left(1 \mathrm{H}, \mathrm{m}, \mathrm{H}_{8 \mathrm{a}}\right) ; 4.47\left(1 \mathrm{H}, \mathrm{s}, \mathrm{CH}_{2} \mathrm{Ph}\right) ; 4.62(1 \mathrm{H}, \mathrm{d}$, $\left.J=5.6 \mathrm{~Hz}, \mathrm{H}_{5}\right) ; 7.28(5 \mathrm{H}, \mathrm{m}, \mathrm{Ar}) .{ }^{13} \mathrm{C} \mathrm{NMR}\left(75 \mathrm{MHz}, \mathrm{D}_{2} \mathrm{O}\right): \delta_{\mathrm{C}} 25.2$ $\left(\mathrm{CH}_{2} \mathrm{CH}_{2} \mathrm{CH}_{2} \mathrm{NH}\right) ; 27.2\left(\mathrm{CH}_{2} \mathrm{CH}_{2} \mathrm{CH}_{2} \mathrm{NH}\right) ; 31.6\left(\mathrm{C}_{6}\right) ; 31.9\left(\mathrm{C}_{1}\right) ; 33.4$ $\left(\mathrm{NHCH}_{2} \mathrm{CH}_{2} \mathrm{CO}\right) ; \quad 35.2 \quad\left(\mathrm{NHCH}_{2} \mathrm{CH}_{2} \mathrm{CO}\right) ; \quad 38.2 \quad\left(\mathrm{C}_{8}\right) ; \quad 40.8$ $\left(\mathrm{CH}_{2} \mathrm{CH}_{2} \mathrm{CH}_{2} \mathrm{NH}\right) ; 41.0\left(\mathrm{C}_{2}\right) ; 51.6\left(\mathrm{C}_{8 \mathrm{a}}\right) ; 53.3\left(\mathrm{C}_{5}\right) ; 70.2\left(\mathrm{CH}_{2} \mathrm{Ph}\right) ; 71.8$ $\left(\mathrm{C}_{7}\right) ; 128.3 ; 128.5$ and $128.7\left(2 \mathrm{C}_{\mathrm{Ar}}, \mathrm{C}_{\mathrm{Ar}}, 2 \mathrm{C}_{\mathrm{Ar}}\right) ; 137.1$ ( $\left.\mathrm{C}_{\text {Arquat }}\right) ; 156.6$ $(\mathrm{C}=\mathrm{N}) ; 171.4,175.8,178.6\left(2 \mathrm{CO}, \mathrm{C}_{3}\right) . \mathrm{MS}\left(\mathrm{ES}^{+}\right): \mathrm{m} / \mathrm{z} 460\left([\mathrm{MH}]^{+}\right)$. HRMS $\left(\mathrm{ES}^{+},[\mathrm{MH}]^{+}\right)$: calcd for $\mathrm{C}_{23} \mathrm{H}_{33} \mathrm{~N}_{5} \mathrm{O}_{5}$ 460.2560, found 460.2552 .

\subsubsection{3-[(2S*,5S*,7S*,8aR*)-[2-(3-Guanidino-propyl)-7-hydroxy-} 3-oxo-octahydro-indolizin-5-carbonyl]-amino]propionic acid 27

To benzyl ether 25 ( $45 \mathrm{mg}, 0.063 \mathrm{mmol}$ ) dissolved in $7 \mathrm{~mL}$ of methanol was added $35 \mathrm{mg}$ of palladium on activated carbon (10\% Pd). The mixture was put under hydrogen and stirred $24 \mathrm{~h}$. After filtration on Celite, washing with ethyl acetate, the solvents were removed under 
vacuo. The residue was purified by flash chromatography on silica gel (ethyl acetate) to give a colorless oil ( $28 \mathrm{mg}, 71 \%$ ).

$R_{f}=0.36$ (AcOEt/MeOH 99:1). ${ }^{1} \mathrm{H} \mathrm{NMR}\left(\mathrm{CDCl}_{3}, 300 \mathrm{MHz}\right): \delta_{\mathrm{H}} 1.14$ $\left(1 \mathrm{H}, \quad\right.$ ddd, $\left.J=11.7,11.7,11.7 \mathrm{~Hz}, \mathrm{H}_{8}\right) ; 1.23-1.38\left(2 \mathrm{H}, \mathrm{m}, \mathrm{H}_{1}\right.$, $\left.\mathrm{CH}_{2} \mathrm{CH}_{2} \mathrm{CH}_{2} \mathrm{~N}\right)$; $1.38-1.45\left(28 \mathrm{H}, \mathrm{s}, \mathrm{H}_{6}, 3 \mathrm{C}\left(\mathrm{CH}_{3}\right)_{3}\right) ; 1.59-1.73(2 \mathrm{H}, \mathrm{m}$, $\left.\mathrm{CH}_{2} \mathrm{CH}_{2} \mathrm{CH}_{2} \mathrm{~N}\right) ; 1.95\left(1 \mathrm{H}, \mathrm{m}, \mathrm{CH}_{2} \mathrm{CH}_{2} \mathrm{CH}_{2} \mathrm{~N}\right) ; 2.21(1 \mathrm{H}, \mathrm{dm}, J=12 \mathrm{~Hz}$, $\left.\mathrm{H}_{8}\right) ; 2.4\left(2 \mathrm{H}, \mathrm{t}, J=6.2 \mathrm{~Hz}, \mathrm{NHCH}_{2} \mathrm{CH}_{2} \mathrm{CO}\right) ; 2.43-2.63\left(3 \mathrm{H}, \mathrm{m}, \mathrm{H}_{2}, \mathrm{H}_{1}\right.$, $\left.\mathrm{H}_{6}\right) ; 3.42\left(2 \mathrm{H}, \mathrm{m}, \mathrm{NHCH}_{2} \mathrm{CH}_{2} \mathrm{CO}\right) ; 3.59\left(1 \mathrm{H}, \mathrm{m}, \mathrm{H}_{8 \mathrm{a}}\right) ; 3.8(1 \mathrm{H}, \mathrm{m}$, $\left.\mathrm{CH}_{2} \mathrm{~N}\right) ; 4.01\left(1 \mathrm{H}, \mathrm{m}, \mathrm{CH}_{2} \mathrm{~N}\right) ; 4.13\left(1 \mathrm{H}, \mathrm{m}, \mathrm{H}_{7}\right) ; 4.73(1 \mathrm{H}, \mathrm{d}, J=5.7 \mathrm{~Hz}$, $\left.\mathrm{H}_{5}\right) ; 6.74(1 \mathrm{H}, \mathrm{t}, J=4.5 \mathrm{~Hz}, \mathrm{NH}) ; 9.26\left(2 \mathrm{H}, \mathrm{br} \mathrm{s}, \mathrm{NH}_{2}\right) \cdot{ }^{13} \mathrm{C} \mathrm{NMR}$ $\left(75 \mathrm{MHz}, \mathrm{CDCl}_{3}\right): \delta_{\mathrm{C}} 26.2\left(\mathrm{CH}_{2} \mathrm{CH}_{2} \mathrm{CH}_{2} \mathrm{~N}\right) ; 28.1$ and $28.3\left(3 \mathrm{C}\left(\mathrm{CH}_{3}\right)_{3}\right)$; 33.3, 33.9, $35.1\left(\mathrm{NHCH}_{2} \mathrm{CH}_{2} \mathrm{CO}, \mathrm{C}_{8}, \mathrm{C}_{6}, \mathrm{C}_{1}\right) ; 41.1\left(\mathrm{C}_{2}\right) ; 41.7,44.3$ $\left(\mathrm{NHCH}_{2} \mathrm{CH}_{2} \mathrm{CO}, \mathrm{CH}_{2} \mathrm{CH}_{2} \mathrm{CH}_{2} \mathrm{~N}\right) ; 50.9,52.3\left(\mathrm{C}_{5}, \mathrm{C}_{8 \mathrm{a}}\right) ; 65.0\left(\mathrm{C}_{7}\right) ; 78.6$, 81.1, and $83.7\left(3 \mathrm{C}\left(\mathrm{CH}_{3}\right)_{3}\right) ; 127.6 ; 128.3\left(2 \mathrm{C}_{\mathrm{Ar}}, \mathrm{C}_{\mathrm{Ar}}, 2 \mathrm{C}_{\mathrm{Ar}}\right) ; 138.5$ $\left(\mathrm{C}_{\text {Arquat }}\right) ; 155(\mathrm{C}=\mathrm{N}) ; 160.5$ and $163.8(\mathrm{C}=\mathrm{N}, \mathrm{CON}) ; 169.9,171.4$, $176.5\left(2 \mathrm{CO}, \mathrm{C}_{3}\right)$. IR ( $\mathrm{NaCl}$ disc, $\left.\mathrm{cm}^{-1}\right): \nu_{\max } 3383,2978,1715,1608$, 1515, 1251, 1151, 1101, 736. MS $\left(\mathrm{ES}^{+}\right): \mathrm{m} / z 626\left([\mathrm{MH}]^{+}\right)$.

The same protocol for deprotection with TFA was applied to compound described above ( $28 \mathrm{mg}, 0.045 \mathrm{mmol}$ ). Guanidyl compound 27 was obtained as an oil in a quantitative yield (17 $\mathrm{mg})$.

${ }^{1} \mathrm{H}$ NMR $\left(\mathrm{D}_{2} \mathrm{O}, 400 \mathrm{MHz}\right): \delta_{\mathrm{H}} 1.14(1 \mathrm{H}$, ddd, $J=11.7,11.7,11.7 \mathrm{~Hz}$, $\left.\mathrm{H}_{8}\right)$; 1.24-1.35 (2H, m, H $\left.\mathrm{CH}_{2} \mathrm{CH}_{2} \mathrm{CH}_{2} \mathrm{~N}\right) ; 1.45-1.55\left(2 \mathrm{H}, \mathrm{m}, \mathrm{H}_{6}\right.$, $\left.\mathrm{CH}_{2} \mathrm{CH}_{2} \mathrm{CH}_{2} \mathrm{~N}\right) ; 1.69\left(1 \mathrm{H}, \mathrm{m}, \mathrm{CH}_{2} \mathrm{CH}_{2} \mathrm{CH}_{2} \mathrm{~N}\right) ; 2.12(1 \mathrm{H}, \mathrm{dm}, J=12.1 \mathrm{~Hz}$, $\left.\mathrm{H}_{8}\right) ; 2.21\left(1 \mathrm{H}, \mathrm{dm}, J=13.2 \mathrm{~Hz}, \mathrm{H}_{6}\right) ; 2.39(1 \mathrm{H}$, ddd, $J=12.6,8.9,7.1 \mathrm{~Hz}$, $\left.\mathrm{H}_{1}\right) ; 2.47\left(1 \mathrm{H}, \mathrm{t}, J=6.4 \mathrm{~Hz}, \mathrm{NHCH}_{2} \mathrm{CH}_{2} \mathrm{CO}\right) ; 2.58(1 \mathrm{H}$, dddd, $J=9.4,9.4$, 9.4, $\left.4.2 \mathrm{~Hz}, \mathrm{H}_{2}\right)$; $3.08\left(2 \mathrm{H}, \mathrm{t}, \mathrm{J}=6.8 \mathrm{~Hz}, \mathrm{CH}_{2} \mathrm{CH}_{2} \mathrm{CH}_{2} \mathrm{~N}\right) ; 3.35(2 \mathrm{H}, \mathrm{t}$, $\left.J=6.4 \mathrm{~Hz}, \mathrm{NHCH}_{2} \mathrm{CH}_{2} \mathrm{CO}\right) ; 3.65-3.75\left(2 \mathrm{H}, \mathrm{m}, \mathrm{H}_{7}, \mathrm{H}_{8 \mathrm{a}}\right) ; 4.62(1 \mathrm{H}, \mathrm{d}$, $\left.J=5.6 \mathrm{~Hz}, \mathrm{H}_{5}\right) .{ }^{13} \mathrm{C}$ NMR $\left(75 \mathrm{MHz}, \mathrm{D}_{2} \mathrm{O}\right): \delta_{\mathrm{C}} 25.2\left(\mathrm{CH}_{2} \mathrm{CH}_{2} \mathrm{CH}_{2} \mathrm{~N}\right) ; 27.3$ $\left(\mathrm{CH}_{2} \mathrm{CH}_{2} \mathrm{CH}_{2} \mathrm{~N}\right) ; 31.5\left(\mathrm{C}_{1}\right) ; 33.5\left(\mathrm{NHCH}_{2} \mathrm{CH}_{2} \mathrm{CO}\right) ; 34.1\left(\mathrm{C}_{6}\right) ; 35.3$ $\left(\mathrm{NHCH}_{2} \mathrm{CH}_{2} \mathrm{CO}\right) ; 40.5\left(\mathrm{C}_{8}\right) ; 40.8\left(\mathrm{CH}_{2} \mathrm{CH}_{2} \mathrm{CH}_{2} \mathrm{~N}\right) ; 41.0\left(\mathrm{C}_{2}\right) ; 51.2\left(\mathrm{C}_{5}\right)$; $53.3\left(\mathrm{C}_{8 \mathrm{a}}\right) ; 64.3\left(\mathrm{C}_{7}\right) ; 156.7(\mathrm{C}=\mathrm{N}) ; 171.7,176.1,178.8\left(2 \mathrm{CO} \mathrm{C}_{3}\right)$. MS $\left(\mathrm{ES}^{+}\right): \mathrm{m} / z 370\left([\mathrm{MH}]^{+}\right), 392\left([\mathrm{MNa}]^{+}\right)$. HRMS $\left(\mathrm{ES}^{+},[\mathrm{MNa}]^{+}\right)$: calcd for $\mathrm{C}_{16} \mathrm{H}_{27} \mathrm{~N}_{5} \mathrm{O}_{5}$ 370.2090, found 370.2078.

\subsubsection{2. $\left(2 R^{*}, 5 S^{*}, 7 S^{*}, 8 a R^{*}\right)$-2-Allyl-7-methoxymethoxy-3-oxo-} octahydro-indolizin-5-carboxylic acid $\mathbf{2 8}$

To alcohol 17b (105 mg, $0.39 \mathrm{mmol}$ ) dissolved in $3.5 \mathrm{~mL}$ of acetone was added dropwise Jones reagent $2.67 \mathrm{M}(220 \mu \mathrm{L}, 0.58 \mathrm{mmol}$, 1.5 equiv) at $0{ }^{\circ} \mathrm{C}$. Stirring was continued for $30 \mathrm{~min}, 3 \mathrm{~mL}$ of isopropanol was added, and the mixture was stirred for $10 \mathrm{~min}$ at $0{ }^{\circ} \mathrm{C}$. After addition of $1 \mathrm{~mL}$ of water and $1 \mathrm{~mL}$ of a saturated solution of $\mathrm{KHSO}_{4}$, the mixture was extracted twice with $100 \mathrm{~mL}$ of dichloromethane. The organic phase was dried $\left(\mathrm{MgSO}_{4}\right)$ and the solvent removed in vacuo. The residue was purified by flash chromatography on silica gel (AcOEt/MeOH/AcOH 97:1:2) and the carboxylic acid 28 was isolated as a white foam $(54 \%, 60 \mathrm{mg})$.

$R_{f}=0.35$ (AcOEt/MeOH/AcOH 97:1:2). ${ }^{1} \mathrm{H}\left(\mathrm{CDCl}_{3}, 300 \mathrm{MHz}\right): \delta_{\mathrm{H}}$ 1.19 ( $1 \mathrm{H}$, ddd, $\left.J=11.8,11.8,11.8 \mathrm{~Hz}, \mathrm{H}_{8 \mathrm{ax}}\right) ; 1.58$ (1H, ddd, $J=12.9,12.9$, $\left.6.8 \mathrm{~Hz}, \mathrm{H}_{6}\right) ; 1.79\left(1 \mathrm{H}\right.$, ddd, $\left.J=13.0,9.2,7.7 \mathrm{~Hz}, \mathrm{H}_{1}\right) ; 2.05\left(1 \mathrm{H}, \mathrm{m}, \mathrm{H}_{1}\right)$; $2.25\left(2 \mathrm{H}, \mathrm{m}, \mathrm{H}_{8}, \mathrm{CH}_{2} \mathrm{CH}=\mathrm{CH}_{2}\right) ; 2.55\left(3 \mathrm{H}, \mathrm{m}, \mathrm{H}_{2}, \mathrm{H}_{6}, \mathrm{CH}_{2} \mathrm{CH}=\mathrm{CH}_{2}\right)$; 3.38 ( $3 \mathrm{H}, \mathrm{s}, \mathrm{CH}_{2} \mathrm{OMe}$ ); 3.70 ( $1 \mathrm{H}$, dddd, $J=11.4,11.4,3.9,3.9 \mathrm{~Hz}, \mathrm{H}_{7 \mathrm{ax}}$ ); $3.82\left(1 \mathrm{H}\right.$, dddd, $\left.J=11.6,8.0,8.0,3.8 \mathrm{~Hz}, \mathrm{H}_{8 \mathrm{a}}\right) ; 4.69\left(2 \mathrm{H}, \mathrm{s}, \mathrm{OCH}_{2} \mathrm{O}\right) ; 4.95$ $\left(1 \mathrm{H}, \mathrm{d}, J=5.4 \mathrm{~Hz}, \mathrm{H}_{5 \mathrm{eq}}\right) ; 5.06\left(1 \mathrm{H}, \mathrm{br} \mathrm{d}, J=17.1 \mathrm{~Hz}, \mathrm{CH}_{2}=\mathrm{CH}\right) ; 5.09(1 \mathrm{H}$, dd, $\left.J=7.0,1.3 \mathrm{~Hz}, \mathrm{CH}_{2}=\mathrm{CH}\right) ; 5.8(1 \mathrm{H}$, dddd, $J=17.1,10.1,7.0,7.0 \mathrm{~Hz}$, $\left.\mathrm{CH}_{2}=\mathrm{CH}\right) .{ }^{13} \mathrm{C}$ NMR $\left(75 \mathrm{MHz}, \mathrm{CDCl}_{3}\right): \delta_{\mathrm{C}} 30.4\left(\mathrm{C}_{1}\right) ; 32.3\left(\mathrm{C}_{6}\right) ; 35.4$ $\left(\mathrm{CH}_{2}-\mathrm{CH}=\mathrm{CH}_{2}\right) ; 39.4\left(\mathrm{C}_{8}\right) ; 41.0\left(\mathrm{C}_{2}\right) ; 50.0\left(\mathrm{C}_{5}\right) ; 52.3\left(\mathrm{C}_{8 \mathrm{a}}\right) ; 55.4$ $\left(\mathrm{CH}_{2} \mathrm{OMe}\right) ; 70.8\left(\mathrm{C}_{7}\right) ; 94.7\left(\mathrm{OCH}_{2} \mathrm{O}\right) ; 117.4\left(\mathrm{CH}_{2}=\mathrm{CH}\right) ; 135.3$ $\left(\mathrm{CH}_{2}=\mathrm{CH}\right) ; 172.3(\mathrm{COOH}) ; 176.4\left(\mathrm{C}_{3}\right)$. IR $\left(\mathrm{NaCl}\right.$ disc, $\left.\mathrm{cm}^{-1}\right): \nu_{\max } 2936$, $2368,1735,1651,1451,1211,1112,1039 . \mathrm{MS}\left(\mathrm{ES}^{+}\right): \mathrm{m} / z 306\left([\mathrm{MNa}]^{+}\right)$. HRMS $\left(\mathrm{ES}^{+},[\mathrm{MNa}]^{+}\right)$: calcd for $\mathrm{C}_{14} \mathrm{H}_{21} \mathrm{NO}_{5} 306.1317$, found: 306.1306 .

4.1.23. (2S)-2-[(2R*,5S*,7S*,8aR*)-(2-Allyl-7-methoxymethoxy-3oxo-octahydro-indolizin-5-carbonyl)-aminolpentanedioic acid tert-butyl ester $\mathbf{2 9}$

The same experimental procedure as described for peptide coupling was applied to carboxylic acid 28 (88 $\mathrm{mg}, 0.31 \mathrm{mmol}$ ) using NMM ( $37 \mu \mathrm{L}, 0.34 \mathrm{mmol}, 1.1$ equiv) and isobutyl chloroformiate ( $44 \mu \mathrm{L}, 0.34 \mathrm{mmol}, 1.1$ equiv). Stirring was maintained $20 \mathrm{~h}$ after addition of amino acid (100 $\mathrm{mg}, 0.34 \mathrm{mmol}, 1.1$ equiv) and $\operatorname{NMM}(74 \mu \mathrm{L}, 0.68 \mathrm{mmol}, 2.2$ equiv). Flash chromatography on silica gel (AcOEt/cyclohexane 80:20) allowed the isolation of a colorless oil $(90 \%, 146 \mathrm{mg})$.

Two diastereoisomers: $R_{f}=0.6$ (AcOEt/cyclohexane 90:10). ${ }^{1} \mathrm{H}$ $\left(\mathrm{CDCl}_{3}, 300 \mathrm{MHz}\right): \delta_{\mathrm{H}} 1.12\left(1 \mathrm{H}, \mathrm{ddd}, J=10.8,10.8,10.8 \mathrm{~Hz}, \mathrm{H}_{8 \mathrm{ax}}\right) ; 1.39$ $\left(19 \mathrm{H}, \mathrm{m}, 2 \mathrm{C}\left(\mathrm{CH}_{3}\right)_{3}, \mathrm{H}_{6}\right) ; 1.72-1.87\left(2 \mathrm{H}, \mathrm{m}, \mathrm{NHCHCH}_{2} \mathrm{CH}_{2} \mathrm{CO}, \mathrm{H}_{1}\right)$; 1.98-2.07 (1H, m, $\left.\mathrm{NHCHCH}_{2} \mathrm{CH}_{2} \mathrm{CO}, \mathrm{H}_{1}\right) ; 2.1-2.3(4 \mathrm{H}, \mathrm{m}$, $\left.\mathrm{NHCHCH}_{2} \mathrm{CH}_{2} \mathrm{CO}, \mathrm{H}_{8}, \mathrm{CH}_{2} \mathrm{CH}=\mathrm{CH}_{2}\right) ; 2.4-2.6\left(3 \mathrm{H}, \mathrm{m}, \mathrm{H}_{2}, \mathrm{H}_{6}\right.$, $\left.\mathrm{CH}_{2} \mathrm{CH}=\mathrm{CH}_{2}\right)$; $3.29\left(3 \mathrm{H}, \mathrm{s}, \mathrm{CH}_{2} \mathrm{OMe}\right) ; 3.66\left(1 \mathrm{H}, \mathrm{m}, \mathrm{H}_{8 \mathrm{a}}\right) ; 3.82 / 3.92$ (1H, dddd/dddd, $\left.J=11.3,11.3,3.9,3.9 / 11.2,11.2,3.9,3.9 \mathrm{~Hz}, \mathrm{H}_{7 \mathrm{ax}}\right)$; $4.33\left(1 \mathrm{H}, \mathrm{m}, \mathrm{NHCHCH}_{2} \mathrm{CH}_{2} \mathrm{CO}\right) ; 4.63\left(2 \mathrm{H}, \mathrm{m}, \mathrm{OCH}_{2} \mathrm{O}\right) ; 4.77 / 4.80(1 \mathrm{H}$, d/d, $\left.J=5.7 / 6.2 \mathrm{~Hz}, \mathrm{H}_{5 \mathrm{eq}}\right) ; 5.06\left(1 \mathrm{H}\right.$, br d, $\left.J=17.1 \mathrm{~Hz}, \mathrm{CH}_{2}=\mathrm{CH}\right) ; 5.04$ $\left(1 \mathrm{H}, \mathrm{m}, \mathrm{CH}_{2}=\mathrm{CH}\right) ; 5.73\left(1 \mathrm{H}, \mathrm{m}, \mathrm{CH}_{2}=\mathrm{CH}\right) ; 6.66 / 6.73(1 \mathrm{H}, \mathrm{d} / \mathrm{d}, J=7.7 /$ $8.0 \mathrm{~Hz}, \mathrm{NH}) .{ }^{13} \mathrm{C} \mathrm{NMR}\left(75 \mathrm{MHz}, \mathrm{CDCl}_{3}\right): \delta_{\mathrm{C}} 27.3 / 27.4\left(2 \mathrm{C}\left(\mathrm{CH}_{3}\right)_{3}\right) ; 30.2$ $\left(\mathrm{C}_{1}, \mathrm{NHCHCH}_{2} \mathrm{CH}_{2} \mathrm{CO}\right) ; 31.2\left(\mathrm{C}_{6}\right) ; 31.5\left(\mathrm{NHCHCH}_{2} \mathrm{CH}_{2} \mathrm{CO}\right) ; 35.4\left(\mathrm{CH}_{2}-\right.$ $\left.\mathrm{CH}=\mathrm{CH}_{2}\right) ; \quad 39.3\left(\mathrm{C}_{8}\right) ; 40.4 \quad\left(\mathrm{C}_{2}\right) ; 50.0,50.9,52.2 \quad\left(\mathrm{C}_{5}, \mathrm{C}_{8 \mathrm{a}}\right.$, $\left.\mathrm{NHCHCH}_{2} \mathrm{CH}_{2} \mathrm{CO}\right) ; 55.3\left(\mathrm{CH}_{2} \mathrm{OMe}\right) ; 70.8\left(\mathrm{C}_{7}\right) ; 80.65\left(\mathrm{C}_{\left.\left(\mathrm{CH}_{3}\right)_{3}\right) ; 82.1 /}\right.$ $82.2\left(\mathrm{C}\left(\mathrm{CH}_{3}\right)_{3}\right) ; 95.2\left(\mathrm{OCH}_{2} \mathrm{O}\right) ; 117.3: 117.5\left(\mathrm{CH}_{2}=\mathrm{CH}\right) ; 135.0 / 035.3$ $\left(\mathrm{CH}_{2}=\mathrm{CH}\right) ; 169.6 / 169.7,170.4 / 170.6,171.8$ (3CO); 176.4/176.4 $\left(\mathrm{C}_{3}\right)$. MS (ES $\left.{ }^{+}\right): m / z 547\left([\mathrm{MNa}]^{+}\right)$.

\subsubsection{4. (2S)-2-[[(2R*,5S*,7S*,8aR*)-2-(3-Hydroxy-propyl)-7- methoxymethoxy-3-oxo-octahydro-indolizin-5-carbonyl]- amino]pentanedioic acid tert-butyl ester 30}

The same experimental procedure as described for hydroboration was applied to 29 ( $139 \mathrm{mg}, 0.27 \mathrm{mmol}$ ) using a $0.5 \mathrm{M}$ solution of 9-BBN (1.6 mL, $0.81 \mathrm{mmol}, 3$ equiv). Stirring was maintained $15 \mathrm{~h}$ after addition of sodium acetate $5 \mathrm{M}(0.57 \mathrm{~mL}$, $2.84 \mathrm{mmol}, 10.5$ equiv) and a $30 \% \mathrm{H}_{2} \mathrm{O}_{2}$ solution ( $0.33 \mathrm{~mL}, 12$ equiv). Flash chromatography on silica gel (AcOEt/MeOH 98:2 to 95:5) allowed the isolation of a colorless oil (65\%, $93 \mathrm{mg})$.

$R_{f}=0.15$ (AcOEt/MeOH 98:2). ${ }^{1} \mathrm{H}\left(\mathrm{CDCl}_{3}, 300 \mathrm{MHz}\right): \delta_{\mathrm{H}} 1.18(1 \mathrm{H}$, ddd, $\left.J=11.2,11.2,11.2 \mathrm{~Hz}, \mathrm{H}_{8}\right) ; 1.3-1.72\left(23 \mathrm{H}, \mathrm{m}, 2 \mathrm{C}\left(\mathrm{CH}_{3}\right)_{3}, \mathrm{H}_{6}\right.$, $\mathrm{CH}_{2} \mathrm{CH}_{2} \mathrm{CH}_{2} \mathrm{OH}$ ); 1.78-1.99 (3H, m, NHCHCH${ }_{2} \mathrm{CH}_{2} \mathrm{CO}, \mathrm{H}_{1}$ ); $1.99-2.12$ $\left(1 \mathrm{H}, \mathrm{m}, \mathrm{H}_{1}\right) ; 2.12-2.3\left(3 \mathrm{H}, \mathrm{m}, \mathrm{NHCHCH}_{2} \mathrm{CH}_{2} \mathrm{CO}, \mathrm{H}_{8}\right) ; 2.45-2.64(2 \mathrm{H}$, $\left.\mathrm{m}, \mathrm{H}_{2}, \mathrm{H}_{6}\right) ; 3.35$ ( $\left.3 \mathrm{H}, \mathrm{s}, \mathrm{CH}_{2} \mathrm{OMe}\right)$; 3.62-3.78 (3H, m, $\left.\mathrm{CH}_{2} \mathrm{OH}, \mathrm{H}_{8 \mathrm{a}}\right)$; $3.89 / 3.99(1 \mathrm{H}$, dddd/dddd, $J=11.2,11.2,3.9,3.9 / 11.2,11.2,4,4 \mathrm{~Hz}$, $\left.\mathrm{H}_{7}\right) ; 4.33-4.45\left(1 \mathrm{H}, \mathrm{m}, \mathrm{NHCHCH} \mathrm{CH}_{2} \mathrm{CO}\right) ; 4.67 / 4.68(1 \mathrm{H}, \mathrm{d} / \mathrm{d}, J=6.8 /$ $\left.6.8 \mathrm{~Hz}, \mathrm{OCH}_{2} \mathrm{O}\right) ; 4.72 / 4.73\left(1 \mathrm{H}, \mathrm{d} / \mathrm{d}, J=6.8 / 6.8 \mathrm{~Hz}, \mathrm{OCH}_{2} \mathrm{O}\right) ; 4.83 / 4.86$ $\left(1 \mathrm{H}, \mathrm{d} / \mathrm{d}, J=6 / 5.3 \mathrm{~Hz}, \mathrm{H}_{5}\right) ; 6.74 / 6.82(1 \mathrm{H}, \mathrm{d} / \mathrm{d}, J=8.1 / 7.7 \mathrm{~Hz}, \mathrm{NH}) .{ }^{13} \mathrm{C}$ NMR (75 MHz, $\left.\mathrm{CDCl}_{3}\right)$ : $\delta_{\mathrm{C}} 25.7,27.4,27.7\left(\mathrm{CH}_{2}\right) ; 28.0\left(2 \mathrm{C}\left(\mathrm{CH}_{3}\right)_{3}\right)$; 30.1, 30.2, $31.5\left(\mathrm{CH}_{2}\right) ; 31.1\left(\mathrm{C}_{6}\right) ; 39.3 / 39.5\left(\mathrm{C}_{8}\right) ; 40.5 / 40.6\left(\mathrm{C}_{2}\right) ; 50.9$ $\left(\mathrm{C}_{5}\right) ; 52.3\left(\mathrm{C}_{8 \mathrm{a}} \quad \mathrm{NHCHCH}_{2} \mathrm{CH}_{2} \mathrm{CO}\right) ; 55.4 \quad\left(\mathrm{CH}_{2} \mathrm{OMe}\right) ; 62.3 / 62.5$ $\left(\mathrm{CH}_{2} \mathrm{OH}\right)$; $70.9\left(\mathrm{C}_{7}\right) ; 80.8 / 81.1,82.5\left(\mathrm{C}\left(\mathrm{CH}_{3}\right)_{3}\right) ; 95.2: 95.3\left(\mathrm{OCH}_{2} \mathrm{O}\right)$; 169.6/169.7, 170.5/171, 172/172.2 (3CO); 177.1/177.3 (C C $_{3}$. IR ( $\mathrm{NaCl}$ disc, $\left.\mathrm{cm}^{-1}\right): \nu_{\max } 3313,2934,1730,1536,1453,1369,1257,1154$. MS $\left(\mathrm{ES}^{+}\right): \mathrm{m} / z \quad 565\left([\mathrm{MNa}]^{+}\right)$. HRMS $\left(\mathrm{ES}^{+},[\mathrm{MNa}]^{+}\right)$: calcd for $\mathrm{C}_{27} \mathrm{H}_{46} \mathrm{~N}_{2} \mathrm{O}_{9}$ 565.3101, found 565.3084.

\subsubsection{Guanidine carbamate 31}

Alcohol 30 (67 mg, $0.127 \mathrm{mmol}$ ) and 1,3-bis(tert-butoxycarbonyl) guanidine $(70 \mathrm{mg}, 0.27 \mathrm{mmol}, 2.1$ equiv) were dried under vacuo, and dissolved in $2.5 \mathrm{~mL}$ of anhydrous THF under argon. Tributylphosphine ( $63 \mu \mathrm{L}, 0.25 \mathrm{mmol}, 2$ equiv) was added to the solution at $\mathrm{rt}$, then dipiperidinazodicarboxylate (ADDP) (63 mg, $0.25 \mathrm{mmol}, 2$ equiv) at $0^{\circ} \mathrm{C}$. The mixture was refluxed $2 \mathrm{~h}$. After addition of water and dichloromethane, the mixture was extracted. The organic phase was dried $\left(\mathrm{MgSO}_{4}\right)$ and the solvent removed in vacuo. The residue was purified by flash chromatography on silica gel ( $\left.\mathrm{Et}_{2} \mathrm{O} / \mathrm{MeOH} 97: 3\right)$ to give a white solid (40 mg, 43\%).

$R_{f}=0.1\left(\mathrm{Et}_{2} \mathrm{O} / \mathrm{MeOH} 98: 2\right) .{ }^{1} \mathrm{H}\left(\mathrm{CDCl}_{3}, 400 \mathrm{MHz}\right): \delta_{\mathrm{H}} 1.18(1 \mathrm{H}, \mathrm{ddd}$, $\left.J=11.7,11.7,11.7 \mathrm{~Hz}, \mathrm{H}_{8}\right) ; 1.27-1.48\left(28 \mathrm{H}, \mathrm{m}, 3 \mathrm{C}\left(\mathrm{CH}_{3}\right)_{3}, \mathrm{H}_{6}\right) ; 1.5-1.63$ $\left(1 \mathrm{H}, \mathrm{m}, \mathrm{CH}_{2} \mathrm{CH}_{2} \mathrm{CH}_{2} \mathrm{OH}\right) ; 1.73-2.28\left(10 \mathrm{H}, \mathrm{m}, \mathrm{H}_{8}, \mathrm{NHCHCH}_{2} \mathrm{CH}_{2} \mathrm{CO}\right.$, 
$\left.\mathrm{CH}_{2} \mathrm{CH}_{2} \mathrm{CH}_{2} \mathrm{OH}, \mathrm{H}_{1}\right) ; 2.43-2.59\left(2 \mathrm{H}, \mathrm{m}, \mathrm{H}_{2}, \mathrm{H}_{6}\right) ; 3.33(3 \mathrm{H}, \mathrm{s}$, $\left.\mathrm{CH}_{2} \mathrm{OMe}\right)$; 3.64-3.76 (1H, m, $\left.\mathrm{H}_{8 \mathrm{a}}\right) ; 3.85 / 3.93(1 \mathrm{H}$, dddd/dddd, $\left.J=11.2,11.2,4.0,4.0 / 11.2,11.2,4.0,4.0 \mathrm{~Hz}, \mathrm{H}_{7}\right) ; 4.05-4.15(2 \mathrm{H}, \mathrm{m}$, $\left.\mathrm{CH}_{2} \mathrm{OH}\right) ; 4.32-4.43\left(1 \mathrm{H}, \mathrm{m}, \mathrm{NHCHCH}_{2} \mathrm{CH}_{2} \mathrm{CO}\right) ; 4.65 / 4.66(1 \mathrm{H}, \mathrm{d} / \mathrm{d}$, $\left.J=6.8 / 6.8 \mathrm{~Hz}, \mathrm{OCH}_{2} \mathrm{O}\right) ; 4.69 / 4.695\left(1 \mathrm{H}, \mathrm{d} / \mathrm{d}, J=6.8 / 6.8 \mathrm{~Hz}, \mathrm{OCH}_{2} \mathrm{O}\right)$; $4.81 / 4.84\left(1 \mathrm{H}, \mathrm{d} / \mathrm{d}, J=6 / 5.8 \mathrm{~Hz}, \mathrm{H}_{5}\right) ; 6.74 / 6.82(1 \mathrm{H}, \mathrm{d} / \mathrm{d}, J=8.0 / 7.6 \mathrm{~Hz}$, $\mathrm{NH}) .{ }^{13} \mathrm{C}$ NMR $\left(75 \mathrm{MHz}, \mathrm{CDCl}_{3}\right): \delta_{\mathrm{C}} 26.5,26.6,27.3,27.4,28.0$ $\left(3 \mathrm{C}\left(\mathrm{CH}_{3}\right)_{3}\right) ; 29.6,31.2,31.5\left(\mathrm{CH}_{2}\right) ; 39.0 / 39.3\left(\mathrm{C}_{8}\right) ; 40.3\left(\mathrm{C}_{2}\right) ; 50.9$ $\left(\mathrm{C}_{5}\right)$; 52/52.1, 52.2/52.4 ( $\left.\mathrm{C}_{8 \mathrm{a}}, \mathrm{NHCHCH}_{2} \mathrm{CH}_{2} \mathrm{CO}\right) ; 55.3\left(\mathrm{CH}_{2} \mathrm{OMe}\right)$; $64.9\left(\mathrm{CH}_{2} \mathrm{OH}\right) ; 70.9\left(\mathrm{C}_{7}\right) ; 80.8,82.2,82.3,82.7\left(\mathrm{C}_{\left.\left(\mathrm{CH}_{3}\right)_{3}\right) ; 95.2}\right.$ $\left(\mathrm{OCH}_{2} \mathrm{O}\right) ; 158.7,169.7,169.8,170.7,172.0(5 \mathrm{CO}, \mathrm{C}=\mathrm{N}) ; 176.4 / 176.8$ $\left(\mathrm{C}_{3}\right)$. IR ( $\mathrm{NaCl}$ disc, $\left.\mathrm{cm}^{-1}\right): \nu_{\max } 3403,2979,1730,1554,1370,1256$, 1156, 1042, 733. MS $\left(\mathrm{ES}^{+}\right): \mathrm{m} / z 750\left([\mathrm{MNa}]^{+}\right)$. HRMS $\left(\mathrm{ES}^{+},[\mathrm{MNa}]^{+}\right)$: calcd for $\mathrm{C}_{34} \mathrm{H}_{57} \mathrm{~N}_{5} \mathrm{O}_{12} 750.3901$, found 750.3885 .

\subsubsection{Peptidomimetic 32}

The same protocol for deprotection with TFA was applied to compound 31 (29 mg; $0.04 \mathrm{mmol}$ ). Guanidyl compound was obtained as a foam in a quantitative yield (19 $\mathrm{mg}$ ).

${ }^{1} \mathrm{H}$ NMR $\left(\mathrm{D}_{2} \mathrm{O}, 400 \mathrm{MHz}\right): \delta_{\mathrm{H}} 1.11(1 \mathrm{H}$, ddd, $J=11.7,11.7,11.7 \mathrm{~Hz}$, $\left.\mathrm{H}_{8}\right) ; 1.4-1.58\left(2 \mathrm{H}, \mathrm{m}, \mathrm{H}, \mathrm{CH}_{2} \mathrm{CH}_{2} \mathrm{CH}_{2} \mathrm{O}\right) ; 1.58-1.7$ (3H, m, $\mathrm{CH}_{2} \mathrm{CH}_{2} \mathrm{CH}_{2} \mathrm{O}$ ); $1.72-1.9$ (2H, m, NHCHCH $\left.\mathrm{CH}_{2} \mathrm{COOH}, \mathrm{H}_{1}\right) ; 1.9-2.17$ $\left(5 \mathrm{H}, \mathrm{m}, \mathrm{NHCHCH} \mathrm{CH}_{2} \mathrm{COOH}, \mathrm{H}_{8}, \mathrm{H}_{1}\right) ; 2.27\left(1 \mathrm{H}, \mathrm{m}, \mathrm{H}_{6}\right) ; 2.53(1 \mathrm{H}, \mathrm{m}$, $\left.\mathrm{H}_{2}\right)$; 3.78-3.9 $\left(2 \mathrm{H}, \mathrm{m}, \mathrm{H}_{7}, \mathrm{H}_{8 \mathrm{a}}\right) ; 4.03\left(1 \mathrm{H}, \mathrm{m}, \mathrm{NHCHCH}_{2} \mathrm{CH}_{2} \mathrm{COOH}\right)$; $4.11\left(2 \mathrm{H}, \mathrm{br} \mathrm{s}, \mathrm{CH}_{2} \mathrm{CH}_{2} \mathrm{CH}_{2} \mathrm{O}\right)$; $\left.4.68\left(1 \mathrm{H}, \mathrm{m}, \mathrm{H}_{4}\right) \cdot \mathrm{HRMS}\left(\mathrm{ES}^{+} \text {, [MNa] }\right]^{+}\right)$: calcd for $\mathrm{C}_{19} \mathrm{H}_{29} \mathrm{~N}_{5} \mathrm{O}_{9} 494.1863$, found 494.1860 .

4.1.27. (2S)-2-[[( $\left.2 R^{*}, 5 S *, 7 S *, 8 a R *\right)-2-(3-B i s(t e r t-b u t y l o x y c a r b o n y l)-$ guanidino-propyl)-7-methoxymethoxy-3-oxo-octahydro-indolizin5-carbonyl]-amino]pentanedioic acid tert-butyl ester 33

The same experimental procedure as described for $\mathbf{2 5}$ above was applied to 30 (33 mg, $0.062 \mathrm{mmol}$ ) using and 1,3-bis(tert-butoxycarbonyl) guanidine ( $39 \mathrm{mg}, 0.15 \mathrm{mmol}, 2$ equiv), triphenylphosphine (40 mg, $0.15 \mathrm{mmol}, 2$ equiv), and diethylazodicarboxylate (DEAD) ( $24 \mu \mathrm{L}, 0.15 \mathrm{mmol}, 2$ equiv). Stirring was continued for 3 days. Flash chromatography on silica gel $\left(\mathrm{Et}_{2} \mathrm{O} /\right.$ cyclohexane $70: 30$ to $100: 0)$ allowed the isolation of $\mathbf{3 3}$ as a colorless oil (29 $\mathrm{mg}, 60 \%)$ (two diastereoisomers).

$R_{f}=0.45\left(\mathrm{Et}_{2} \mathrm{O}\right) .{ }^{1} \mathrm{H}\left(\mathrm{CDCl}_{3}, 400 \mathrm{MHz}\right): \delta_{\mathrm{H}} 1.21(1 \mathrm{H}, \mathrm{ddd}, J=11.7$, $\left.11.7,11.7 \mathrm{~Hz}, \mathrm{H}_{8}\right) ; 1.35-1.6\left(37 \mathrm{H}, \mathrm{m}, 4 \mathrm{C}\left(\mathrm{CH}_{3}\right)_{3}, \mathrm{H}_{6}\right) ; 1.62-2.12(8 \mathrm{H}, \mathrm{m}$, $\left.\mathrm{CH}_{2} \mathrm{CH}_{2} \mathrm{CH}_{2} \mathrm{NH}, \mathrm{H}_{8}, \mathrm{NHCHCH}_{2} \mathrm{CH}_{2} \mathrm{CO}, \mathrm{H}_{1}\right) ; 2.15-2.3(3 \mathrm{H}, \mathrm{m}$, $\left.\mathrm{NHCHCH}_{2} \mathrm{CH}_{2} \mathrm{CO}, \mathrm{H}_{8}\right) ; 2.47-2.63\left(2 \mathrm{H}, \mathrm{m}, \mathrm{H}_{6}, \mathrm{H}_{2}\right) ; 3.36(3 \mathrm{H}, \mathrm{s}$, $\left.\mathrm{CH}_{2} \mathrm{OMe}\right)$; 3.7-4.06 $\left(4 \mathrm{H}, \mathrm{m}, \mathrm{H}_{8 \mathrm{a}}, \mathrm{CH}_{2} \mathrm{CH}_{2} \mathrm{CH}_{2} \mathrm{NH}, \mathrm{H}_{7}\right) ; 4.09(1 \mathrm{H}, \mathrm{m}$, $\left.\mathrm{NHCHCH}_{2} \mathrm{CH}_{2} \mathrm{CO}\right) ; 4.67\left(1 \mathrm{H}, \mathrm{d}, J=6.8 \mathrm{~Hz}, \mathrm{OCH}_{2} \mathrm{O}\right) ; 4.71(1 \mathrm{H}, \mathrm{d}$, $\left.J=6.8 \mathrm{~Hz}, \mathrm{OCH}_{2} \mathrm{O}\right) ; 4.74\left(1 \mathrm{H}, \mathrm{d}, J=5.4 \mathrm{~Hz}, \mathrm{H}_{5}\right) ; 6.72(1 \mathrm{H}, \mathrm{d}, J=7.6 \mathrm{~Hz}$, $\mathrm{NH}) ; 9.26\left(2 \mathrm{H}\right.$, br s, $\left.\mathrm{NH}_{2}\right) .{ }^{13} \mathrm{C} \mathrm{NMR}\left(75 \mathrm{MHz}, \mathrm{CDCl}_{3}\right): \delta_{\mathrm{C}} 26.3,26.5$, $27.4\left(\mathrm{CH}_{2} \mathrm{CH}_{2} \mathrm{CH}_{2} \mathrm{NH} \mathrm{NHCHCH} \mathrm{CH}_{2} \mathrm{CO}\right) ; 28.1,28.3\left(4 \mathrm{C}\left(\mathrm{CH}_{3}\right)_{3}\right) ; 30.8$, 31.5, $31.6\left(\mathrm{CH}_{2} \mathrm{CH}_{2} \mathrm{CH}_{2} \mathrm{NH}, \mathrm{NHCHCH}_{2} \mathrm{CH}_{2} \mathrm{CO}, \mathrm{C}_{6}, \mathrm{C}_{1}\right)$; 38.9/39.2 $\left(\mathrm{C}_{8}\right)$; $40.1\left(\mathrm{C}_{2}\right) ; 44.2\left(\mathrm{CH}_{2} \mathrm{CH}_{2} \mathrm{CH}_{2} \mathrm{NH}\right) ; 51,52,52.1,52.3,55.4\left(\mathrm{C}_{8 \mathrm{a}}, \mathrm{C}_{5}\right.$, $\left.\mathrm{NHCHCH}_{2} \mathrm{CH}_{2} \mathrm{CO}, \mathrm{CH}_{2} \mathrm{OMe}\right) ; 64 ; 70.9,71.0\left(\mathrm{C}_{7}\right) ; 78.6,80.8,82.3,83.7$ $\left(4 \mathrm{C}\left(\mathrm{CH}_{3}\right)_{3}\right) ; 95.2\left(\mathrm{OCH}_{2} \mathrm{O}\right) ; 155.0,160.5$, and $163.8(\mathrm{C}=\mathrm{N}, \mathrm{N}-\mathrm{CO})$; $169.8,170.5,170.7,172.0,176.9,177.2\left(4 \mathrm{CO}, \mathrm{C}_{3}\right)$. IR $\left(\mathrm{NaCl}\right.$ disc, $\left.\mathrm{cm}^{-1}\right)$ : $\nu_{\max } 3382,2977,1715,1609,1513,1368,1251,1152,737 . \mathrm{MS}\left(\mathrm{ES}^{+}\right)$: $\mathrm{m} / \mathrm{z} 784\left([\mathrm{MH}]^{+}\right)$.

\subsubsection{8. (2S)-2-[[(2R*,5S*,7S*,8aR*)-2-(3-Guanidino-propyl)- \\ 7-hydroxy-3-oxo-octahydro-indolizin-5-carbonyl]- aminolpentanedioic acid $\mathbf{3 4}$}

The same protocol for deprotection with TFA was applied to compound 33 ( $46 \mathrm{mg}, 0.06 \mathrm{mmol}$ ). Guanidyl compound was obtained as a white solid in a quantitative yield (33 $\mathrm{mg})$.

$\mathrm{Mp}: 60{ }^{\circ} \mathrm{C} .{ }^{1} \mathrm{H}\left(\mathrm{D}_{2} \mathrm{O}, 400 \mathrm{MHz}\right): \delta_{\mathrm{H}} 1.1\left(1 \mathrm{H}, \mathrm{m}, \mathrm{H}_{8}\right) ; 1.35-1.53(5 \mathrm{H}$, m, $\left.\mathrm{CH}_{2} \mathrm{CH}_{2} \mathrm{CH}_{2} \mathrm{NH}, \mathrm{H}_{6}\right)$; $1.77-1.98\left(3 \mathrm{H}, \mathrm{m}, \mathrm{NHCHCH}_{2} \mathrm{CH}_{2} \mathrm{CO}, \mathrm{H}_{8}\right)$; $1.98-2.15\left(2 \mathrm{H}, \mathrm{m}, \mathrm{H}_{8}\right) ; 2.21\left(1 \mathrm{H}, \mathrm{m}, \mathrm{H}_{6}\right) ; 2.31(2 \mathrm{H}, \mathrm{br} \mathrm{s}$, $\left.\mathrm{NHCHCH}_{2} \mathrm{CH}_{2} \mathrm{CO}\right) ; 2.52\left(1 \mathrm{H}\right.$, br s, $\left.\mathrm{H}_{2}\right) ; 3.06(2 \mathrm{H}, \mathrm{t}, J=5.9 \mathrm{~Hz}$, $\left.\mathrm{CH}_{2} \mathrm{CH}_{2} \mathrm{CH}_{2} \mathrm{NH}\right) ; 3.71\left(1 \mathrm{H}, \mathrm{m}, \mathrm{H}_{7}\right) ; 3.79\left(1 \mathrm{H}, \mathrm{m}, \mathrm{H}_{8 \mathrm{a}}\right) ; 4.25(1 \mathrm{H}, \mathrm{m}$,
$\left.\mathrm{NHCHCH}_{2} \mathrm{CH}_{2} \mathrm{CO}\right) ; 4.63\left(1 \mathrm{H}, \mathrm{m}, \mathrm{H}_{5}\right) .{ }^{13} \mathrm{C}$ NMR $\left(100 \mathrm{MHz}, \mathrm{D}_{2} \mathrm{O}\right): \delta_{\mathrm{C}}$ 25.5, 25.6 $\left(\mathrm{CH}_{2} \mathrm{CH}_{2} \mathrm{CH}_{2} \mathrm{NH} \mathrm{NHCHCH} \mathrm{CH}_{2} \mathrm{CO}\right) ; 27.7\left(\mathrm{CH}_{2} \mathrm{CH}_{2} \mathrm{CH}_{2} \mathrm{NH}\right)$; 30.1, $30.3\left(\mathrm{NHCHCH}_{2} \mathrm{CH}_{2} \mathrm{CO}, \mathrm{C}_{1}\right) ; 34.0\left(\mathrm{C}_{6}\right) ; 39.8\left(\mathrm{C}_{8}\right) ; 40.8\left(\mathrm{C}_{2}\right) ; 40.9$ $\left(\mathrm{CH}_{2} \mathrm{CH}_{2} \mathrm{CH}_{2} \mathrm{NH}\right) ; 51.0 / 51.1\left(\mathrm{C}_{5}\right) ; 52.4\left(\mathrm{NHCHCH}_{2} \mathrm{CH}_{2} \mathrm{CO}\right) ; 53.7 / 53.9$ $\left(\mathrm{C}_{8 \mathrm{a}}\right) ; 64.6\left(\mathrm{C}_{7}\right) ; 156.7(\mathrm{C}=\mathrm{N}) ; 171.9,172.1 \quad(\mathrm{CONH}) ; 175.1$ $(\mathrm{NHCHCOOH}) ; 177.1(\mathrm{COOH}) ; 179.3\left(\mathrm{C}_{3}\right) . \mathrm{MS}\left(\mathrm{ES}^{+}\right): \mathrm{m} / \mathrm{z} 428$ $\left([\mathrm{MH}]^{+}\right)$. HRMS $\left(\mathrm{ES}^{+},[\mathrm{MH}]^{+}\right)$: calcd for $\mathrm{C}_{18} \mathrm{H}_{29} \mathrm{~N}_{5} \mathrm{O}_{7} 428.2145$, found 428.2146.

4.1.29. (5S*,7R*,8aR*)-7-Benzyloxy-5-methyl-3-oxo-octahydroindolizin-5-carboxylic acid ethyl ester 35

To 12a (430 mg, $1.42 \mathrm{mmol}$ ) dissolved in $90 \mathrm{~mL}$ of anhydrous THF under argon at $-78{ }^{\circ} \mathrm{C}$ was added $23.3 \mathrm{~mL}(11.7 \mathrm{mmol}$, 1.1 equiv) of KHMDS $0.5 \mathrm{M}$ in toluene. After $30 \mathrm{~min}$, methyl iodide (filtered on neutral aluminum oxide; $725 \mu \mathrm{L}, 11.65 \mathrm{mmol}, 1.1$ equiv) was added. Stirring was continued for $3 \mathrm{~h}$ at $-78^{\circ} \mathrm{C}$ and the reaction was quenched with a saturated solution of $\mathrm{NH}_{4} \mathrm{Cl}$. The product was extracted twice with $\mathrm{CH}_{2} \mathrm{Cl}_{2}$. The organic phase was dried $\left(\mathrm{MgSO}_{4}\right)$ and the solvent removed in vacuo. Flash chromatography on silica gel (AcOEt/cyclohexane 50:50) allowed the isolation of $\mathbf{3 5}$ as a pale yellow oil (3.5 $\mathrm{mg}, 99 \%$ ).

$R_{f}=0.37$ (AcOEt/cyclohexane: $\left.70 / 30\right) .{ }^{1} \mathrm{H} \mathrm{NMR}\left(\mathrm{CDCl}_{3}, 300 \mathrm{MHz}\right)$ : $\delta_{\mathrm{H}} 1.12\left(3 \mathrm{H}, \mathrm{t}, J=7.1 \mathrm{~Hz} ; \mathrm{CH}_{3} \mathrm{CH}_{2}\right) ; 1.36(1 \mathrm{H}, \mathrm{ddd}, J=13.5,12.2,2.6 \mathrm{~Hz}$, $\left.\mathrm{H}_{8 \mathrm{ax}}\right) ; 1.50\left(1 \mathrm{H}\right.$, dddd, $\left.J=10.4,10.4,10.4,10.4 \mathrm{~Hz}, \mathrm{H}_{1}\right) ; 1.56(1 \mathrm{H}, \mathrm{dd}$, $\left.J=14.4,2.5 \mathrm{~Hz}, \mathrm{H}_{6 \mathrm{ax}}\right) ; 1.89$ (3H, s, Me); $2.12\left(2 \mathrm{H}, \mathrm{m}, \mathrm{H}_{1}, \mathrm{H}_{8 \mathrm{eq}}\right), 2.33$ $\left(2 \mathrm{H}, \mathrm{m}, 2 \mathrm{H}_{2}\right) ; 2.65\left(1 \mathrm{H}\right.$, ddd, $\left.J=14.4,3.5,2.2 \mathrm{~Hz}, \mathrm{H}_{6 \mathrm{eq}}\right) ; 3.77(1 \mathrm{H}$, dddd, $\left.J=2.9,2.9,2.9,2.9 \mathrm{~Hz}, \mathrm{H}_{7 \mathrm{eq}}\right) ; 3.94(1 \mathrm{H}, \mathrm{dq}, J=10.7,7.1 \mathrm{~Hz}$, $\left.\mathrm{OCH}_{2} \mathrm{CH}_{3}\right) ; 3.94\left(1 \mathrm{H}, \mathrm{m}, \mathrm{H}_{8 \mathrm{a}}\right) ; 4.04\left(1 \mathrm{H}, \mathrm{dq}, J=10.7,7.1 \mathrm{~Hz}, \mathrm{OCH}_{2} \mathrm{CH}_{3}\right)$; $4.40\left(1 \mathrm{H}, \mathrm{d}, J=11.9 \mathrm{~Hz}, \mathrm{CH}_{2} \mathrm{Ph}\right) ; 4.51\left(1 \mathrm{H}, \mathrm{d}, J=11.9 \mathrm{~Hz}, \mathrm{CH}_{2} \mathrm{Ph}\right) ; 7.29$ (5H, m, Ar). ${ }^{13} \mathrm{C} \mathrm{NMR}\left(75 \mathrm{MHz}, \mathrm{CDCl}_{3}\right): \delta_{\mathrm{C}} 14.0\left(\mathrm{CH}_{3} \mathrm{CH}_{2}\right) ; 26.0(\mathrm{Me})$; $26.6\left(\mathrm{C}_{1}\right) ; 31.9\left(\mathrm{C}_{2}\right) ; 36.7\left(\mathrm{C}_{8}\right) ; 40.4\left(\mathrm{C}_{6}\right) ; 52.1\left(\mathrm{C}_{8 \mathrm{a}}\right) ; 59.2\left(\mathrm{C}_{5}\right) ; 61.3$ $\left(\mathrm{OCH}_{2} \mathrm{CH}_{3}\right) ; 70.1\left(\mathrm{CH}_{2} \mathrm{Ph}\right) ; 70.7\left(\mathrm{C}_{7}\right) ; 127.2\left(2 \mathrm{C}_{\mathrm{Ar}}\right) ; 127.5\left(\mathrm{C}_{\mathrm{Ar}}\right) ; 128.3$ $\left(\mathrm{C}_{\mathrm{Ar}}\right) ; 138.5$ ( $\left.\mathrm{C}_{\text {Arquat }}\right)$; $173.1,177.7\left(\mathrm{CO}, \mathrm{C}_{3}\right)$. IR ( NaCl disc, $\left.\mathrm{cm}^{-1}\right)$ : $\nu_{\max }$ $3460,2938,1682,1455,1271,1027,731 . \mathrm{HRMS}\left(\mathrm{ES}^{+},[\mathrm{MNa}]^{+}\right)$: calcd for $\mathrm{C}_{19} \mathrm{H}_{25} \mathrm{NO}_{4} 354.1681$, found 354.1665.

4.1.30. $\left(2 R^{*}, 5 S^{*}, 7 R^{*}, 8 a R^{*}\right)-2-$ Allyl-7-benzyloxy-5-methyl-3-oxooctahydro-indolizin-5-carboxylic acid ethyl ester 36 and $\left(2 S^{*}, 5 S^{*}, 7 R^{*}, 8 a R^{*}\right)$-2-allyl-7-benzyloxy-5-methyl-3-oxo-octahydroindolizin-5-carboxylic acid ethyl ester 37

The same experimental procedure as described for allylation was applied to 35 (1.5 g, $4.53 \mathrm{mmol})$ using KHMDS $0.5 \mathrm{M}(9.5 \mathrm{~mL}$, $4.75 \mathrm{mmol}, 1.01$ equiv) in $40 \mathrm{~mL}$ of THF. After 20 min stirring at $-78{ }^{\circ} \mathrm{C}$, solution was cooled at $-110^{\circ} \mathrm{C}$ before addition of distillated allyl bromide ( $470 \mu \mathrm{L}, 5.4 \mathrm{mmol}, 1.2$ equiv) stirring was continued $1 \mathrm{~h}$, then $3 \mathrm{~h} 30$ at $-78^{\circ} \mathrm{C}$. Flash chromatography on silica gel (AcOEt/cyclohexane 50:50) allowed the isolation of $\mathbf{3 6}$ as a pale yellow oil (561 g, 33\%) and 37 as a pale yellow oil (366 mg, 22\%). Starting material was also recovered (35\%).

Compound 36: $R_{f}=0.33$ (Et $2 \mathrm{O} /$ cyclohexane 50:50). ${ }^{1} \mathrm{H}$ NMR $\left(\mathrm{CDCl}_{3}, 300 \mathrm{MHz}\right): \delta_{\mathrm{H}} 1.13\left(3 \mathrm{H}, \mathrm{t}, J=7.1 \mathrm{~Hz}, \mathrm{CH}_{3} \mathrm{CH}_{2}\right) ; 1.20(1 \mathrm{H}, \mathrm{q}$, $\left.J=10.9 \mathrm{~Hz}, \mathrm{H}_{1}\right) ; 1.32\left(1 \mathrm{H}\right.$, ddd, $\left.J=14.6,12.2,2.4 \mathrm{~Hz}, \mathrm{H}_{8 \mathrm{ax}}\right) ; 1.56(1 \mathrm{H}$, $\left.\mathrm{dd}, J=14.4,2.4 \mathrm{~Hz}, \mathrm{H}_{6 \mathrm{ax}}\right) ; 1.90(3 \mathrm{H}, \mathrm{s}, \mathrm{Me}) ; 2.18\left(3 \mathrm{H}, \mathrm{m}, \mathrm{CH}_{2} \mathrm{CH}=\mathrm{CH}_{2}\right.$, $\left.\mathrm{H}_{1}, \mathrm{H}_{8 \mathrm{eq}}\right) ; 2.48\left(1 \mathrm{H}, \mathrm{m}, \mathrm{H}_{2}\right) ; 2.66$ (1H, ddd, $\left.J=14.4,3.4,1.8 \mathrm{~Hz}, \mathrm{H}_{6 \mathrm{equ}}\right)$; $2.68\left(1 \mathrm{H}, \mathrm{m}, \mathrm{CH}_{2} \mathrm{CH}=\mathrm{CH}_{2}\right) ; 3.77\left(1 \mathrm{H}\right.$, br s, $\left.\mathrm{H}_{7 \text { equ }}\right) ; 3.88\left(1 \mathrm{H}, \mathrm{m}, \mathrm{H}_{8 \mathrm{a}}\right)$; $3.93\left(1 \mathrm{H}, \mathrm{dq}, J=10.7,7.1 \mathrm{~Hz}, \mathrm{OCH}_{2} \mathrm{CH}_{3}\right) ; 4.04(1 \mathrm{H}, \mathrm{dq}, J=10.7,7.1 \mathrm{~Hz}$, $\left.\mathrm{OCH}_{2} \mathrm{CH}_{3}\right) ; 4.40\left(1 \mathrm{H}, \mathrm{d}, J=11.9 \mathrm{~Hz}, \mathrm{CH}_{2} \mathrm{Ph}\right) ; 4.52(1 \mathrm{H}, \mathrm{d}, J=11.9 \mathrm{~Hz}$, $\left.\mathrm{CH}_{2} \mathrm{Ph}\right) ; 5.04\left(1 \mathrm{H}\right.$, br d, $\left.J=17 \mathrm{~Hz}, \mathrm{CH}_{2} \mathrm{CH}=\mathrm{CH}_{2}\right) ; 5.09(1 \mathrm{H}$, br d, $\left.J=17 \mathrm{~Hz}, \mathrm{CH}_{2} \mathrm{CH}=\mathrm{CH}_{2}\right) ; 5.80(1 \mathrm{H}$, dddd, $J=17,10.1,6.9,6.9 \mathrm{~Hz}$, $\left.\mathrm{CH}_{2} \mathrm{CH}=\mathrm{CH}_{2}\right) ; 7.28(5 \mathrm{H}, \mathrm{m}, \mathrm{Ar}) .{ }^{13} \mathrm{C} \mathrm{NMR}\left(75 \mathrm{MHz}, \mathrm{CDCl}_{3}\right): \delta_{\mathrm{C}} 13.9$ $\left(\mathrm{CH}_{3} \mathrm{CH}_{2}\right) ; 26.2(\mathrm{Me}) ; 32.8\left(\mathrm{C}_{1}\right) ; 35.0\left(\mathrm{CH}_{2} \mathrm{CH}=\mathrm{CH}_{2}\right) ; 36.5\left(\mathrm{C}_{8}\right) ; 40.2$ $\left(\mathrm{C}_{6}\right) ; 42.1\left(\mathrm{C}_{2}\right) ; 49.9\left(\mathrm{C}_{8 \mathrm{a}}\right) ; 59.1\left(\mathrm{C}_{5}\right) ; 61.3\left(\mathrm{OCH}_{2} \mathrm{CH}_{3}\right) ; 70.0\left(\mathrm{CH}_{2} \mathrm{Ph}\right)$; $70.6\left(\mathrm{C}_{7}\right) ; 116.4\left(\mathrm{CH}_{2} \mathrm{CH}=\mathrm{CH}_{2}\right) ; 127.1\left(2 \mathrm{C}_{\mathrm{Ar}}\right) ; 127.4\left(\mathrm{C}_{\mathrm{Ar}}\right) ; 128.2$ $\left(2 \mathrm{C}_{\mathrm{Ar}}\right) ; 136.0\left(\mathrm{CH}_{2} \mathrm{CH}=\mathrm{CH}_{2}\right) ; 138.5$ ( $\left.\mathrm{C}_{\text {Arquat }}\right) ; 173.1,178.5\left(\mathrm{CO}, \mathrm{C}_{3}\right) . \mathrm{IR}$ $\left(\mathrm{NaCl}\right.$ disc, $\left.\mathrm{cm}^{-1}\right): \nu_{\max } 2925,1737,1698,1454,1396,1307,1274$, $1207,1130,1028,913,736 . \mathrm{MS}\left(\mathrm{ES}^{+}\right): \mathrm{m} / z 394\left([\mathrm{MNa}]^{+}\right)$. Anal. Calcd 
for $\mathrm{C}_{22} \mathrm{H}_{29} \mathrm{NO}_{4}$ : C, 71.13; $\mathrm{H}, 7.87 ; \mathrm{N}, 3.77$. Found: $\mathrm{C}, 71.52 ; \mathrm{H}, 7.96 ; \mathrm{N}$, $3.77 \%$.

Compound 37: $R_{f}=0.2\left(\mathrm{Et}_{2} \mathrm{O} /\right.$ cyclohexane $\left.50: 50\right) .{ }^{1} \mathrm{H} \mathrm{NMR}\left(\mathrm{CDCl}_{3}\right.$, $300 \mathrm{MHz}): \delta_{\mathrm{H}} 1.14\left(3 \mathrm{H}, \mathrm{t}, J=7.2 \mathrm{~Hz}, \mathrm{CH}_{3} \mathrm{CH}_{2}\right) ; 1.34(1 \mathrm{H}$, ddd, $J=13.3$ $\left.12.3,2.5 \mathrm{~Hz}, \mathrm{H}_{8 \mathrm{ax}}\right) ; 1.54\left(1 \mathrm{H}, \mathrm{dd}, J=14.4,2.5 \mathrm{~Hz}, \mathrm{H}_{6 \mathrm{ax}}\right) ; 1.60(1 \mathrm{H}, \mathrm{m}$, $\mathrm{H}_{1}$ ); 1.89 (3H, s, Me); 1.97 ( $\left.1 \mathrm{H}, \mathrm{dd}, J=12.7,6.0 \mathrm{~Hz}, \mathrm{H}_{1}\right) ; 2.10$ (1H, ddd, $\left.J=13.4,13.4,13.4 \mathrm{~Hz}, \mathrm{H}_{8 \mathrm{eq}}\right) ; 2.28\left(1 \mathrm{H}, \mathrm{m}, \mathrm{CH}_{2} \mathrm{CH}=\mathrm{CH}_{2}\right) ; 2.45(1 \mathrm{H}, \mathrm{m}$, $\left.\mathrm{H}_{2}\right) ; 2.50\left(1 \mathrm{H}, \mathrm{m}, \mathrm{CH}_{2} \mathrm{CH}=\mathrm{CH}_{2}\right) ; 2.64(1 \mathrm{H}, \mathrm{ddd}, J=14.4,3.3,2.2 \mathrm{~Hz}$, $\left.\mathrm{H}_{6 \mathrm{equ}}\right) ; 3.76\left(1 \mathrm{H}, \mathrm{q}, J=2.7 \mathrm{~Hz}, \mathrm{H}_{7}\right)$; $3.95(1 \mathrm{H}, \mathrm{dq}, J=10.8,7.1 \mathrm{~Hz}$, $\left.\mathrm{OCH}_{2} \mathrm{CH}_{3}\right) ; 3.98\left(1 \mathrm{H}, \mathrm{m}, \mathrm{H}_{8 \mathrm{a}}\right) ; 4.04\left(1 \mathrm{H}, \mathrm{dq}, J=10.7,7.1 \mathrm{~Hz}, \mathrm{OCH}_{2} \mathrm{CH}_{3}\right)$; $4.38\left(1 \mathrm{H}, \mathrm{d}, J=11.9 \mathrm{~Hz}, \mathrm{CH}_{2} \mathrm{Ph}\right) ; 4.52\left(1 \mathrm{H}, \mathrm{d}, J=11.9 \mathrm{~Hz}, \mathrm{CH}_{2} \mathrm{Ph}\right) ; 5.06$ $\left(1 \mathrm{H}\right.$, br d, $\left.J=10.1 \mathrm{~Hz}, \mathrm{CH}_{2} \mathrm{CH}=\mathrm{CH}_{2}\right) ; 5.09(1 \mathrm{H}$, dd, $J=17.1,1.4 \mathrm{~Hz}$, $\left.\mathrm{CH}_{2} \mathrm{CH}=\mathrm{CH}_{2}\right) ; 5.85\left(1 \mathrm{H}\right.$, dddd, $\left.J=17,10.1,7.8,6.0 \mathrm{~Hz}, \mathrm{CH}_{2} \mathrm{CH}=\mathrm{CH}_{2}\right)$; $7.28(5 \mathrm{H}, \mathrm{m}, \mathrm{Ar}) .{ }^{13} \mathrm{C}$ NMR $\left(75 \mathrm{MHz}, \mathrm{CDCl}_{3}\right): \delta_{\mathrm{C}} 14.0\left(\mathrm{CH}_{3} \mathrm{CH}_{2}\right) ; 25.9$ (Me); $30.7\left(\mathrm{C}_{1}\right) ; 34.7\left(\mathrm{CH}_{2} \mathrm{CH}=\mathrm{CH}_{2}\right) ; 36.8\left(\mathrm{C}_{8}\right) ; 40.2\left(\mathrm{C}_{6}\right) ; 41.9\left(\mathrm{C}_{2}\right)$; $50.0\left(\mathrm{C}_{8 \mathrm{a}}\right) ; 59.0\left(\mathrm{C}_{5}\right) ; 61.3\left(\mathrm{OCH}_{2} \mathrm{CH}_{3}\right) ; 70.1\left(\mathrm{CH}_{2} \mathrm{Ph}\right) ; 70.6\left(\mathrm{C}_{7}\right) ; 116.7$ $\left(\mathrm{CH}_{2} \mathrm{CH}=\mathrm{CH}_{2}\right) ; 127.2\left(2 \mathrm{C}_{\mathrm{Ar}}\right) ; 127.5\left(\mathrm{C}_{\mathrm{Ar}}\right) ; 128.3\left(2 \mathrm{C}_{\mathrm{Ar}}\right) ; 136.4$ $\left(\mathrm{CH}_{2} \mathrm{CH}=\mathrm{CH}_{2}\right) ; 138.3\left(\mathrm{C}_{\text {Arquat }}\right) ; 173.0,178.8\left(\mathrm{CO}, \mathrm{C}_{3}\right)$. IR ( $\mathrm{NaCl}$ disc, $\left.\mathrm{cm}^{-1}\right): \nu_{\max } 2937,1736,1694,1446,1396,1276,1208,1132,1067$, 912, 729. $\mathrm{MS}\left(\mathrm{ES}^{+}\right): \mathrm{m} / z 394\left([\mathrm{MNa}]^{+}\right)$.

4.1.31. $\left(2 R^{*}, 5 S^{*}, 7 R^{*}, 8 a R^{*}\right)-7-$ Benzyloxy-2-(3-bis(tert-

butyloxycarbonyl)guanidino-propyl)-5-methyl-3-oxo-octahydro-

indolizin-5-carboxylic acid ethyl ester $\mathbf{3 8}$

trans intermediate alcohol: the same experimental procedure as described for hydoboration was applied to alkene 36 (309 mg, $0.83 \mathrm{mmol}$ ) using a $0.5 \mathrm{M}$ solution of 9 -BBN in THF $(5 \mathrm{~mL}$, $2.49 \mathrm{mmol}, 3$ equiv). Stirring was maintained $16 \mathrm{~h}$ after addition of sodium acetate $5 \mathrm{M}\left(2 \mathrm{~mL}, 9.9 \mathrm{mmol}, 12\right.$ equiv) and a $30 \% \mathrm{H}_{2} \mathrm{O}_{2}$ solution ( $1 \mathrm{~mL}, 12$ equiv). Flash chromatography on silica gel (AcOEt/cyclohexane 90:10) allowed the isolation of a yellow oil (60\%, $193 \mathrm{mg})$.

$R_{f}=0.24$ (AcOEt/cyclohexane 95:5). ${ }^{1} \mathrm{H}$ NMR $\left(\mathrm{CDCl}_{3}, 300 \mathrm{MHz}\right)$ : $\delta_{\mathrm{H}} 1.09\left(3 \mathrm{H}, \mathrm{t}, J=7.1 \mathrm{~Hz}, \mathrm{CH}_{3} \mathrm{CH}_{2}\right) ; 1.17(1 \mathrm{H}$, ddd, $J=11.4,11.4,11.4 \mathrm{~Hz}$, $\left.\mathrm{H}_{1}\right) ; 1.31\left(1 \mathrm{H}\right.$, ddd, $\left.J=13.9,11.4,2.4 \mathrm{~Hz}, \mathrm{H}_{8 \mathrm{ax}}\right) ; 1.44(1 \mathrm{H}, \mathrm{m}$, $\left.\mathrm{CH}_{2} \mathrm{CH}_{2} \mathrm{CH}_{2} \mathrm{OH}\right) ; 1.54\left(1 \mathrm{H}\right.$, dd, $\left.J=14.3,2.3 \mathrm{~Hz}, \mathrm{H}_{6}\right) ; 1.6(2 \mathrm{H}, \mathrm{m}$, $\left.\mathrm{CH}_{2} \mathrm{CH}_{2} \mathrm{CH}_{2} \mathrm{OH}\right) ; 1.78-1.95\left(4 \mathrm{H}, \mathrm{s}, \mathrm{Me}, \mathrm{CH}_{2} \mathrm{CH}_{2} \mathrm{CH}_{2} \mathrm{OH}\right) ; 2.14(1 \mathrm{H}$, $\left.\mathrm{dm}, J=11.4 \mathrm{~Hz}, \mathrm{H}_{8}\right) ; 2.25\left(1 \mathrm{H}, \mathrm{ddd}, J=11.5,7.9,5.4 \mathrm{~Hz}, \mathrm{H}_{1}\right) ; 2.38(1 \mathrm{H}$, $\left.\mathrm{m}, \mathrm{H}_{2}\right) ; 2.62\left(1 \mathrm{H}\right.$, br d, $\left.J=14.4 \mathrm{~Hz}, \mathrm{H}_{6}\right) ; 3.6(2 \mathrm{H}, \mathrm{t}, J=6.3 \mathrm{~Hz}$, $\left.\mathrm{CH}_{2} \mathrm{CH}_{2} \mathrm{CH}_{2} \mathrm{OH}\right) ; 3.75\left(1 \mathrm{H}, \mathrm{m}, \mathrm{H}_{7}\right) ; 3.85\left(1 \mathrm{H}, \mathrm{m}, \mathrm{H}_{8 \mathrm{a}}\right) ; 3.93(1 \mathrm{H}, \mathrm{dq}$, $\left.J=10.7,7.1 \mathrm{~Hz}, \mathrm{OCH}_{2} \mathrm{CH}_{3}\right)$; $3.97\left(1 \mathrm{H}\right.$, dq, $\left.J=10.7,7.1 \mathrm{~Hz}, \mathrm{OCH}_{2} \mathrm{CH}_{3}\right)$; $4.38\left(1 \mathrm{H}, \mathrm{d}, J=11.9 \mathrm{~Hz}, \mathrm{CH}_{2} \mathrm{Ph}\right) ; 4.49\left(1 \mathrm{H}, \mathrm{d}, J=11.9 \mathrm{~Hz}, \mathrm{CH}_{2} \mathrm{Ph}\right) ; 7.29$ (5H, m, Ar). ${ }^{13} \mathrm{C}$ NMR $\left(75 \mathrm{MHz}, \mathrm{CDCl}_{3}\right): \delta_{\mathrm{C}} 13.9\left(\mathrm{CH}_{3} \mathrm{CH}_{2}\right) ; 26.1(\mathrm{Me})$; $26.6\left(\mathrm{CH}_{2} \mathrm{CH}_{2} \mathrm{CH}_{2} \mathrm{OH}\right) ; 30.1\left(\mathrm{CH}_{2} \mathrm{CH}_{2} \mathrm{CH}_{2} \mathrm{OH}\right) ; 33.3\left(\mathrm{C}_{1}\right) ; 36.4\left(\mathrm{C}_{8}\right)$; $40.2\left(\mathrm{C}_{6}\right) ; 42.2\left(\mathrm{C}_{2}\right) ; 50.0\left(\mathrm{C}_{8 \mathrm{a}}\right) ; 59.1\left(\mathrm{C}_{5}\right) ; 61.3\left(\mathrm{OCH}_{2} \mathrm{CH}_{3}\right) ; 62.1$ $\left(\mathrm{CH}_{2} \mathrm{CH}_{2} \mathrm{CH}_{2} \mathrm{OH}\right) ; 70.0\left(\mathrm{CH}_{2} \mathrm{Ph}\right) ; 70.5\left(\mathrm{C}_{7}\right) ; 127.1\left(2 \mathrm{C}_{\mathrm{Ar}}\right) ; 127.4\left(\mathrm{C}_{\mathrm{Ar}}\right)$; $128.2\left(2 \mathrm{C}_{\mathrm{Ar}}\right) ; 138.3$ ( $\left.\mathrm{C}_{\text {Arquat }}\right) ; 173.0,179.7$ (CO, $\left.\mathrm{C}_{3}\right)$. IR ( $\mathrm{NaCl}$ disc, $\left.\mathrm{cm}^{-1}\right): \nu_{\max } 3412,2928,1734,1681,1399,1307,1273,1210,1131,735$. MS $\left(\mathrm{ES}^{+}\right): m / z 412\left([\mathrm{MNa}]^{+}\right)$.

The same experimental procedure as described for $\mathbf{2 5}$ was applied to intermediate trans (300 $\mathrm{mg}, 0.77 \mathrm{mmol}$ ) using and 1,3bis(tert-butoxycarbonyl) guanidine ( $311 \mathrm{mg}, 1.2 \mathrm{mmol}, 1.5$ equiv), triphenylphosphine ( $315 \mathrm{mg}, 1.2 \mathrm{mmol}, 1.5$ equiv), and diethylazodicarboxylate (DEAD) ( $190 \mu \mathrm{L}, 1.2 \mathrm{mmol}, 1.5$ equiv). Stirring was continued for $24 \mathrm{~h}$. Flash chromatography on silica gel $\left(\mathrm{Et}_{2} \mathrm{O} / \mathrm{cy}-\right.$ clohexane 50:50) allowed the isolation of $\mathbf{3 8}$ as a white solid (436 mg, 90\%).

$R_{f}=0.27\left(\mathrm{Et}_{2} \mathrm{O} / \mathrm{cyclohexane} 50: 50\right), \mathrm{mp}: 132{ }^{\circ} \mathrm{C} .{ }^{1} \mathrm{H}$ NMR $\left(\mathrm{CDCl}_{3}\right.$, $300 \mathrm{MHz}): \delta_{\mathrm{H}} 1.04\left(3 \mathrm{H}, \mathrm{t}, J=7.1 \mathrm{~Hz}, \mathrm{CH}_{3} \mathrm{CH}_{2}\right) ; 1.07\left(1 \mathrm{H}, \mathrm{m}, \mathrm{H}_{1}\right) ; 1.25$ (2H, m, $\left.\mathrm{CH}_{2} \mathrm{CH}_{2} \mathrm{CH}_{2} \mathrm{~N} \mathrm{H}_{8}\right) ; 1.4-1.55\left(19 \mathrm{H}, \mathrm{m}, 2 \mathrm{C}\left(\mathrm{CH}_{3}\right)_{3} \mathrm{H}_{6}\right) ; 1.58(2 \mathrm{H}$, m, $\left.\mathrm{CH}_{2} \mathrm{CH}_{2} \mathrm{CH}_{2} \mathrm{~N}\right) ; 1.81$ (3H, s, Me); $1.85\left(1 \mathrm{H}, \mathrm{m}, \mathrm{CH}_{2} \mathrm{CH}_{2} \mathrm{CH}_{2} \mathrm{~N}\right) ; 2.08$ $\left(1 \mathrm{H}\right.$, br d, $\left.J=12.5 \mathrm{~Hz}, \mathrm{H}_{8}\right) ; 2.34\left(2 \mathrm{H}, \mathrm{m}, \mathrm{H}_{2}, \mathrm{H}_{1}\right) ; 2.59(1 \mathrm{H}, \mathrm{br} \mathrm{d}$, $\left.J=14.2 \mathrm{~Hz}, \mathrm{H}_{6}\right) ; 3.62-3.75\left(2 \mathrm{H}, \mathrm{m}, \mathrm{H}_{7}, \mathrm{CH}_{2} \mathrm{CH}_{2} \mathrm{CH}_{2} \mathrm{~N}\right) ; 3.75-3.89(2 \mathrm{H}$, $\left.\mathrm{H}_{8 \mathrm{a}}, \mathrm{OCH}_{2} \mathrm{CH}_{3}\right) ; 3.89-4.0\left(2 \mathrm{H}, \mathrm{m}, \mathrm{CH}_{2} \mathrm{CH}_{2} \mathrm{CH}_{2} \mathrm{~N} \mathrm{OCH}_{2} \mathrm{CH}_{3}\right) ; 4.32(1 \mathrm{H}$, d, $\left.J=11.9 \mathrm{~Hz}, \mathrm{CH}_{2} \mathrm{Ph}\right) ; 4.45\left(1 \mathrm{H}, \mathrm{d}, J=11.9 \mathrm{~Hz}, \mathrm{CH}_{2} \mathrm{Ph}\right) ; 7.21(5 \mathrm{H}, \mathrm{m}$, Ar); $9.22\left(2 \mathrm{H}, \mathrm{m}, \mathrm{NH}_{2}\right) .{ }^{13} \mathrm{C} \mathrm{NMR}\left(75 \mathrm{MHz}, \mathrm{CDCl}_{3}\right): \delta_{\mathrm{C}} 13.9\left(\mathrm{CH}_{3} \mathrm{CH}_{2}\right)$;
26.1 (Me); $27.6\left(\mathrm{CH}_{2} \mathrm{CH}_{2} \mathrm{CH}_{2} \mathrm{~N}\right) ; 28.0$ and $28.3\left(\mathrm{CH}_{2} \mathrm{CH}_{2} \mathrm{CH}_{2} \mathrm{~N}\right.$, $\left.2 \mathrm{C}\left(\mathrm{CH}_{3}\right)_{3}\right) ; 33.1\left(\mathrm{C}_{1}\right) ; 36.5\left(\mathrm{C}_{8}\right) ; 40.3\left(\mathrm{C}_{6}\right) ; 42.0\left(\mathrm{C}_{2}\right) ; 44.3$ $\left(\mathrm{CH}_{2} \mathrm{CH}_{2} \mathrm{CH}_{2} \mathrm{~N}\right) ; 49.9\left(\mathrm{C}_{8 \mathrm{a}}\right) ; 59.0\left(\mathrm{C}_{5}\right) ; 61.2\left(\mathrm{OCH}_{2} \mathrm{CH}_{3}\right) ; 69.9\left(\mathrm{CH}_{2} \mathrm{Ph}\right)$;

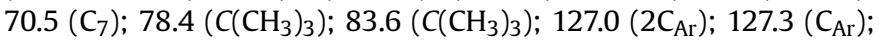
$128.2\left(2 \mathrm{C}_{\mathrm{Ar}}\right) ; 138.3$ ( $\left.\mathrm{C}_{\text {Arquat }}\right) ; 155.0 ; 160.5 ; 163.8(\mathrm{C}=\mathrm{N}, \mathrm{NCOO})$; 173.0, 179.1 (CO, $\left.\mathrm{C}_{3}\right)$. IR ( $\mathrm{NaCl}$ disc, $\left.\mathrm{cm}^{-1}\right): \nu_{\max } 3390,2881,1714$, 1608, 1271, 1150. MS $\left(\mathrm{ES}^{+}\right): m / z 653\left([\mathrm{MNa}]^{+}\right)$.

4.1.32. (2S*,4R*,6R*)-6-[(2R*)-2-Carboxy-5-guanidino-pentyl]-4hydroxy-2-methyl-piperidin-2-carboxylic acid 39

Compound 38 ( $70 \mathrm{mg}, 0.11 \mathrm{mmol}$ ) was dissolved in $5 \mathrm{~mL}$ of $\mathrm{HCl}$ $3 \mathrm{M}$. The mixture was refluxed for $20 \mathrm{~h}$. The solvent was evaporated under vacuo. To the residue were added $1 \mathrm{~mL}$ of diethyl ether and $2 \mathrm{~mL}$ of water, insoluble solids were filtered and the product was extracted three times with $2 \mathrm{~mL}$ of water. The aqueous phase was lyophilized to leave an orange oil in a $100 \%$ yield ( $38 \mathrm{mg}$ ).

${ }^{1} \mathrm{H}$ NMR $\left(\mathrm{D}_{2} \mathrm{O}, 400 \mathrm{MHz}\right): \delta_{\mathrm{H}} 1.3-1.65\left(8 \mathrm{H}, \mathrm{m}, \mathrm{CH}_{2} \mathrm{CHCOOH}, \mathrm{H}_{5}\right.$, Me, $\left.\mathrm{CH}_{2} \mathrm{CH}_{2} \mathrm{CH}_{2} \mathrm{~N}\right) ; 1.67\left(1 \mathrm{H}\right.$, br d, $\left.J=15.0 \mathrm{~Hz}, \mathrm{H}_{3}\right) ; 1.75-1.95(3 \mathrm{H}, \mathrm{m}$, $\left.\mathrm{CH}_{2} \mathrm{CH}_{2} \mathrm{CH}_{2} \mathrm{~N}, \mathrm{CH}_{2} \mathrm{CHCOOH}, \mathrm{H}_{5}\right) ; 2.3-2.5\left(2 \mathrm{H}, \mathrm{m}, \mathrm{H}_{3}, \mathrm{CH}_{2} \mathrm{CHCOOH}\right)$; $3.0\left(2 \mathrm{H}\right.$, br s, $\left.\mathrm{CH}_{2} \mathrm{CH}_{2} \mathrm{CH}_{2} \mathrm{~N}\right) ; 3.67\left(1 \mathrm{H}, \mathrm{m}, \mathrm{H}_{6}\right) ; 4.05\left(1 \mathrm{H}\right.$, br s, $\left.\mathrm{H}_{4}\right) .{ }^{13} \mathrm{C}$ NMR (75 MHz, D $\left.{ }_{2} \mathrm{O}\right): \delta_{\mathrm{C}} 24.4(\mathrm{Me}) ; 25.4\left(\mathrm{CH}_{2} \mathrm{CH}_{2} \mathrm{CH}_{2} \mathrm{~N}\right) ; 28.7$ $\left(\mathrm{CH}_{2} \mathrm{CH}_{2} \mathrm{CH}_{2} \mathrm{~N}\right) ; 33.2\left(\mathrm{C}_{5}\right) ; 34.4\left(\mathrm{CH}_{2} \mathrm{CHCOOH}\right) ; 37.8\left(\mathrm{C}_{3}\right) ; 40.7$ $\left(\mathrm{CH}_{2} \mathrm{CHCOOH}, \mathrm{CH}_{2} \mathrm{CH}_{2} \mathrm{CH}_{2} \mathrm{~N}\right) ; 47.5\left(\mathrm{C}_{6}\right) ; 59.2\left(\mathrm{C}_{2}\right) ; 61.7\left(\mathrm{C}_{4}\right) ; 156.6$ $(\mathrm{C}=\mathrm{N}) ; 173.8,178.6\left(\mathrm{CO}, \mathrm{C}_{3}\right) . \mathrm{MS}\left(\mathrm{ES}^{+}\right): \mathrm{m} / z 313\left(\left[\mathrm{M}-\mathrm{H}_{2} \mathrm{O}\right]^{+}\right), 331$ $\left([\mathrm{M}-\mathrm{H}]^{+}\right)$. HRMS $\left(\mathrm{ES}^{+},[\mathrm{MH}]^{+}\right)$: calcd for $\mathrm{C}_{14} \mathrm{H}_{26} \mathrm{~N}_{4} \mathrm{O}_{5} 331.1981$, found 331.1965.

\subsubsection{3. (2S*,5S*,7R*,8aR*)-7-Benzyloxy-2-(3-bis(tert-}

butyloxycarbonyl)guanidino-propyl)-5-methyl-3-oxo-octahydroindolizin-5-carboxylic acid ethyl ester $\mathbf{4 0}$

cis intermediate alcohol: the same experimental procedure as described for hydroboration was applied to alkene 37 (178 mg, $0.48 \mathrm{mmol}$ ) using a $0.5 \mathrm{M}$ solution of 9 -BBN in THF $(2 \mathrm{~mL}, 1 \mathrm{mmol}$, 2.1 equiv). Stirring was maintained $16 \mathrm{~h}$ after addition of sodium acetate $5 \mathrm{M}\left(1.15 \mathrm{~mL}, 5.76 \mathrm{mmol}, 12\right.$ equiv) and a $30 \% \mathrm{H}_{2} \mathrm{O}_{2}$ solution ( $0.6 \mathrm{~mL}, 5.76 \mathrm{mmol}, 12$ equiv). Flash chromatography on silica gel (AcOEt/Et $\left.{ }_{2} \mathrm{O} 90: 10\right)$ allowed the isolation of a yellow oil (87\%, $162 \mathrm{mg})$.

$R_{f}=0.18($ AcOEt/Et $2 \mathrm{O} 90: 10) .{ }^{1} \mathrm{H}$ NMR $\left(\mathrm{CDCl}_{3}, 300 \mathrm{MHz}\right): \delta_{\mathrm{H}} 1.15$ $\left(3 \mathrm{H}, \mathrm{t}, J=7.1 \mathrm{~Hz}, \mathrm{CH}_{3} \mathrm{CH}_{2}\right) ; 1.34$ (1H, ddd, $\left.J=13.611 .2,2.4 \mathrm{~Hz}, \mathrm{H}_{8}\right) ; 1.57$ (1H, dd, J=14.4, $\left.2.5 \mathrm{~Hz}, \mathrm{H}_{6}\right)$; $1.61-1.96\left(9 \mathrm{H}, \mathrm{m}, \mathrm{Me}, \mathrm{CH}_{2} \mathrm{CH}_{2} \mathrm{CH}_{2} \mathrm{OH}\right.$, $\left.\mathrm{H}_{1}\right) ; 2.13\left(1 \mathrm{H}, \mathrm{dm}, J=13.5 \mathrm{~Hz}, \mathrm{H}_{8}\right) ; 2.28(1 \mathrm{H}, \mathrm{br} \mathrm{s}, \mathrm{OH}) ; 2.46(1 \mathrm{H}, \mathrm{m}$, $\left.\mathrm{H}_{2}\right) ; 2.67\left(1 \mathrm{H}\right.$, ddd, $\left.J=14.4,3.4,2.1 \mathrm{~Hz}, \mathrm{H}_{6}\right) ; 3.7(2 \mathrm{H}, \mathrm{m}$, $\left.\mathrm{CH}_{2} \mathrm{CH}_{2} \mathrm{CH}_{2} \mathrm{OH}\right) ; 3.78\left(1 \mathrm{H}, \mathrm{m}, \mathrm{H}_{7}\right) ; 3.93-4.09\left(3 \mathrm{H}, \mathrm{m}, \mathrm{H}_{8 \mathrm{a}}, \mathrm{OCH}_{2} \mathrm{CH}_{3}\right)$; $4.41\left(1 \mathrm{H}, \mathrm{d}, J=11.9 \mathrm{~Hz}, \mathrm{CH}_{2} \mathrm{Ph}\right) ; 4.53\left(1 \mathrm{H}, \mathrm{d}, J=11.9 \mathrm{~Hz}, \mathrm{CH}_{2} \mathrm{Ph}\right) ; 7.3$ $(5 \mathrm{H}, \mathrm{m}, \mathrm{Ar}) .{ }^{13} \mathrm{C}$ NMR $\left(100 \mathrm{MHz}, \mathrm{CDCl}_{3}\right): \delta_{\mathrm{C}} 14.1\left(\mathrm{CH}_{3} \mathrm{CH}_{2}\right) ; 26.0(\mathrm{Me})$; $27.2\left(\mathrm{CH}_{2} \mathrm{CH}_{2} \mathrm{CH}_{2} \mathrm{OH}\right) ; 30.5\left(\mathrm{CH}_{2} \mathrm{CH}_{2} \mathrm{CH}_{2} \mathrm{OH}\right) ; 32.4\left(\mathrm{C}_{1}\right) ; 34.7$ $\left(\mathrm{CH}_{2} \mathrm{CH}=\mathrm{CH}_{2}\right) ; 36.9\left(\mathrm{C}_{8}\right) ; 40.3\left(\mathrm{C}_{6}\right) ; 41.9\left(\mathrm{C}_{2}\right) ; 50.3\left(\mathrm{C}_{8 \mathrm{a}}\right) ; 59.1\left(\mathrm{C}_{5}\right)$; $61.5\left(\mathrm{OCH}_{2} \mathrm{CH}_{3}\right) ; 62.6\left(\mathrm{CH}_{2} \mathrm{CH}_{2} \mathrm{CH}_{2} \mathrm{OH}\right) ; 70.2\left(\mathrm{CH}_{2} \mathrm{Ph}\right) ; 70.6\left(\mathrm{C}_{7}\right)$; $127.3\left(2 \mathrm{C}_{\mathrm{Ar}}\right) ; 127.6\left(\mathrm{C}_{\mathrm{Ar}}\right) ; 128.4\left(2 \mathrm{C}_{\mathrm{Ar}}\right) ; 138.4\left(\mathrm{C}_{\text {Arquat }}\right) ; 173.1179 .6$ (CO, C3). IR $\left(\mathrm{NaCl}\right.$ disc, $\left.\mathrm{cm}^{-1}\right): \nu_{\max } 3389,2952,1651,1454,1286$, 1066, 910, 728. MS $\left(\mathrm{ES}^{+}\right): m / z 412\left([\mathrm{MNa}]^{+}\right)$.

The same experimental procedure as described for $\mathbf{2 5}$ was applied to cis intermediate (24 mg, $0.062 \mathrm{mmol}$ ) using and 1,3-bis(tert-butoxycarbonyl) guanidine (26 mg, $0.1 \mathrm{mmol}, 1.6$ equiv), triphenylphosphine (26 mg, $0.1 \mathrm{mmol}, 1.6$ equiv), and diethylazodicarboxylate (DEAD) ( $16 \mu \mathrm{L}, 0.1 \mathrm{mmol}, 1.6$ equiv). Stirring was continued for $44 \mathrm{~h}$. Flash chromatography on silica gel $\left(\mathrm{Et}_{2} \mathrm{O} /\right.$ cyclo- $^{-}$ hexane 70:30) allowed the isolation of $\mathbf{4 0}$ as a white solid (40 mg, $100 \%)$.

$R_{f}=0.31 \quad\left(\right.$ AcOEt $\left./ \mathrm{Et}_{2} \mathrm{O} \quad 70: 30\right), \mathrm{mp}>60{ }^{\circ} \mathrm{C} .{ }^{1} \mathrm{H}$ NMR $\left(\mathrm{CDCl}_{3}\right.$, $300 \mathrm{MHz}): \delta_{\mathrm{H}} 1.13\left(3 \mathrm{H}, \mathrm{t}, J=7.2 \mathrm{~Hz}, \mathrm{CH}_{3} \mathrm{CH}_{2}\right) ; 1.31\left(1 \mathrm{H}, \mathrm{m}, \mathrm{H}_{8}\right) ; 1.41-$ $1.62\left(2 \mathrm{OH}, \mathrm{m}, \mathrm{CH}_{2} \mathrm{CH}_{2} \mathrm{CH}_{2} \mathrm{~N}, 2 \mathrm{C}\left(\mathrm{CH}_{3}\right)_{3}, \mathrm{H}_{6}\right) ; 1.63-1.62(4 \mathrm{H}, \mathrm{m}$, $\left.\mathrm{CH}_{2} \mathrm{CH}_{2} \mathrm{CH}_{2} \mathrm{~N}, \mathrm{H}_{1}\right) ; 1.95\left(4 \mathrm{H}, \mathrm{m}, \mathrm{Me}, \mathrm{H}_{1}\right) ; 2.12(1 \mathrm{H}$, br d, $J=13.4 \mathrm{~Hz}$, $\left.\mathrm{H}_{8}\right) ; 2.4\left(1 \mathrm{H}, \mathrm{m}, \mathrm{H}_{2}\right) ; 2.67\left(1 \mathrm{H}, \mathrm{br} \mathrm{d}, \mathrm{H}_{6}\right) ; 3.78\left(1 \mathrm{H}\right.$, br s, $\left.\mathrm{H}_{7}\right) ; 3.82-$ $4.09\left(5 \mathrm{H}, \mathrm{m}, \mathrm{CH}_{2} \mathrm{CH}_{2} \mathrm{CH}_{2} \mathrm{~N}, \mathrm{H}_{8 \mathrm{a}}, \mathrm{OCH}_{2} \mathrm{CH}_{3}\right) ; 4.39(1 \mathrm{H}, \mathrm{d}, \mathrm{J}=12 \mathrm{~Hz}$, 
$\mathrm{CH}_{2} \mathrm{Ph}$ ); 4.52 (1H, d, J=12 Hz, $\left.\mathrm{CH}_{2} \mathrm{Ph}\right) ; 7.3$ (5H, m, Ar); 9.23 (2H, br s, $\left.\mathrm{NH}_{2}\right) .{ }^{13} \mathrm{C} \mathrm{NMR}\left(75 \mathrm{MHz}, \mathrm{CDCl}_{3}\right): \delta_{\mathrm{C}} 14.0\left(\mathrm{CH}_{3} \mathrm{CH}_{2}\right) ; 25.9(\mathrm{Me}) ; 26.8$ and $27.3\left(\mathrm{CH}_{2} \mathrm{CH}_{2} \mathrm{CH}_{2} \mathrm{~N}, \mathrm{CH}_{2} \mathrm{CH}_{2} \mathrm{CH}_{2} \mathrm{~N}\right) ; 28.0$ and $28.3\left(2 \mathrm{C}\left(\mathrm{CH}_{3}\right)_{3}\right)$; $31.6\left(\mathrm{C}_{1}\right) ; 36.9\left(\mathrm{C}_{8}\right) ; 40.2\left(\mathrm{C}_{6}\right) ; 42.0\left(\mathrm{C}_{2}\right) ; 44.5\left(\mathrm{CH}_{2} \mathrm{CH}_{2} \mathrm{CH}_{2} \mathrm{~N}\right) ; 50.1$ $\left(\mathrm{C}_{8 \mathrm{a}}\right) ; 59.0\left(\mathrm{C}_{5}\right) ; 61.3\left(\mathrm{OCH}_{2} \mathrm{CH}_{3}\right) ; 70.0\left(\mathrm{CH}_{2} \mathrm{Ph}\right) ; 70.6\left(\mathrm{C}_{7}\right) ; 78.6$

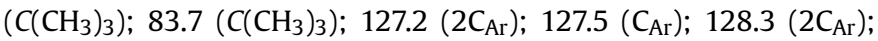
138.3 ( CArquat $\left._{\text {Ar }}\right) ; 155.1,156.8,163.9(\mathrm{C}=\mathrm{N}, \mathrm{NCOO}) ; 173.0,179.2(\mathrm{CO}$, $\mathrm{C}_{3}$ ). IR ( $\mathrm{NaCl}$ disc, $\left.\mathrm{cm}^{-1}\right): \nu_{\max } 3382,2930,1714,1614,1454,1359$, 1255, 1152. $\mathrm{MS}\left(\mathrm{ES}^{+}\right): m / z 631\left([\mathrm{MNa}]^{+}\right)$.

4.1.34. $\left(2 S^{*}, 4 R^{*}, 6 R^{*}\right)-6-\left[\left(2 S^{*}\right)-2-C a r b o x y-5\right.$-guanidino-pentyl]-4hydroxy-2-methyl-piperidin-2-carboxylic acid $\mathbf{4 1}$

The same experimental procedure as described for $\mathbf{3 9}$ was applied to 40 (67 mg, $0.1 \mathrm{mmol}$ ) in $5 \mathrm{~mL}$ of $\mathrm{HCl} 3 \mathrm{M}$. The aqueous phase was lyophilized to leave brown oil in a $100 \%$ yield (44 mg).

${ }^{1} \mathrm{H}$ NMR $\left(\mathrm{D}_{2} \mathrm{O}, 400 \mathrm{MHz}\right): \delta_{\mathrm{H}} 1.45$ (3H, s, Me); $1.46-1.6(5 \mathrm{H}, \mathrm{m}$, $\left.\mathrm{CH}_{2} \mathrm{CHCOOH}, \mathrm{H}_{5}, \mathrm{CH}_{2} \mathrm{CH}_{2} \mathrm{CH}_{2} \mathrm{~N}\right) ; 1.75\left(1 \mathrm{H}\right.$, br d, $\left.J=14.4 \mathrm{~Hz}, \mathrm{H}_{3}\right)$; 1.78-1.93 (3H, m, $\left.\mathrm{CH}_{2} \mathrm{CH}_{2} \mathrm{CH}_{2} \mathrm{~N}, \mathrm{CH}_{2} \mathrm{CHCOOH}, \mathrm{H}_{5}\right) ; 2.48(1 \mathrm{H}$, br d, $\left.J=15.1 \mathrm{~Hz}, \mathrm{H}_{3}\right) ; 2.58\left(1 \mathrm{H}, \mathrm{q}, J=6.4 \mathrm{~Hz}, \mathrm{CH}_{2} \mathrm{CHCOOH}\right) ; 3.09(2 \mathrm{H}, \mathrm{t}$, $\left.J=6.5 \mathrm{~Hz}, \mathrm{CH}_{2} \mathrm{CH}_{2} \mathrm{CH}_{2} \mathrm{~N}\right) ; 3.75\left(1 \mathrm{H}, \mathrm{m}, \mathrm{H}_{6}\right) ; 4.09\left(1 \mathrm{H}\right.$, br s, $\left.\mathrm{H}_{4}\right) .{ }^{13} \mathrm{C}$ NMR (75 MHz, D $\left.\mathrm{D}_{2} \mathrm{O}\right): \delta_{\mathrm{C}} 24.5(\mathrm{Me}) ; 25.2\left(\mathrm{CH}_{2} \mathrm{CH}_{2} \mathrm{CH}_{2} \mathrm{~N}\right) ; 28.2$ $\left(\mathrm{CH}_{2} \mathrm{CH}_{2} \mathrm{CH}_{2} \mathrm{~N}\right) ; 33.5\left(\mathrm{C}_{5}\right) ; 34.1\left(\mathrm{CH}_{2} \mathrm{CHCOOH}\right) ; 37.7\left(\mathrm{C}_{3}\right) ; 40.7$ $\left(\mathrm{CH}_{2} \mathrm{CH}_{2} \mathrm{CH}_{2} \mathrm{~N}\right) ; 40.9\left(\mathrm{CH}_{2} \mathrm{CHCOOH}\right) ; 47.8\left(\mathrm{C}_{6}\right) ; 59.4\left(\mathrm{C}_{2}\right) ; 61.8\left(\mathrm{C}_{4}\right)$; $156.6(\mathrm{C}=\mathrm{N}) ; 174.1,179.1\left(\mathrm{CO}, \mathrm{C}_{3}\right) . \mathrm{MS}\left(\mathrm{ES}^{+}\right): \mathrm{m} / \mathrm{z} 331\left([\mathrm{M}-\mathrm{H}]^{+}\right)$. HRMS $\left(\right.$ ES $^{+},[\mathrm{MH}]^{+}$): calcd for $\mathrm{C}_{14} \mathrm{H}_{26} \mathrm{~N}_{4} \mathrm{O}_{5} 331.1981$, found 331.1965 .

\subsection{Cell culture and cell-adhesion assay}

S180 and Eahy926 cells were cultured in DMEM+10\% FCS and DMEM $+20 \%$ FCS + HAT, respectively. For adhesion assays, cells were harvested with cell dissociation non-enzymatic solution (SIGMA). Cells were pelleted by centrifugation and resuspended at a density of $1 \times 10^{5}$ cells $/ \mathrm{ml}$ in PBS/CaMg. Assays of cell adhesion to coated substrates were performed on non-tissue culture treated 96-well plates. The wells were incubated with FN or VN at $10 \mu \mathrm{g} \mathrm{ml}^{-1}$ in PBS overnight at $4{ }^{\circ} \mathrm{C}$ followed by a 30 -min incubation with $3 \mathrm{mg} \mathrm{ml}^{-1}$ bovine serum albumin in PBS (previously heat-inactivated for $3 \mathrm{~min}$ at $80^{\circ} \mathrm{C}$ ). The substrates were thoroughly washed and maintained in PBS until use. The peptidomimetics solutions were prepared either at $20 \mu \mathrm{M}, 400 \mu \mathrm{M}$ or $1 \mathrm{mM}$ in PBSCaMg. $50 \mu \mathrm{l}$ of peptidomimetic solution were added to the well with $50 \mu$ l of the cell suspension reaching the final peptidomimetic solution to $10 \mu \mathrm{M}, 200 \mu \mathrm{M}$ or $500 \mu \mathrm{M}$ for the assay. Each test was done in triplicate. The plates were incubated at $37^{\circ} \mathrm{C}$ for $1 \mathrm{~h}$ and washed with PBS to remove the non-adherent cells. Then, the wells were fixed in $5 \%$ glutaraldehyde in PBS, washed, stained with $1 \%$ crystal violet in $200 \mathrm{mM}$ MES, and washed in $200 \mathrm{mM}$ MES buffer, pH 6. The crystal violet fixed to the cells was dissolved in $100 \mu \mathrm{L}$ of $10 \%$ acetic acid and OD was read with a microplate reader at $570 \mathrm{~nm}$.
Data are the mean \pm SD of triplicates and are expressed as the \% of cell adhesion obtained on FN in the absence of competitor. The positive and negative controls for the inhibition of cell adhesion were done using the cyclic c(RGDfV) and GRGES peptides, respectively. Two independent experiments were done for each competitor and for each cell type.

\section{Acknowledgements}

We thank the ministere de l'enseignement supérieur et de la recherche for a grant and the DRAB for a financial support. We thank Drs. Isabelle Berque-Bestel and Sandrine Ongeri Sandrine for a molecular modeling of a peptidomimetic model.

\section{References and notes}

1. (a) Hynesw, R. O. Cell 1992, 69, 11-25; Gottschalk, K. E.; Kessler, H. Angew. Chem. Int. Ed. 2002, 41, 3767-3774; (b) Benneth, J. S. J. Clin. Invest. 2005, 115, 3363-3369.

2. (a) Brooks, P. C. Eur J. Cancer 1996, 32A, 2423-2429; (b) Friedlander, M.; Brooks, P. C.; Shaffer, R. W.; Kincaid, C. M.; Varner, J. A.; Cheresh, D. A. Science 1995, 270 1500-1502; (c) Brooks, P. C.; Montgomery, A. M. P.; Rosenfeld, M.; Reisfeld, R. A.; Hu, T.; Klier, G.; Cherech, D. A. Cell 1994, 79, 1157-1164; (d) Enns, A.; Korb, T.; Schlüter, K.; Gassmann, P.; Spiegel, H.-U.; Senninger, N.; Mitjans, F.; Haier, J. Eur. J. Cancer 2005, 41, 1065-1072.

3. (a) Ruoslahti, E. Annu. Rev. Cell Dev. Biol. 1996, 12, 697-715; (b) Marinelli, L.; Lavecchia, A.; Gottschalk, K.-E.; Novellino, E.; Kessler, H. J. Med. Chem. 2003, 46 4393-4404; (c) Moitessier, N.; Henry, C.; Maigret, B.; Chapleur, Y. J. Med. Chem 2004, 47, 4178-4187.

4. Kumar, S.; Wang, Q.; Sasaki, A. Tetrahedron 2007, 63, 2084-2090 and references cited herein.

5. (a) Dechantstreiter, M. A.; Planker, E.; Mathä, B.; Lohof, E.; Hölzemann, G.; Jonczyk, A.; Goodman, S. L.; Kessler, H. J. Med. Chem. 1999, 42, 3033-3040; (b) Uman, S.; Gaus, K.; Yang, Y.; Strijowski, U.; Sewald, N.; De Pol, S.; Reiser, O. Angew. Chem., Int. Ed. 2007, 46, 3976-3978; (c) Macdonald, T.; Stewart, C. F.; Kocak, M.; Goldman, S.; Ellenbogen, R. G.; Phillips, P.; Lafond, D.; Poussaint, T. Y.; Kieran, M. W.; Boyet, J. M.; Kun, L. E. J. Clin. Oncol. 2008, 26, 919-924; (d) Zanardi, F.; Burreddu, P.; Rassu, P.; Auzzas, G.; Battistini, L.; Curti, L.; Sartori, C.; Nicastro, A. Menchi, G.; Cini, G.; Bottonocetti, N.; Raspanti, A.; Casiraghi, G.J. Med. Chem. 2008, 51, 1771-1782.

6. (a) Belvisi, L.; Colombo, L.; Manzoni, L.; Potenza, D.; Scolastico, C. Synlett 2004, 1449-1471; (b) Maison, W.; Prenzel, A. H. G. P. Synthesis 2005, 1031-1048; (c) Manzoni, L.; Bassanini, M.; Belvisi, L.; Motto, I.; Scolastico, C.; Castorina, M. Pisano, C. Eur. J. Org. Chem. 2007, 1309-1317.

7. Halie, D.; Pérard-Viret, J.; Royer, J. Heterocycles 2006, 68, 2471-2476.

8. Baussanne, I.; Dudot, B.; Perard-Viret, J.; Planas, L.; Royer, J. ARKIVOC 2006, 57-66.

9. (a) Osterkamp, F.; Ziemer, B.; Koert, U.; Wiesner, M.; Raddatz, P.; Goodman, S. L. Chem.-Eur. J. 2000, 6, 666-683; (b) Chen, Z.; Kende, A. S.; Colson, A. O.; Mendezandino, J. L.; Ebetino, F. H.; Bush, R. D.; Hu, X. E. Synth. Commun. 2006 36, 473-479; (c) Osterkamp, F.; Wehlan, H.; Koert, U.; Wiesner, M.; Raddatz, P.; Goodman, S. L. Tetrahedron 1999, 55, 10713-10734.

10. Tsunoda, T.; Yamamiya, Y.; Itô, S. Tetrahedron Lett. 1993, 34, 1639-1642.

11. Robinson, D. E.; Seth, P. P.; Jefferson, E. A. Synth. Commun. 2004, 34, 2743-2749. This paper described the same reaction. But, we do not agree with the proposed mechanism. We suggest a simple transesterification type reaction since we obtained the same product in the absence of ADDP and $\mathrm{Bu}_{3} \mathrm{P}$.

12. Beauvais, A.; Erickson, A.; Goins, T.; Craig, S. E.; Suzan, E.; Humphries, J. P.; Dufour, S. J. Cell Biol. 1995, 128, 699-713. 